\title{
Investigations of diterpene alkaloids isolated from Aconitum anthora L. and A. moldavicum L., and of aconitine-derived lipo-alkaloids
}

\author{
Ph.D. Thesis \\ Dr. Botond Lajos Borcsa
}


Department of Pharmacognosy

University of Szeged

Investigations of diterpene alkaloids isolated from

Aconitum anthora $L$. and A. moldavicum L., and of aconitine-derived lipo-alkaloids

Ph.D. Thesis

Dr. Botond Lajos Borcsa

Supervisor:

Prof. Dr. Judit Hohmann

Dr. Dezső Csupor

Szeged, Hungary

2013 


\section{TABLE OF CONTENTS}

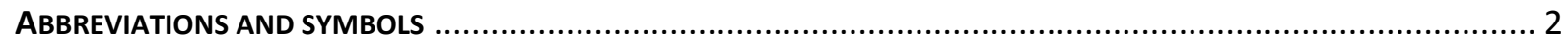

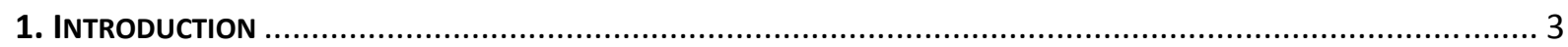

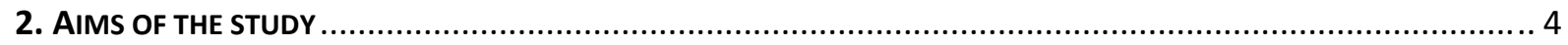

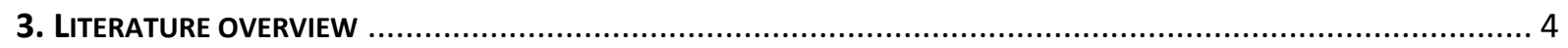

3.1. Botany of the Aconitum genus and the investigated species ............................................. 4

3.1.1 Supra-generic taxonomic classification of the genus Aconitum .......................................... 4

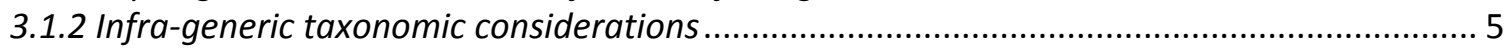

3.1.3 Description of the studied species ...................................................................................... 5

3.2 Recent advances in the chemistry of the Aconitum genus and the investigated species.......... 6

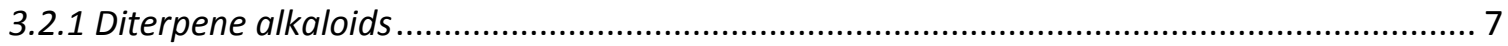

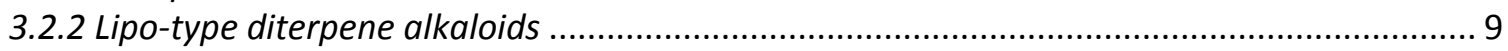

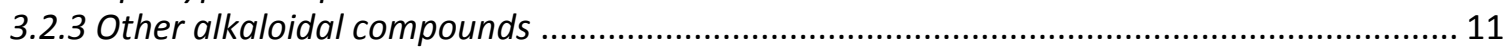

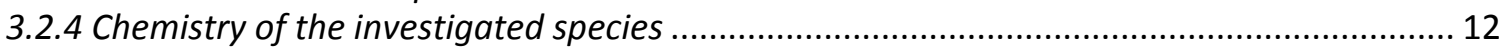

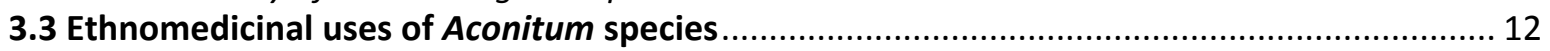

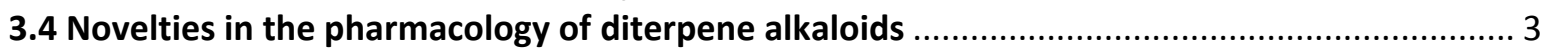

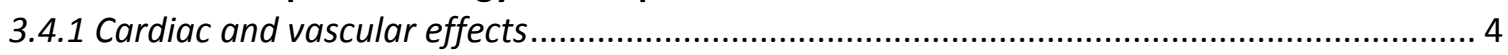

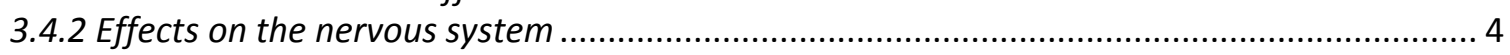

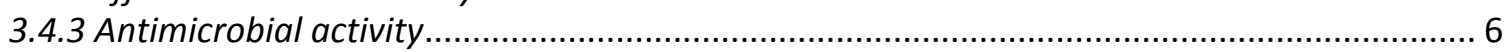

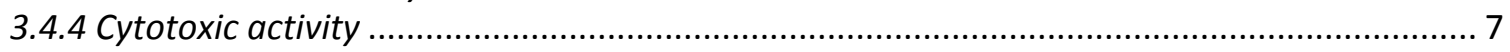

3.4.5 Anti-inflammatory and antioxidant activities ................................................................... 7

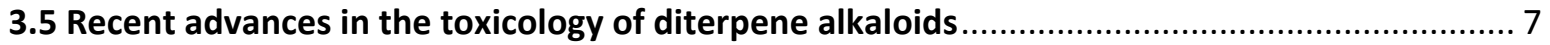

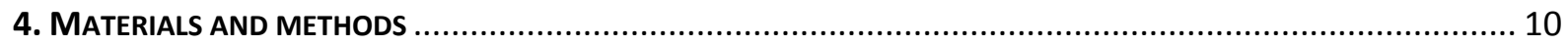

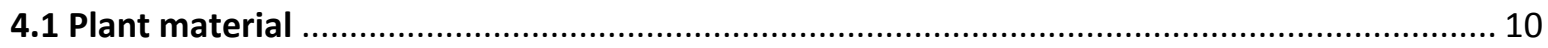

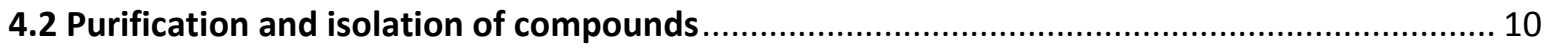

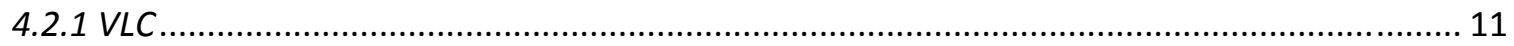

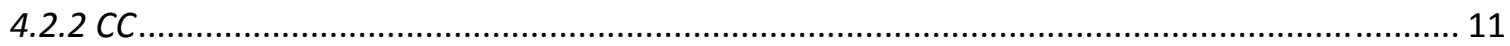

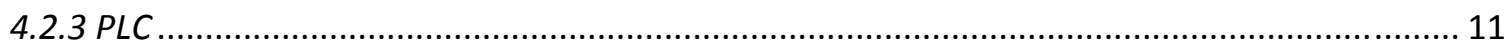

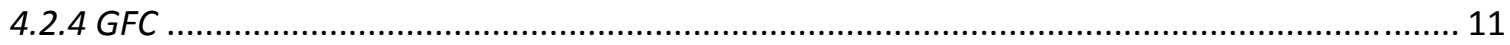

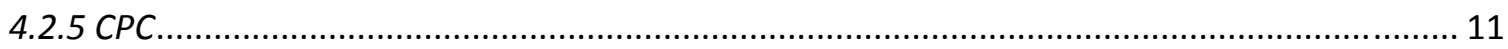

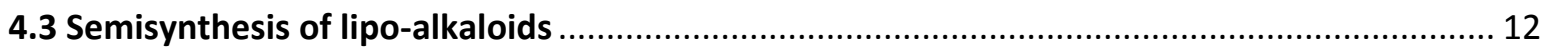

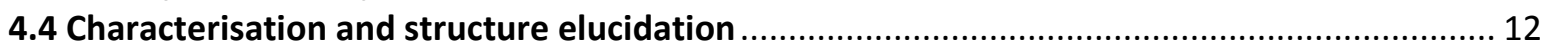

4.5 Pharmacological tests carried out with isolated and semisynthesised alkaloids .................... 12

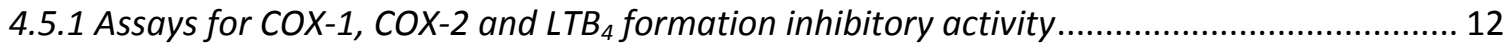

4.5.2 Alkaloids tested in the bioassays of $h E R G$ and $N a_{v} 1.2$ channels ...................................... 12

4.6 Determination of toxic alkaloid contents of processed Radix aconiti samples ....................... 13

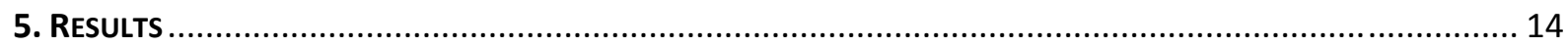

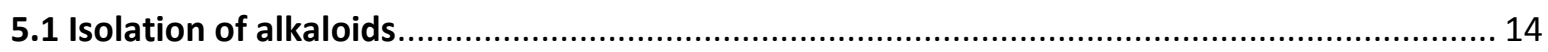

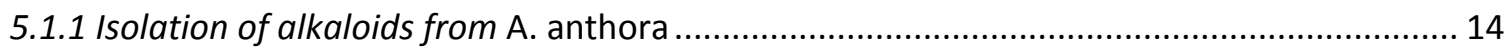

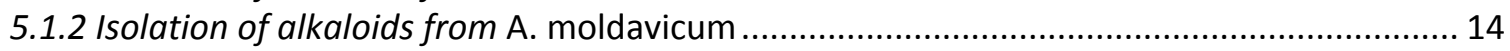

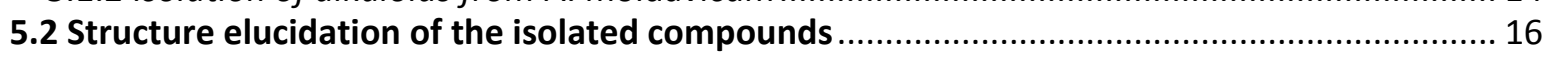

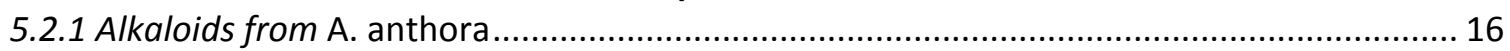

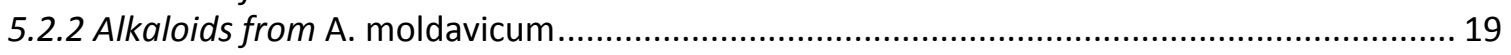

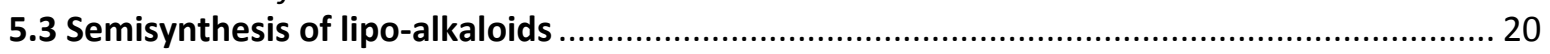

5.4 Pharmacological tests with the isolated and semisynthesised alkaloids .................................. 21

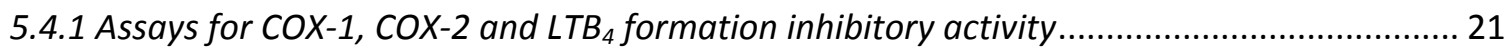

5.4.2 Assessment of the hERG-inhibiting ability of Aconitum alkaloids ...................................... 22

5.4.3 Assessment of $\mathrm{Na}_{v} 1.2$ sodium channel activity of Aconitum alkaloids .............................. 23

5.5 Determination of toxic alkaloid contents of processed Radix aconiti...................................... 24

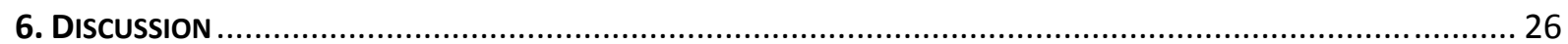

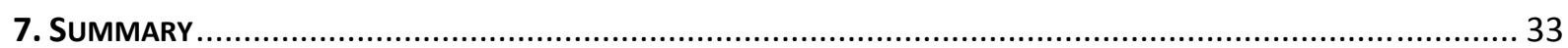

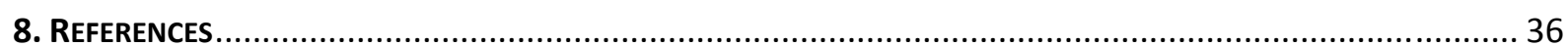




\section{ABBREVIATIONS AND SYMBOLS}

$1 D, 2 D$

one-dimensional, two-dimensional

Alkaloid types: $\quad$ DAs = diterpene alkaloids; TDAs, DDAs, MDAs, LAs = triester, diester, monoester, lipo-type diterpene alkaloids

COSY correlated spectroscopy

Ester groups: $\quad \mathrm{Ac}=$ acetyl, $\mathrm{As}=$ anisoyl, $\mathrm{Bz}=$ benzoyl, $\mathrm{Cn}=$ cinnamoyl, $\mathrm{Vr}=$ veratroyl

Functionalities: $\quad \mathrm{Et}=$ ethyl, $\mathrm{Me}=$ methyl, $\mathrm{OMe}=$ methoxy

hERG

human ether-à-go-go-related gene

$\mathrm{HMBC}$

heteronuclear multiple-bond correlation

HREIMS

high-resolution electron ionisation mass spectrometry

HRMS

high-resolution mass spectrometry

HSQC

heteronuclear single-quantum correlation

J

coupling constant

JMOD

J-modulated spin-echo experiment

m.p.

melting point

Methods: $\quad \mathrm{CC}=$ open-column chromatography, $\mathrm{CPC}=$ centrifugal planar chromatography, GFC = gel-filtration chromatography, $\mathrm{PLC}=$ preparative layer chromatography, TLC = thin-layer chromatography, VLC = vacuum liquid chromatography, NP = normal phase, $\mathrm{RP}=$ reversed phase

nAChR nicotinic acetylcholine receptor

$\mathrm{Na}_{\mathrm{v}} 1.2$ voltage-gated sodium channel isoform 1.2

NMR nuclear magnetic resonance

NOESY nuclear Overhauser effect spectroscopy

QSAR quantitative structure-activity relationship

Solvents: $\quad \mathrm{EtOH}=$ ethanol, $\mathrm{EtOAc}=$ ethyl acetate; $\mathrm{MeOH}=$ methanol, $n \mathrm{Hex}=$ normal hexane, To = toluene, $\mathrm{CH}_{2} \mathrm{Cl}_{2}=$ dichloromethane, $\mathrm{CHCl}_{3}=$ chloroform

syn. synonym

TMS tetramethylsilane

UV ultraviolet chemical shift 


\section{INTRODUCTION}

The buttercup family (Ranunculaceae) has more than 2000 species and by producing specific compounds possessing a very wide range of pharmacological characteristics and physiological effects $^{1+}$, thus it has been in the focus of an ever-growing scientific interest worldwide. Species belonging to the most actively investigated genera (Aconitum, Delphinium, Consolida) are widely distributed throughout the Northern hemisphere. Based on common empiric knowledge these plants are considered to be poisonous. Species of these genera accumulate highly toxic DAs, which have attracted considerable interest motivated by their complex structures, interesting chemistry and noteworthy physiological effects. This exponentially increasing interest is well illustrated by the fact that since 1833, when GEIGER had discovered the archetypical representative of these compounds, aconitine, more than 900 natural compounds were discovered by $2008{ }^{2}$

Although being violently toxic in character, a widely distributed species, A. napellus, gained certain healing reputation at the beginning of the European professional official therapy as its roots (Aconiti tuber) and main alkaloid, aconitine, were used for the treatment of trigeminal neuralgia. ${ }^{3}$ From the beginning to the late second third of the $20^{\text {th }}$ century, in parallel with the recognition of the very narrow therapeutic range of DAs, the medicinal use of aconite drugs had disappeared from Western medicinal practices. Nevertheless, in Far Eastern traditional medicinal systems (Traditional Chinese Medicine (TCM), Ayurveda, Kampo, Unani etc.) aconite drugs have been applied for centuries as painkillers and antirheumatic agents. ${ }^{4}$ Several unprocessed and processed aconite drugs are still official in the national pharmacopoeias of numerous Far Eastern countries.

In spite of our rapidly growing knowledge concerning the chemistry of processed drugs there is still no sufficient information on their pharmacology and toxicology. With the worldwide increasing spread of these medicinal systems, and with the increasing public interest towards phytomedicines, phytoanalytical studies on aconite drugs are of growing importance with respect to their safe application. In consequence of the harmonization of TCM and modern, evidence based medicinal systems aconite preparations are attracting increasing interest today in Western medicine too. The European Directorate for the Quality of Medicines and Health Care (EDQM) devotes special attention to the quality control of herbal drugs of TCM, within the frame of which the incorporation of Aconitum drugs into the European Pharmacopoeia is currently in progress.

Nowadays special emphasis has been placed to research activities aiming the study of the effects of traditional processing methods on the chemical composition of aconite drugs, elaboration of adequate analytical methods for the quality control of these processing methods, and pharmacological-toxicological evaluations of their alkaloids. 


\section{AIMS OF THE STUDY}

In 2001 the research group of HoHMANN et al. (Department of Pharmacognosy, University of Szeged) has started a research program dealing with Aconitum species native to the Carpathian Basin. The aim of this programme is to study these species since chemical and pharmacological characteristics of the rare and/or endemic Aconitum species are partially or completely unexplored. Within the frame of this programme CSUPOR carried out a comprehensive screening of 6 taxa from which $A$. toxicum and A. vulparia were the first selected species to be thoroughly examined as part of his doctoral thesis. ${ }^{3}$ By joining to this ongoing comprehensive research the main goals of my work were to

1. provide review of recent advances in the topic of diterpene alkaloids;

2. phytochemically examine the alkaloid contents of $A$. anthora and $A$. moldavicum, i.e. isolate their DAs via preparative chromatographic methods in order to gain information concerning the chemistry of the species of the Ranunculaceae family;

3. elucidate the structures of isolated compounds via NMR and HRMS techniques, provide characteristic spectral data on the isolated new compounds, and supplement missing NMR data on the already-known compounds;

4. carry out the semisynthesis and purification of a series of LAs derived from aconitine;

5. in the frame of co-operations, carry out and evaluate in vitro anti-inflammatory activity of LAs and hERG and $\mathrm{Na}_{\mathrm{v}} 1.2$ channel activities of previously or newly isolated DAs;

6. carry out quantitative determination of toxic DDAs in authentic processed $A$. carmichaelii and A. kusnezoffii samples.

\section{LITERATURE OVERVIEW ${ }^{*}$}

\subsection{Botany of the Aconitum genus and the investigated species}

\subsubsection{Supra-generic taxonomic classification of the genus Aconitum}

Division: Spermatophyta, subdivision: Angiospermatophyta, class: Dicotyledonopsida, subclass: Ranunculidae, superorder: Ranunculanae, order: Ranunculales, family: Ranunculaceae. ${ }^{5}$

Recently the subfamilial rank of the tribe of Delphinieae is used to comprise the species-rich genera, Aconitum and Delphinium (the latter including Consolida and Aconitella). By comprising 650700 species this tribe represents to some $25 \%$ of all Ranunculaceae species. ${ }^{6}$ Species belonging to this tribe are mostly holarctic in distribution and occupying mainly circumboreal and/or alpine habitats, with only a few species to occur on mountains from tropical Africa. The center of species

\footnotetext{
CSUPOR summarised the topic until the year 2007 in his thesis, therefore the present work aims to review the
} literature published after this date. Some recitation could not be avoided, these are marked with $\mathrm{a}^{\dagger}$. 
diversity and diversification is deducted to Southwest China and eastern Himalayas, where Aconitum has 166 species (from all the approximated 300-350 taxa). ${ }^{6}$ Life histories of Delphinieae species show relatively high diversity varying from short-living strictly annual, pseudo-annual and facultative annual forms occurring mainly in the Mediterranean and the xeric Irano-Turanian regions; to biennial and perennial forms of longer life-span (even up to six-seven decades) occurring mostly in cold and wet high altitude habitats in Southeast Asia and North America.

\subsubsection{Infra-generic taxonomic considerations}

Considering the genus Aconitum a widely accepted classification specifies three infra-generic ranks: the subgeneras of the biennial/pseudo-annual tuberous root growing Aconitum, the perennial rhizome having Lycoctonum and the monospecific facultative annual or biannual Gymnaconitum. ${ }^{3,6,7}$ According to the recent results on the phylogeny of Delphinieae obtained by using molecular phylogenetic and phylogeographic methods (besides considering the extremely variable morphological aspects) the tribe is proposed to consist of three natural genera: Staphisagria, Aconitum and Delphinium. ${ }^{6}$

According to the taxonomic system employed in the latest edition of Flora Europaea ${ }^{8}$ only 7 taxa are recognised as individual species of the genus Aconitum, 5 of which is native to the Carpathian Basin. ${ }^{3}$ In this system the case of $A$. anthora (subgenus: Aconitum) is fairly uncomplicated which is supported by the plant's distinct appearance and morphology, while the case of $A$. moldavicum (subgenus: Lycoctonum) may be regarded as more problematic, because it is referred as a subspecies in the form of $A$. lycoctonum L. subsp. moldavicum (Hacq.) Jalas. UTELLI et al. conducted a molecular systematics study on all European and Caucasian species belonging of the subgenus Lycoctonum. They found that in spite of the obvious morphological difference in flower colour between A. lycoctonum (yellow) and A.moldavicum (blue), these taxa are genetically indistinguishable. Since flower colour is an evolutionarily labile, thus variable character in Aconitum and because of the smaller distribution area of A. moldavicum, which is situated at the eastern border of the distribution of $A$. lycoctonum, they suggested that $A$. moldavicum may be a derived form of $A$. lycoctonum as a quantum speciation product appeared during the ice ages. ${ }^{7}$ From this synonymy we have chosen and in the present work using the form A. moldavicum Hacq. because it is a more widely accepted form in Hungary.

\subsubsection{Description of the studied species}

Aconitum anthora L. (anthora, yellow monkshood, healing wolfsbane) is a $50-120 \mathrm{~cm}$ tall, upstanding, normally not branching, soft stemmed plant. Its tuberaceous roots are small; leaves are deeply palmately lobed into many thin filaments. The basal leaves and the radical leaves on the stem have 2 or 3 times longer petioles than the leaf blades, and they are generally dry before flowering. 
The upper leaves on the stem have a short petiole $(10 \mathrm{~mm})$, and they are progressively become smaller towards to the top of the stem. Compact, terminal, simple or branched off racemes contain pale yellow flowers, which have typical dorsiventral and spirocyclic symmetry, and they are also peculiar to a helmet. Atrophied petals inside the helmet are forming nectaries. The spur of the two petals is contorted. Its fruit is follicle. The plant has a blooming period between the end of August to the beginning of October. A. anthora occurs in calciferous xerotherm forests and lawns, loose and arid rupestral, rubble, loam, clay and forest soils. It is an alpine plant living in the southern part of Central Europe. It is distributed from the Pyrenees to the Far East. ${ }^{7,9,10}$

A. moldavicum Hacq. (Carpathian or eastern monkshood) is $60-150 \mathrm{~cm}$ tall, upstanding, normally not branching, soft stemmed plant. Its rhizomatous roots are fleshy; its leaves are dark green and palmately lobed into their half or two-third, and having 4-6 bigger segments. The inflorescence is covered with short, crispate eglandular hairs, and it appears as terminal, simple or branched off racemes containing characteristic flowers, which have typical dorsiventral and spirocyclic symmetry, and they are also peculiar to a helmet. The colour of the flowers may vary from reddish to deep bluish purple. Atrophied petals inside the helmet are forming nectaries. The spur of the two petals is contorted. It has also follicular fruits. The plant has a blooming period between the beginning of June to the end of July. A. moldavicum occurs mainly in montane beeches. It is a montane-subalpine (subendemic) Carpathian plant living in the eastern and central parts of Europe with a habitat extending to Romania and West Ukraine. ${ }^{7,9,10}$

A. anthora and A. moldavicum are protected species in Hungary. Our examinations were carried out by the permission of the environmental protection authorities.

\subsection{Recent advances in the chemistry of the Aconitum genus and the investigated species}

Ranunculaceae species contain alkaloids which can be divided into three main classes: $\mathrm{C}_{18}$ bisnorditerpene, $C_{19}$ norditerpene and $C_{20}$ DAs. Further grouping of compounds belonging to each main class is based on the type of the carbon skeletons (for examples see Annex I). ${ }^{18}$ DAs are aminated derivatives of nitrogen-free terpenes, which means that these compounds should be considered biogenetically as pseudoalkaloids. It is very interesting that some diterpenoid alkaloids have also been isolated from greenflies (Brachycaudus aconiti and B. napelli, Aphididae) living on Aconitum species. ${ }^{11}$ 


\subsubsection{Diterpene alkaloids}

\section{A) $C_{18}$ bisnorditerpene alkaloids}

To date these compounds are represented by two skeletal types.

1. Lappaconitine-type compounds (I) which are structurally characterised by the presence of a $C_{1}$ unit at C-4. The majority of lappaconitines are reported from Aconitum and Delphinium species. Acotoxicine (1) isolated by CSUPOR et al. from A. toxicum ${ }^{12}$ and piepunendine B (2) containing an exceptional 2-(p-hydroxyphenyl)ethoxy substituent at C-8 can be mentioned in this group. Kiridine (3) is the first example of DAs that contain a 9,14-methylenedioxy group besides possessing a C-3,C-4 epoxide functionality. ${ }^{18}$

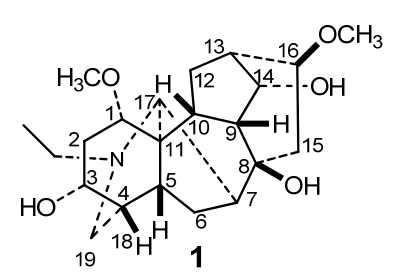

2. Ranaconitine-type compounds (II) have an oxygen-containing functionality at C-7. An interesting example is linearilin (4) containing the rare hydroperoxyl group at C-7. ${ }^{13,18}$

B) $C_{19}$ norditerpene alkaloids
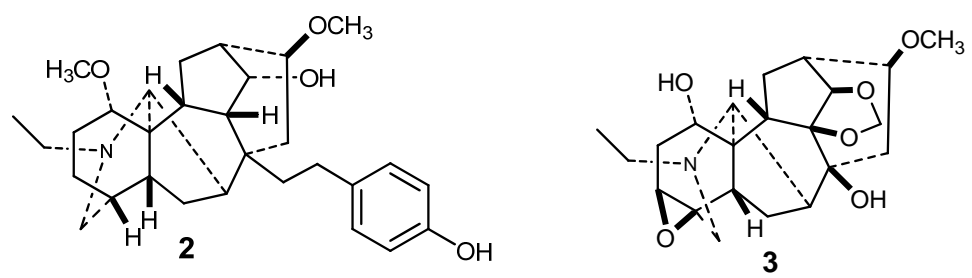

1. Aconitine-type compounds (III) are the most common representatives of the $\mathrm{C}_{19}$ NDAs with the aconitane core. Among all DAs known today more than $50 \%$ contain the aconitane core. 115 new representatives belonging to this skeletal type were reported only within the period from 1998 to $2008 .{ }^{18}$ The first diterpenoid

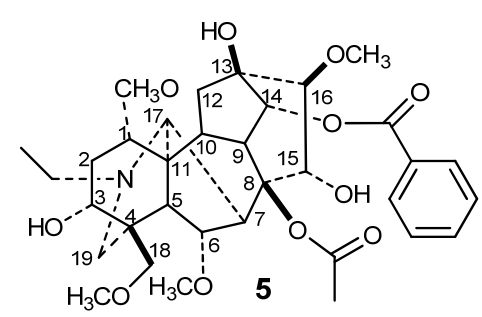
alkaloid, aconitine (5) was isolated from $A$. napellus in 1821 by PESCHIER, but its structure was discovered only later. Despite of numerous chemical modifications, it was only as early as 1959, when the X-ray analysis of a derivative, demethanolaconinone-hydroiodide-trihydrate helped to define the entire structure, including the configuration of the 13 chirality centres. ${ }^{14}$ These compounds have no oxygen functionality at C-7, most of them are characterised by an $\alpha$-oriented hydroxyl group at C-6. Based on the nitrogen functionality further four subtypes have been described: amines, $\mathrm{N}, \mathrm{O}$-mixed acetals, imines and amides. ${ }^{18}$

\section{Lycoctonine-type compounds}

(IV) embody probably the second largest group of DAs, which are characterised by the presence of an oxygenated group at C-7. These

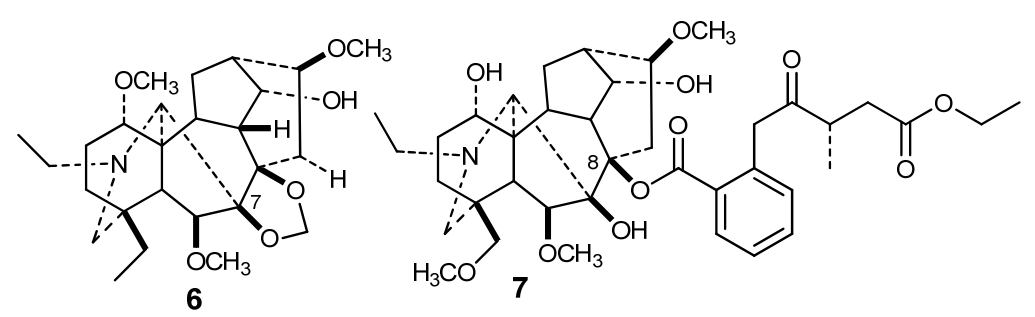


can also be subdivided to amine, $\mathrm{N}, \mathrm{O}$-mixed acetal, imine and amide subtypes. Further distinctions are based on the oxygen-containing groups to be found at C-7/C-8. 7,8-Methylenedioxy moiety containing compounds were mainly reported from Delphinium species, but isodelatine (6) was isolated from the roots of $A$. taipaicum, presenting a rare occurrence of such an alkaloid in an Aconitum species. Jiufengsine (7) is the first example of lycoctonine-type alkaloids to contain an anthranoyl group at C-8. ${ }^{18}$

3. Pyro-type compounds (V) contain a $\Delta^{8,15}$ double bond or an $8-\mathrm{H} / 15$-ketone unit and are considered to be decomposition derivatives of aconitine-type compounds which have lost their C-8 substituent. These compounds were only reported from processed aconite drugs, therefore can be recoginsed as artefacts. $^{18}$

\section{Lactone-type compounds (VI)}

are very rare alkaloids having a $\delta$ lactonised C ring. Until 2008, only nine such compounds were reported. ${ }^{18}$
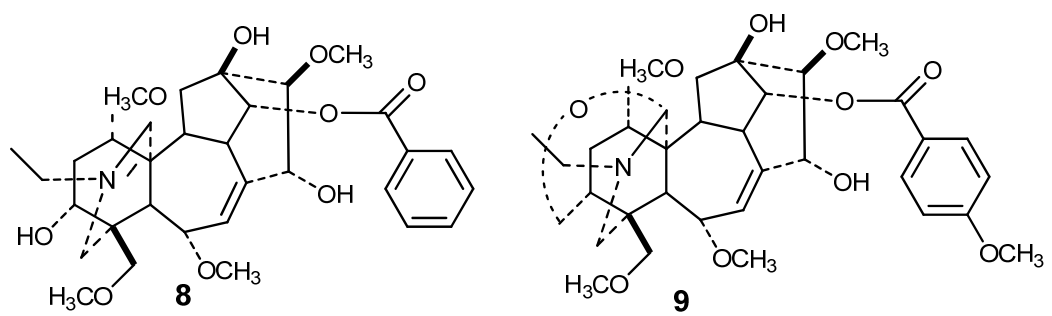

5. 7,17-seco-type compounds (VII) have a $\Delta^{7,8}$ double bond and biosynthetically originate from aconitine-type alkaloids via Grob fragmentation. Representatives of this group are secokaraconitine (8) and secoyunaconitine (9), the former possessesing the unusual $C-17=N$ unit. ${ }^{18}$

6. Rearranged-type compounds (VIII) contain unusual bridges (e.g. C-8-C17 instead of C-7-C-17. A recently reported compound, vilmoraconitine (10) found in A. vilmorinianum is the first DA to contain a threemembered ring $(C-8, C-9, C-10){ }^{18}$

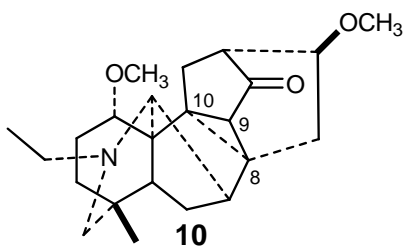

\section{C) $C_{20}$ diterpene alkaloids}

Alkaloids belonging to this chemical class are usually less oxidised having only 2-5 oxygen substituents, but by formation of more variant core types these compounds may also claim significant perspectives. Major subclasses are the followings:

1. Atisine-type compounds (IX) have a pentacyclic core and form one of the most common DA group to occur outside the Ranunculaceae family in Spiraea species (Rosaceae). An unprecedented structure was proven for delphatisine $B(\mathbf{1 1})$ having a $\gamma$-lactone-fused oxazolidine ring. ${ }^{18}$

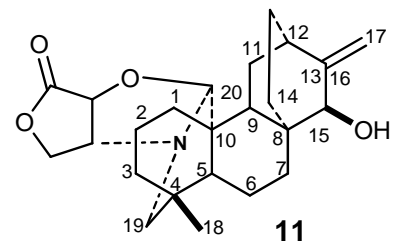

2. Denudatine-type compounds $(\mathbf{X})$ are a subclass of hexacyclic $C_{20}$ DAs based on atisines with an additional bond between $\mathrm{C}-20$ and $\mathrm{C}-7 .{ }^{18}$

3. Hetidine-type compounds (XI) are also hexacyclic $\mathrm{C}_{20}$ DAs based on atisines having an additional bond between $\mathrm{C}-20$ and $\mathrm{C}-14{ }^{18}$ 
4. Hetisine-type compounds (XII) are heptacyclic compounds formed by an extra bond between the $N$ and C- 6 atoms and represent one of the most complex structural group derived from atisine core. An example of these compounds, guan-fu base $S$ (12) was obtained along with a new ent-kaurane diterpene, which may support the hypothesised biogenetic pathway of $C_{20}$ DAs involving nitrogenfree diterpenes. ${ }^{18}$

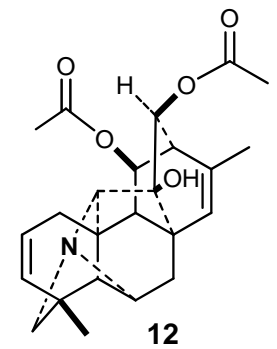

5. Vakognavine-type compounds (XIII) have an N,19-seco hetisine skeleton in addition to a C-4 aldehyde group. ${ }^{18}$

6. Napelline-type compounds (XIV) in comparison with veatchine-type compounds have a hexacyclic skeleton with an additional C-20-C-7 bridge. ${ }^{18}$

7. Kusnezoline-type compounds (XV) having an adamantane skeleton were firstly prepared from hetisine via acid-catalysed rearrangement but later found in nature, as it is illustrated by the isolation of guan-fu base $\mathrm{K}(\mathbf{1 3}){ }^{18}$

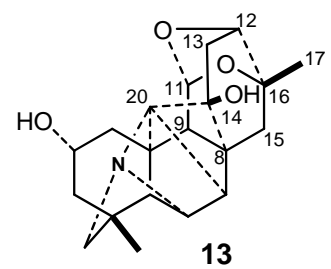

8. Racemulosine-type compounds (XVI) are novel $C_{20}$ DAs with a unique skeleton and proposed to be originated from the denudatine-type DAs through double Wagner-Meerwein rearrangements of rings $A$ and $C$. So far racemulosine (14) reported from A. racemulosum var. pengzhouense is the only member of this subclass. ${ }^{18}$

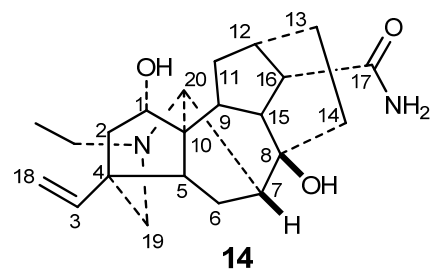

9. Arcutine-type compounds (XVII) also represent unusual structures having a C-5-C-20 bond in lieu of the traditional C-10-C-20 bond being typical to $\mathrm{C}_{20}$ DAs. ${ }^{18}$

A part of the $C_{20}$ diterpenoid alkaloids, such as the atidane (XVIII) [including ajaconine (XIX)], hetisane (XX), vilmoridine (XXI), and delnudine (XXII) types are probably structurally related to atisane diterpenoids. However, compounds with a veatchine (XXIII), and 14,20-cycloveatchine (XXIV) skeleton show structural relationship with the kaurane diterpenoids. ${ }^{15}$

Based on the number of ester groups present in the molecules, DAs can be classified otherwise into the main types of diester (DDAs), monoester (MDAs), and triester DAs (TDAs). As concerns the latter group only a few compounds were detected by highly sensitive analytical methods, but no such compound was isolated.

It is noteworthy to mention that some very intriguing bisditerpenoid alkaloids have also been reported, which are biosynthesised by connecting $2 C_{20}$ DA units or of $1 C_{20}$ and $1 C_{19}$ unit. $^{16}$

\subsubsection{Lipo-type diterpene alkaloids}

In 1982, when examining Aconiti tuber (Chuanwu) KITAGAWA et al. isolated alkaloid mixtures containing long-chain fatty acid residues. Based on the results of the structure elucidation of isolated components carried out via certain indirect methods of chemical degradation the authors proposed 
the general term 'lipo-alkaloid' to describe the isolates (lipoaconitine, lipohypaconitine, lipomesaconitine, lipodeoxyaconitine). ${ }^{17}$ Scientific data and knowledge on these compounds has shown continuously intensifying accumulation since the time of their first recognition, therefore it was interesting to see that although in their recently published review covering the period from 1998 to 2008 , WANG et $a .^{18}$ summarised comprehensively the current information on the native $C_{18}, C_{19}$ and $\mathrm{C}_{20}$ diterpenoid alkaloids; yet, LAs were referred only shortly in their work. Therefore, our research group has compelled a review paper to summarise the structures, chemistry, semisynthesis, analytics and bioactivities of LAs revealed to date, thus based on 32 references we provided the first comprehensive study on this topic covering the data of 173 compounds. ${ }^{19}$

From the chemical-structural point of view LAs are transesterified derivatives of $C_{19}$ aconitane DDAs containing one or two long-chain fatty acid residues. All LAs identified so far are based on the $\mathrm{C}_{19}$ aconitane skeleton, on which the positions $\mathrm{C}-1, \mathrm{C}-3, \mathrm{C}-10, \mathrm{C}-13, \mathrm{C}-14, \mathrm{C}-15$ and the $\mathrm{N}$ atom can be substituted by different functional groups. The fatty acid residues primarily bond at C-8, but according to the recent report of $\mathrm{XU}$ et $a .^{20}$ these residues can also connect at position $\mathrm{C}-3$, forming dilipo derivatives. The already reported 173 LAs are formed by the combination of 12 parent DDAs and 36 fatty acids (compounds produced only semisynthetically are also taken into account). These fatty acids vary from $C_{3}$ propanoic acid to $C_{25}$ pentacosanoic acid, the grade of unsaturation also varies in a broad spectrum from the compounds being monounsaturated up to compounds containing 6 double bonds. Structures of the already known LAs along with their parent DDAs and the structures of by-products of semisynthetic reactions were also summarized in our before mentioned paper. ${ }^{19}$

Many papers on the isolation of LAs from plant material ${ }^{21-25}$ reported these compounds to be complex mixtures, and stated that direct chromatographic isolation of the individual components is extremely difficult because of their very similar physico-chemical properties and chromatographic behaviour. Therefore, at the beginning of the research on the topic indirect degradation $\left(\right.$ methanolic $^{17}$, alkaline ${ }^{24,25}$ ) methods were elaborated, while later on and along with the development

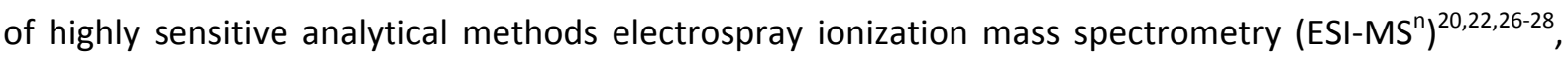
matrix assisted laser desorption/ionization mass spectrometry (MALDI-MS $\left.{ }^{n}\right)^{23,29,30}$, and atmosphericpressure chemical ionization mass spectrometry $\left(\mathrm{APCI}-\mathrm{MS}^{n}\right)^{31}$ were and are the main methods used for unambiguous compound identification and structure elucidation. However, as a major drawback of such mass spectrometric methods it should be noted that mass spectrometric data are not appropriate to obtain exact details about the positions of double bonds in the esterifying fatty acid side chains (determination of bonding isomers of e.g. linolenic acid). This aspect may have special significance since it could have major influence on the pharmacological effects of the compounds concerned, as it can be observed in the case of certain n-3 and n- 6 fatty acids. ${ }^{32}$ 
As for origin, LAs are native minor compounds of crude aconite drugs (A. carmichaelii $\operatorname{roots}^{22,31,30,33}$, A. ferox - roots ${ }^{21}, A$. kusnezoffii - flowers ${ }^{28}$ ), yet as part of the study of the traditional Chinese drug processing methods of aconite roots, WANG et al. proved for the first time that during the decoction of the roots artificial production of LAs can be observed. ${ }^{33}$ This was demonstrated by adding palmitic acid to aconite root before decoction, and the resulting processed drug was found to be containing 14-benzoylaconine-8-O-palmitate, 14-benzoylhypaconine-8-O-palmitate, and 14benzoyldeoxyaconine-8-O-palmitate in amounts which were not present previously in the alkaloid mixture of the processed drugs. This experiment served as direct evidence for the previous speculations that LAs can be formed by transesterification reactions during processing of the crude drugs. The facts that LAs can be found in both unprocessed and processed aconite drugs, and that processing results in the increase of LA content in parallel with the decrease of DDAs concentration besides the formation of hydrolysed products also were confirmed by the work of CSUPOR et al. ${ }^{31}$ Figure 1 shows the general scheme of the transesterification reaction using the example of aconitine (5).

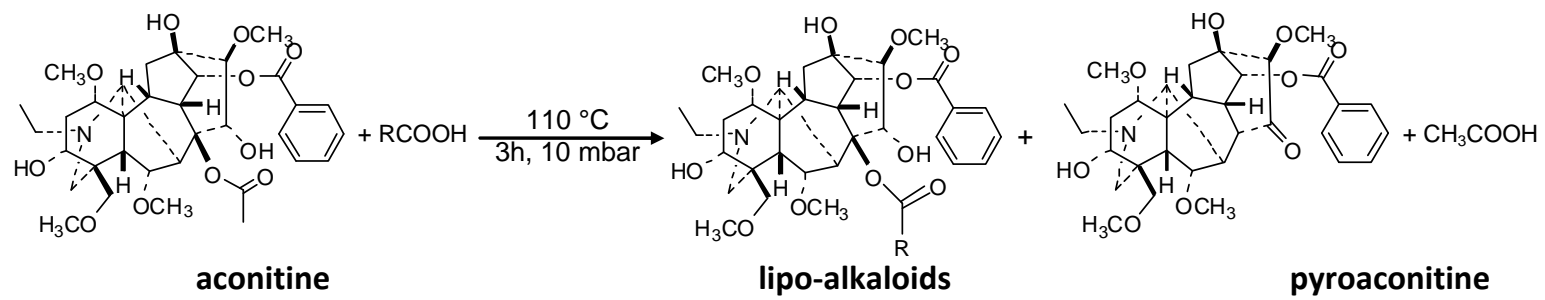

Figure 1. General scheme of the transesterification reaction ( $R=$ esterifying fatty acid moiety)

\subsubsection{Other alkaloidal compounds}

Sporadic occurrences of miscellaneous type alkaloidal compounds have been reported from Delphinieae species. From the aerial parts of D.fangshanense atypical occurrence of the tetrahydrobenzylisoquinoline alkaloid, $\mathrm{O}$-methylroefractine $\mathrm{N}$-oxide and the aporphine alkaloid, magnoliflorine were reported. ${ }^{34}$ The latter has also been detected in the aerial parts of $D$. pentagynum. ${ }^{35}$ A tetrahydroisoquinoline alkaloid, oleracein $\mathrm{E}$ along with two pyrrole alkaloids, aconicaramide and 5-hydroxymethyl-pyrrole-2-carbaldehide, have been isolated from the lateral roots of $A$. carmichaelii. These compounds showed moderate antibacterial activity against several pathogenic bacterial strains, while the latter exerted protective activity against cardiomyocyte damage induced by pentobarbital sodium in primary cultured neonatal rat cardiomyocytes. ${ }^{36} \mathrm{~A}$ new quinazoline alkaloid, 2-(2-methyl-4-oxo-4H-quinazoline-3-yl)benzoic acid methyl ester was found in the roots of $A$. pseudo-laeve var. erectum. ${ }^{37} \mathrm{~A}$ strange occurrence of a Spirea alkaloid, spiratine $\mathrm{A}$ has been reported from a Turkish population sample of Consolida anthoroidea being the first and until now only report of such a compound in a Ranunculaceae species. ${ }^{38}$ Two new amide alkaloids, 3- 
isopropyl-tetrahydropyrrolo [1,2-a] pyrimidine-2,4 (1H,3H)-dione and 1-acetyl-2,3,6-triisopropyltetrahydropyrimidine- $4(1 H)$-one were isolated from the roots of $A$. taipeicum. ${ }^{39}$

\subsubsection{Chemistry of the investigated species}

In 2000 MeriçLI et al. reported 6 diterpenoid alkaloids of a Turkish population of $A$. anthora from the $\mathrm{EtOH}$ extract of the aerial parts of the plant, $\mathrm{C}_{20} \mathrm{DAs}$ : isoatisine (15), 19-epi-isoatisine (16), a mixture of $20 \alpha$-atisine $+20 \beta$-atisine (17), hetisine (18), guan-fu base $Y(\mathbf{1 9}) ; C_{19} D A$ : isotalatizidine (20). ${ }^{40}$ In a recent study conducted by PIRILDAR et al. on another Turkish population of this species guan-fu base $A(\mathbf{2 1})$, condelphine (22), nudicaulamine (23), and isotalatizidine (20) were reported from the $90 \% \mathrm{EtOH}$ extract of the roots. ${ }^{41}$ Italian researchers studied the flavonoids of $A$. anthora. Two new, and two previously known, but from Ranunculaceae species formerly undetected 7,3-0-glycosides of quercetin and kaempferol were reported along with the detection of a very modest antioxidant activity of these compounds in three different antioxidant assays. ${ }^{42}$

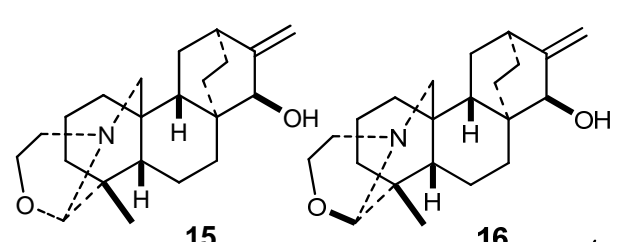

15

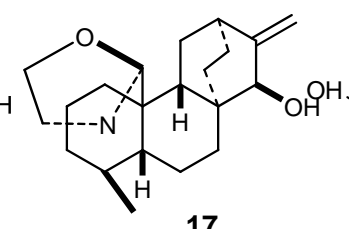

17

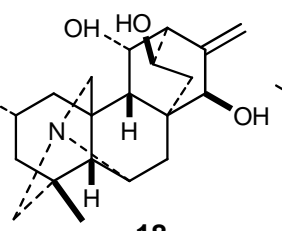

18

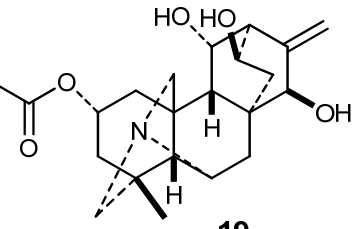

19
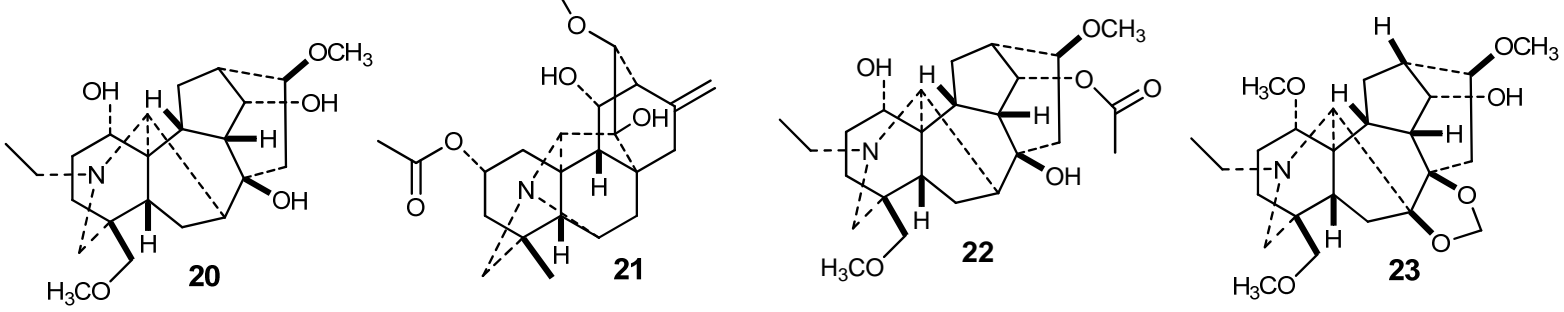

Preceding our herein detailed work no phytochemical studies have been carried out with A. moldavicum.

\subsection{Ethnomedicinal uses of Aconitum species}

European folk medicinal records prove the use of Aconitum species as poisons applied even for homicides since the antiquity. On the contrary, Middle and Far Eastern Aconitum and Delphinium species have a long history of diverse ethnomedicinal uses. In the present thesis only a few characteristic examples are summarised (Table 1). 
Table 1. Ethnomedicinal usage of (non-Chinese) Delphinieae species

\begin{tabular}{|c|c|c|c|}
\hline Country & Species & Ethnomedicinal use(s) & Ref. \\
\hline Bhutan & $\begin{array}{l}\text { A. laciniatum } \\
\text { A. laciniatum, } \\
\text { A. violaceum, } \\
\text { A. orochryseum }\end{array}$ & $\begin{array}{l}\text { anthelmintic; chronic infections including leprosy, bone diseases, } \\
\text { mumps and gout } \\
\text { ingredients in traditional medicinal formulas with various indications }\end{array}$ & 44,45 \\
\hline India & $\begin{array}{l}\text { A. heterophyllum } \\
\text { D. denudatum }\end{array}$ & $\begin{array}{l}\text { diarrhoea, dysentery, cough, dyspepsia, chronic enteritis; as a } \\
\text { febrifuge and bitter tonic in combating debility after malaria } \\
\text { management of nervous disorders and opium addiction }\end{array}$ & 46 \\
\hline Japan & $\begin{array}{l}\text { A. carmichaelii } \\
\text { A. carmichaelii, } \\
\text { A. japonicum }\end{array}$ & $\begin{array}{l}\text { pain, coldness of distal extremities, recurrent cold episodes, heavy } \\
\text { depression, low basal body temperature, vertigo, general fatigue } \\
\text { common cold, polyarthralgia, skin wounds, depression, diarrhoea, } \\
\text { heart failure }\end{array}$ & 48 \\
\hline Kazakhstan & A. monticola & $\begin{array}{l}\text { rheumatoid arthritis, neuralgia, deforming osteoarthritis, athetoid } \\
\text { spasm }\end{array}$ & 49 \\
\hline Kyrgyzstan & A. karacolicum & cancer & $50^{+}$ \\
\hline Korea & $\begin{array}{l}\text { A. ciliare } \\
\text { A. chiisanense } \\
\text { A. pseudo-laeve } \\
\text { var. erectum }\end{array}$ & $\begin{array}{l}\text { sinew and joint pain } \\
\text { neuralgia, arthritis, rheumatism, paralysis, astomia, coldness of } \\
\text { extremities, heart disease } \\
\text { analgetic and antispasmodic agent; neuralgic and rheumatic } \\
\text { conditions }\end{array}$ & $\begin{array}{l}51 \\
52\end{array}$ \\
\hline Mongolia & Delphinium spp. & infectious fever, diarrhoea caused by bilious disorder, toothache & $53^{+}$ \\
\hline Nepal & $\begin{array}{l}\text { Delphinium spp. } \\
\text { D. scabriflorum } \\
\text { A. orochryseum }\end{array}$ & $\begin{array}{l}\text { rheumatism, cough, fever, toothache; usage recorded even as } \\
\text { adulterant to aconites } \\
\text { rheumatism and fever, leaf-juice for wound healing } \\
\text { treatment of fever, diarrhoea, dysentery, cold and cough, tonsillitis, } \\
\text { headache, and high altitude sickness }\end{array}$ & $\begin{array}{l}55 \\
44\end{array}$ \\
\hline Turkey & $\begin{array}{l}\text { Consolida spp., } \\
\text { Delphinium spp. } \\
\text { Consolida spp., } \\
\text { Delphinium spp. } \\
\text { Delphinium spp. }\end{array}$ & $\begin{array}{l}\text { analgetics, sedatives, emetics, anthelmintics } \\
\text { rheumatic pain, sciatica, body lice } \\
\text { epileptic seizures, tetanus tremors, rabies, lice }\end{array}$ & 57,58 \\
\hline
\end{tabular}

The fact that besides the two most widely known species (A. carmichaelii and A. kusnezoffii) literature sources cite that about 76 Aconitum, and several Delphinium taxa (with the majority being endemic) are currently used in different regions of $\mathrm{China}^{60}$ (e.g. A. bulleyanum ${ }^{61}$, A. coreanum ${ }^{62}$ A. delavay ${ }^{63}$, A. hemsleyanum ${ }^{64}$, A. nagarum var. lasiandrum $^{65}, D$. densiflorum ${ }^{66}, D$. trifoliatum ${ }^{67}$ etc.) provides the reason to discuss Chinese usage separately. In China, major and most common applications of drugs from these plants include analgetic, anaesthetic, cardiotonic and antirheumatic indications. ${ }^{68}$ They are also frequently recommended for the treatment of kidney disorders and analgesia. ${ }^{69}$ In the Tibetan area, extracts of $A$. spicatum, A. naviculare, and A. macrorhynchum are used in analgesic balms, as sedative and febrifuge, and for the treatment of gastricism, hepatitis, and nephritis, respectively. ${ }^{70,71,72}$ In the same region, the roots of $A$. richardsonianum var. pseudosessiliflorum and the aerial parts of D. crhysotrichum ${ }^{73}$ have been used for rheumatism and neuralgia. ${ }^{74}$ It was reported also from Tibet that for the treatment of infectious fever, pneumonia 
and inflammation $A$. tanguticum ${ }^{7576}$, and for the treatment of arthralgia, dysmenorrhea, and colic $A$. habaense ${ }^{77}$ have long been used as traditional Tibetan medicines.

A very strange culinary tradition has been recorded from different provinces of China, particularly in mountain areas, where people use the roots of certain cultivated aconite species as main ingredient of a tonifying soup predominantly prepared and consumed in the cold season. The soup is boiled for extremely long periods (from 8 hours to two days), and edibility is checked by tasting if numbness of the tongue or the buccal area of the mouth may or may not occur. ${ }^{4,78}$

Concerning Western official applications of aconite drugs Extractum aconiti and Tinctura aconiti can be mentioned, which were official in the $1^{\text {st }}$ and $2^{\text {nd }}$ editions of the Pharmacopoea Hungarica. ${ }^{79,80}$ From the $3^{\text {rd }}$ edition, the Hungarian Pharmacopoeal Commission was among the firsts to omit both the drug and its preparations form the official pharmacopoeia. ${ }^{81}$ Interestingly, Aconiti radix was included in the French Pharmacopoeia until 1972, in the British Pharmacopoeia until 1973, and it was still official in the Swiss Pharmacopoeia in 1988. ${ }^{3,82}$ Currently, there are no Aconitum monographs neither in the U.S. Pharmacopoeia (USP) nor in the European Pharmacopoeia (Ph. Eur.). However, the monographs for Aconiti carmichaelii radix, Aconiti radix praeparata, Aconiti radix lateralis praeparata, Aconiti kusnezoffii radix praeparata, and Aconitum napellus ad praeparationes homeopathicas are under preparation according to the on-line database of Ph. Eur. ${ }^{83}$ Official use in Far Eastern countries is provided by the inclusion of both crude and processed drugs of the used species in the respective national pharmacopoeias.

Tuberous roots of $A$. carmichaelii and $A$. kusnezoffii are subjected to various pretreatment methods which result in characteristically different processed drugs. Considering all species used in TCM and the applied processing methods an extensive summary was given by SINGHUBER et al. $^{4}$ It has to be mentioned that the current (i.e. available in English) $8^{\text {th }}$ edition of the Pharmacopoeia of the People's Republic of China (PhPRC) contains monographs of the crude and processed roots of $A$. kusnezoffii (Radix aconiti kusnezoffii, Caowu; Radix aconiti kusnezoffii praeparata, Zhicaowu), the crude and processed mother (Radix aconiti, Chuanwu; Radix aconiti praeparata, Zhichuanwu) and processed daughter roots (Radix aconiti lateralis praeparata, Fuzi) of $A$. carmichaelii. ${ }^{84}$ This taxon also serves as source of a herbal drug in the $7^{\text {th }}$ edition of the Korean Pharmacopoeia. ${ }^{85}$ According to HANUMAN et al. ${ }^{86 \dagger} A$. ferox serves the same purpose within the Ayurvedic system.

\subsection{Novelties in the pharmacology of diterpene alkaloids}

DAs act predominantly on the central nervous and cardiovascular systems; where one of their sites of action is the voltage-gated $\mathrm{Na}^{+}$channel of the cell membranes of excitable tissues, on which they act either as activators or as inhibitors. ${ }^{1+, 87^{\dagger}}$. Besides this $\mathrm{Na}^{+}$ion channel further molecular targets have also been identified, including the NMDA-type glutamate receptor, the A-type GABA receptor, and 
voltage-gated $\mathrm{K}^{+}$channels, just to mention the most important examples. ${ }^{18,88}$ Other components acts as antagonists on the nicotinic acetylcholine receptors. ${ }^{89+}$ Furthermore, it is well known that some diterpenoid alkaloids have thyrosinase inhibitor, antifeedant and insecticide activities. ${ }^{90,91}$ Alkaloids of the genera Aconitum and Delphinium are of great interest for developing new medicinal preparations because these compounds are known to possess remarkably diverse pharmacological bioactivities on which an extensive list covering the period between 1981 and 2006 has been compiled by SINGHUBER et al. ${ }^{4}$

\subsubsection{Cardiac and vascular effects}

Although most of the cardiovascular and neurologic effects and poisoning with Aconitum products are explained by the activation of $\mathrm{Na}^{+}$channels, insufficient evidence is available as concerns other possible mechanisms of action, such as the involvement of the $\mathrm{K}^{+}$channels. A previous study reported only on the hERG channel inhibitory effect of aconitine. ${ }^{92}$

Since DAs are known to have different cardiovascular activities, DESAl et al..$^{93}$ conducted a study with semisynthetically produced falconerine-8-O-stearate and falconerine-8-O-linolenate, besides further 12 semisynthetic derivatives. The authors investigated the hypotensive and bradycardic actions of these compounds at two doses $(200 \mu \mathrm{g} / \mathrm{kg}, 400 \mu \mathrm{g} / \mathrm{kg}$. iv.) using $\mathrm{N}$ deacetyllappaconitine (NDAL) as reference compound by measuring the differences in heart rate and in blood pressure in male Sprague-Dawley rats. It was observed that both compounds had relatively strong activities by reaching, and especially at the dose of $400 \mu \mathrm{g} / \mathrm{kg}$, surpassing the activities of NDAL. The authors concluded that the examined compounds produced at least $10 \%$ fall in heart rate or a $20 \%$ decline in blood pressure at both doses. Interestingly, pyrodelphinine was also tested within the same study, but it expressed NDAL-equivalent activity only at the dose of $200 \mu \mathrm{g} / \mathrm{kg}$, and its activity fell far behind from the activity of NDAL at the dose of $400 \mu \mathrm{g} / \mathrm{kg}$.

Guan-fu base A, isolated from A. coreanum have been developed into a new anti-arrhythmic drug, especially to treat ventricular premature beats and paroxysmal supraventricular tachycardia. ${ }^{62}$ This compound, beside lappaconitine hydrobromide ${ }^{94 \dagger}$, is the second diterpene alkaloid to be applied in the modern medicine as anti-arrhythmic agent.

\subsubsection{Effects on the nervous system}

Neurobiologically the diterpenoid alkaloids can be divided into three groups. The members of the first group (eg. aconitine, mesaconitine, 3-acetylaconitine) are diesters and are strongly toxic. These compounds activate the voltage sensitive $\mathrm{Na}^{+}$channel by linking to the $\alpha$ subunit of the transmembrane glycoprotein. This mechanism is the basis of their antinociceptive effect. The compounds of the second group (eg. lappaconitine, 6-benzoyl-heteratizine, 1-benzoyl-napelline) are monoesters. They are less toxic and are the blockers of the $\mathrm{Na}^{+}$channel. Due to this effect they have 
explicit antinociceptive, antiarrhythmic and antiepileptic effects. The compounds of the third group (eg. heteratisine, napelline, lappaconitine), are not esters. They have no neuronal activity, and experimentally only their antiarrythmic effect was verified. ${ }^{87^{+}}$

Concerning the new results of antinociceptive activities of DAs and aconite drugs it is interesting that this effect was found to be the same in both cases of crude and processed Radix aconiti lateralis, while in case of the latter the toxicity as function of aconitine content was found to be reduced. ${ }^{95}$ When applying a systems biology approach to detect Aconitum alkaloids induced toxicity by mapping the toxic substances into a biological pathway context WANG et al. found that aconitine has a direct link with 4 types of ion channels: $\mathrm{Na}$ (v) I alpha, SCN 3A ( $\left.\mathrm{Na}_{v} 1.3\right), \operatorname{SCN} 2 \mathrm{~A}$ $\left(\mathrm{Na}_{\mathrm{v}} 1.2\right)$, and the tetrodotoxin resistant $\mathrm{Na}(\mathrm{l})$ channel, and that the activity towards serotonin, histamine and dopamine receptors is a common bioactivity of Aconitum alkaloids. ${ }^{96}$ As concerns of the antinociceptive action of Aconitum alkaloids it has been revealed that two affinity group of alkaloids can be distinguished: a high and a low affinity group both binding to the $\mathrm{Na}^{+}$channel epitope site 2 (without proper specification on the channel subtype). Affinity differences indicate different pharmacological characters in mice (high affinity compounds: induce an increase in synaptosomal $\left[\mathrm{Na}^{+}\right] \mathrm{i}$ and $\left[\mathrm{Ca}^{2+}\right] \mathrm{i}\left(\mathrm{ED}_{50} 3 \mu \mathrm{M}\right)$, exert antinociception $\left(\mathrm{ED}_{50} 25 \mu \mathrm{g} / \mathrm{kg}\right)$, provoke tachyarrhythmias, and are highly toxic $\left(\mathrm{LD}_{50} 70 \mu \mathrm{g} / \mathrm{kg}\right)$; low affinity compounds: reduce $\left[\mathrm{Ca}^{2+}\right] \mathrm{i}$, induce bradycardia, exert less antinociception $\left(\mathrm{ED}_{50} 50 \mathrm{\mu g} / \mathrm{kg}\right)$, and are less toxic $\left.\left(\mathrm{LD}_{50} 30 \mathrm{mg} / \mathrm{kg}\right)\right)$, but due to their narrow $L D_{50} / E D_{50}$ values, even the compounds of the low affinity group are deemed unsuitable as analgesics. ${ }^{4,87+, 183^{\dagger}}$ Guiwuline, a new franchetine-type $C_{19}$ DA isolated from the root bark of $A$. carmicahelii exhibited potential analgesic activity (hot plate test, $\mathrm{ED}_{50} 15 \mathrm{mg} / \mathrm{kg}$ ) and little acute toxicity $\left(\mathrm{LD}_{50} 500 \mathrm{mg} / \mathrm{kg}\right.$ ) in a mice, for which the compound can be considered as a lead molecule for the development of novel analgesic agents. ${ }^{97}$ Another intensively researched field of CNS-related antinociception effects is the inhibitory effect of processed Aconiti tuber on the development of antinociceptive tolerance to morphine, and its underlying mechanism of the activation of kappaopioid receptors. ${ }^{98-102}$ It has been reported that bulleyaconitine A, a DDA isolated from A. bulleyanum is approved for the treatment of chronic pain and rheumatoid arthritis in China. When investigating its underlying effects it was detected that this compound reduces neuronal $\mathrm{Na}^{+}$currents in a strong and use-dependent manner that can result in a long-acting local anaesthetic effect, which considering its particular characteristics merits further detailed investigation. ${ }^{103}$

KAWATA et al. ${ }^{104}$ investigated the conversion of aconitine to lipoaconitines by the human intestinal bacterial flora. The converting activities of Bacteroides fragilis, Klebsiella pneumoniae and Clostridium butyricum were studied by co-incubation with aconitine (5), and LAs being esterified with anteiso-pentadeceoic, pentadecenoic, palmitic, palmitoleic, stearic and oleic acids. The esterifying fatty acids were characteristic to the strains used, and the respective LAs were found even after co- 
incubation of aconitine with sterile bacterial cells or a precipitate of disrupted bacterial cells in a phosphate buffer. As part of this study, antinociceptive activities of 14-benzoylaconine (14-BzA) -8-Opalmitate and 14-BzA-8-O-oleate were also tested in mice using aconitine as reference compound. Aconitine exerted a significant nociceptive threshold increasing effect with nociceptive hypersensitivity at the dose of $1 \mathrm{mg} / \mathrm{kg}$, but $14-\mathrm{BzA}-8-\mathrm{O}-$ oleate exhibited this at $3 \mathrm{mg} / \mathrm{kg}$, and it was found to be toxic. 14-BzA-8-O-palmitate was active only at the dose of $30 \mathrm{mg} / \mathrm{kg}$, therefore the authors concluded that LAs are not playing an important role in the antinociceptive action of aconite roots.

Further important pharmacological effect that can be related to this group is manifested on the nAChR. Methyllycaconitine, nudicauline and elatine have a selective antagonist effect on the neuronal nAChR at the $\alpha$-bungarotoxine binding site even in nanomolar concentrations. Experiments made on numerous norditerpenoid alkaloids in order to identify the structure-activity relationship revealed, that the 2-(methyl-succinimido)-benzoyl group is essential for this effect. ${ }^{89+105,106+}$ The outstanding activity of methyllycaconitine on nAChR can bring new therapeutic possibilities in the therapy of Alzheimer's disease.

Different pharmacological activities were reported about $\mathrm{C}_{20}$ diterpenoid alkaloids. Peripheral vasodilator effect of kobusine was described in 1997 by WADA et al. ${ }^{107}$ Panicutine, found in Delphinium denudatum, has antifungal effect. ${ }^{108+}$ Hetisine and related diterpenoid alkaloids were described as repellents and insecticides. ${ }^{109+110^{+}, 111^{+}}$

\subsubsection{Antimicrobial activity}

DAs isolated from Turkish Consolida species, namely lycoctonine, 18-O-methyllycoctonine, delcosine, 14-acetyldelcosine and 14-acetylbrowniine presented notable antibacterial effect towards Klebsiella pneumoniae and Acinetobacter baumannii measured by microdilution method (reference drugs: ampicilline, ofloxacine); quite considerable antifungal activity against Candida albicans (reference drug: ketoconazole), and selective and strong inhibitory effect against the RNA virus, Parainfluenza (PI-3; reference drugs: acyclovir, oseltamivir) with minimum and maximum cytopathogenic inhibitory concentrations ranging between 1 and $32 \mu \mathrm{g} / \mathrm{ml}^{112}$ Although methanolic extracts of Iranian Consolida species previously demonstrated significant activities against Bacillus subtilis and Morganella morganii (C. orientalis), and against Escherichia coli and Candida albicans (C. rugulosa), no compounds exerting these effects were exactly identified or reported. ${ }^{112}$ The anti-trypanosomal atisinium chloride isolated from the aerial parts of $A$. orochryseum was found to have moderate antiplasmodial activity against the TM4 (wild) and K1 (chloroquin and antifolate resistant) Plasmodium falciparum strains, and because of some in vivo toxicity of this alkaloid seen in mice its structure may only be considered as a lead molecule for further research. ${ }^{44}$ 


\subsubsection{Cytotoxic activity}

CHOdoeva et al. reported the activity guided isolation 8-O-azeoyl-14-benzoylaconine having a truly unique zwitterionic structure and remarkable antiproliferative properties against three human cell lines. ${ }^{50+}$ Later, this research group presented a series of mono- and diacylated compounds, differing in the lenght of the alkyl linker, among which compounds containing two aconine moieties interlinked through two ester bonds provided by a pimelate, suberate or azelate at C-11 have been proven to be effective in MCF-7 (breast) and HCT-15 (colon) tumour xenograft bearing in vivo mice models with effective doses largely below the maximum tolerated dose. ${ }^{113}$

WADA and HAZAWA investigated natural $C_{19}$ and $C_{20}$ DAs and their analogues against A172 human malignant glioma cells. They found that while the atisine-type alkaloid pseudokobusine did not have antiproliferative properties, its 11-cinnamoate, 11-anisoate and 11-p-nitrobenzoate derivatives exerted the highest cytotoxicity activity. They concluded important structure-activity relationships for the cytotoxicity activity. ${ }^{114115}$

Further alkaloidal compounds that have been reported to show significant in vitro cytotoxic activity against various tumor cell lines delelatine (P388, leukaemia) $)^{74}$; delphatisine (A549, lung cancer $^{73}$; aconitine, hypaconitine, mesaconitine and oxonitine (HePG2, liver cancer) ${ }^{116}$; honatisine (MCF-7, breast cancer) ${ }^{117}$; and benzoyldeoxyaconine (HL-60, promyelocytic leukaemia). ${ }^{118}$

\subsubsection{Anti-inflammatory and antioxidant activities}

CHANG et al. ${ }^{119}$ reported that the extract of Radix aconiti stimulates the secretion of IL-1 $\beta$, TNF- $\alpha$ and GM-CSF produced by human peripheral mononuclear cells. Although in this study only the extract was studied and no isolated components responsible for the effects were investigated, these results provided the first evidence for pharmacological effects explaining the traditional utilization of aconite drugs in inflammatory conditions. The ethanol extract of the roots of $A$. vilmorinianum used in China as a local substitute for Aconiti radix and Aconiti kusnezoffii radix was found to induce significant improvement of joint allodynia, swelling, hyperaemia and vascular permeability in an arthritis knee model in the rat. ${ }^{120}$ Cochlearenine and lycoctonine, isolated from the roots of $D$. linearilobum were detected to exert significant DPPH radical scavenging and metal chelation, respectively. ${ }^{121}$

\subsection{Recent advances in the toxicology of diterpene alkaloids}

Due to the fact that aconitine, hypaconitine, and mesaconitine, the major alkaloidal constituents of the most widely applied Aconitum species are the most active and the most toxic DDAs (primarily cardio- and neurotoxicity), not just their pharmacology and mode of action, but their toxicological characteristics have also been exhaustively explored. ${ }^{122+}$ 
The major difference observed in the Asian application of tubers and roots of aconites is that these drugs are used only after cautious processing (usually boiling) to reduce their toxicity. The role of processing in the detoxification of aconite drugs has been and is still being in the focus of attention, which is demonstrated by the mere fact that by 2010 more than 70 methods of investigation have been published. ${ }^{134}$ In brief: processing reduces toxicity because of hydrolysis of the ester groups of aconitine-type alkaloids, which results in the formation of less toxic derivatives. ${ }^{132}$ First, the acetyl group is hydrolyzed and in the second step the benzoyl group is hydrolyzed (Figure 2).

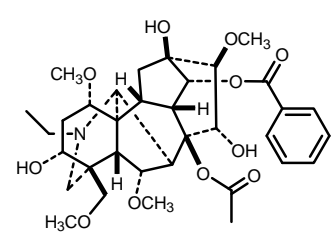

aconitine

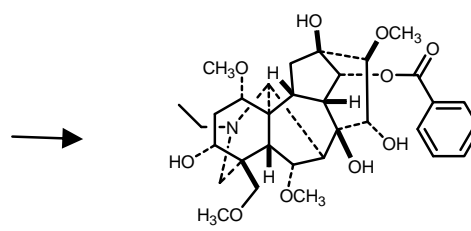

14-benzoylaconine

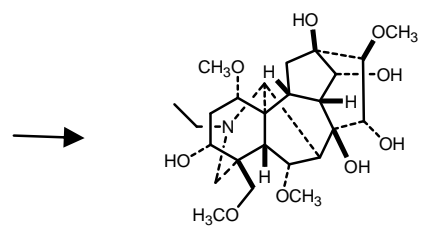

aconine

Figure 2. Decomposition of aconitine during processing of Aconitum drugs

Because the benzoyl ester is more stable, in the properly processed plant material the concentration of 14-benzoylaconine, 14-benzoylmesaconine, and 14-benzoylhypaconine is remarkable. Aconitum roots also contain LAs, which are substantially less toxic than aconitine-type compounds as evidenced by the difference in the lethal intravenous single doses (>10 mg/kg for LAs). ${ }^{31} \mathrm{~A}$ rather alarming possibility of poisoning is that DAs in topically applied aconite preparations are able to permeate through human skin, meaning that in case of such an administration method the risk of developing systemic toxicity is significant, especially with preparations made of unprocessed drugs (e.g. tinctures). ${ }^{123}$ From a forensic toxicological/medicolegal point of view it is important to know that according to the regulations stipulated by the Chinese State Food and Drug Administration selling unprocessed Aconitum drugs on the Chinese market is forbidden ${ }^{4}$, and only processed drugs are authorised for marketing and human use.

With the increasing worldwide spread of traditional oriental healing systems the toxicological issues (including forensic and/or medicolegal cases) raised by incidental or intentional (e.g. suicidal $\left.\right|^{124} /$ homicidal $^{125}$ ) usage of (crude/processed) aconite drugs have gained particular attention and publicity. In Asia, aconite poisoning is much more common because of the continuing and widespread use of aconite roots (unprocessed or processed with reduced DA content) ${ }^{126+127-131}$; however, with easy access to Asian herbal medicines in Western societies, aconite poisoning can occur anywhere in the world. ${ }^{132}$ Although SINGHUBeR et al. cites several reports on the (Chinese) clinical cases of aconite toxicosis, these cannot be regarded as exhaustive reviewal, but as simple illustrations used to underline the severity of this issue. ${ }^{4}$ The number of victims of aconite poisonings 
reported in the literature varies from the two-digit range to even the four-digit range ${ }^{4,133-136, *}$, figuratively culminating around five thousand poisoning cases reported in the past years from China, Hong Kong, Japan, Germany and other countries ${ }^{143}$; and unfortunately, the number of forensic case reports is constantly increasing. ${ }^{48,137-142}$ The main causes of death are refractory ventricular arrhythmias and asystole and the overall in-hospital mortality is $5.5 \%$. Amongst the causes of these poisonings not just the insufficiency of (official) control, but the diversity of the alkaloid content of the starting material, improper processing, and last but not least the lack of appropriate quality control can be identified. ${ }^{136}$

Quality control criteria of pharmacopoeias are not always sufficient to warrant safety (as it can be seen in cases of pharmacopeial monographs on Radix aconiti and Radix aconiti kusnezoffii, in which the PhPRC stipulates no limit for DA contents.) The phenomenon that the usage of these drugs remains a constant source of poisoning urges for better and better methods for controlling the drug processing procedure, and eventually for the assurance of patient safety. ${ }^{134}$ This immense need for quality control concerning aconite drugs of human use is highlighted e.g. by a recent investigation on Radix aconiti lateralis preparata in which the sum of aconitine, mesaconitine and hypaconitine measured in 8 drug sample types was found to be $3.91-34.8 \%$ of that to be found in the corresponding crude drugs. ${ }^{143}$ Nonetheless, this latest demonstration of significant variation in the toxic alkaloid contents is in line with practically all other previous studies conducted with the same purpose of DA content comparison in commercial TCM aconite samples. ${ }^{4}$ However, it is interesting to note that there are several papers dealing with the detection of the toxic DA alkaloids aconitine, hypaconitine and mesaconitine in human body fluids (urine and blood/plasma samples) by different highly sensitive methods. ${ }^{132,144-}$

Frequent application of aconite preparation increases the danger of toxicosis. From a comparative investigation using pure aconitine and extract of Radix aconiti lateralis praeparata (Fuzi) it was observed that repeated administration only changed the pharmacokinetics of the Fuzi extract with AUC and $t_{\max }$ values indicating that multiple administration might increase the bioavailability of aconitine, which in pure form has proven to have low bioavailability, and rapid elimination due to low protein bounding. ${ }^{154}$

Pharmacologic and toxicologic profiles of aconites are influenced by the metabolites of the major alkaloids as well. In vitro incubation of the extract of Radix aconiti with intestinal bacteria of the rat resulted in the C-8 propionyl, butyryl, an valeryl substituted metabolites of the corresponding

\footnotetext{
* It should be noted due to the language barrier imposed by the difficulties in accessing and interpreting the Chinese language literature, these literature sources frequently remain unverifiable for non-Chinese speaking researchers.
} 
DDAs (aconitine, hypaconitine and mesaconitine), which metabolites may be biologically still active. In the liver, aconitine can be transformed into at least six CYP-mediated metabolites in human liver microsomes, and CYP 3A4/5 and 2D6 were found to be the most important CYP isoforms responsible for the de-methylation, $\mathrm{N}$-deethylation, dehydrogenation and hydroxylation of this $\mathrm{DDA}^{155}$; while besides these enzyme isoforms CYP 2C8/9 and 2D6 also played a minor role in the transformation of mesaconitine into at least nine metabolites following the same processes. ${ }^{156} 157$ Results showing reduction of toxicity in an interesting in vivo experiment of coadministration of aconitine and paeoniflorin in the rat seems to be supporting the tradition of herbal drug combinations, although, the exact mechanism of this synergistic effect has not been clarified yet. ${ }^{158}$ Since data on $L D_{50}$ values ( $\mathrm{mg} / \mathrm{kg}$ body weigh) of the main DAs measured via different administration methods applied in different animal species or observed in human fatalities, and on the acute $\mathrm{LD}_{50}(\mathrm{mg} / \mathrm{kg})$ values of extracts or compounds of different Aconitum species measured in mice are provided comprehensively by SINGHUBER et al. ${ }^{4}$, and taken into account that CSUPOR summarised the mechanisms of toxicity of DAs and the symptoms of human toxicosis in detail ${ }^{3}$, thus rediscussion of these topics is hereby disregarded.

\section{MATERIALS AND METHODS}

\subsection{Plant material}

A. anthora was collected at Füzéri Várhegy and Tar-kő in the North-Hungarian Mountains in the flowering period in September 2002, and A. moldavicum was collected near to Eger in October 2006. The plant material was identified by Attila Molnár V. (Department of Botany, University of Debrecen, Hungary). The plant material of $A$. anthora was dried and stored at room temperature until preparation, while the roots of $A$. moldavicum were freshly ground and extracted. Voucher specimens (numbers: 768 and 807, respectively) are deposited in the Herbarium of Department of Pharmacognosy, University of Szeged.

\subsection{Purification and isolation of compounds}

For CC, $\mathrm{Al}_{2} \mathrm{O}_{3}\left(\mathrm{Al}_{2} \mathrm{O}_{3}\right.$ Neutral, Brockman II, Reanal), for $\mathrm{VLC}, \mathrm{Al}_{2} \mathrm{O}_{3} \mathrm{G}\left(\mathrm{Al}_{2} \mathrm{O}_{3} 60 \mathrm{G}\right.$ neutral, type $\mathrm{E}$, Merck 1090) was used. Preparative TLC was performed on $\mathrm{Al}_{2} \mathrm{O}_{3}$ plates $\left(20 \times 20 \mathrm{~cm} \mathrm{Al} \mathrm{O}_{3} 60 \mathrm{~F}_{254}, 1.5 \mathrm{~mm}\right.$, Merck 5715), and GFC on Sephadex ${ }^{\circledR}$ LH-20 (25-100 $\mu$ m, Pharmacia Fine Chemicals), or on lipophilic Sephadex ${ }^{\circledR}$ LH20100-100G (Sigma-Aldrich). Purification steps applying CPC were carried out on a Chromatotron ${ }^{\circledast}$ (Model 8924, Harrison Research) instrument by using $\mathrm{Al}_{2} \mathrm{O}_{3} \mathrm{G}\left(\mathrm{Al}_{2} \mathrm{O}_{3} 60\right.$ G neutral type E; Merck 1090) layers. Chromatographic fractions were monitored by $\mathrm{TLC}$ on $\mathrm{Al}_{2} \mathrm{O}_{3}$ plates with the use of cyclohexane- $\mathrm{CHCl}_{3}-\mathrm{MeOH}$ (50:50:3), and visualized by spraying with $\mathrm{cc}$. $\mathrm{H}_{2} \mathrm{SO}_{4}$, followed by heating or with Dragendorff's reagent. 
4.2.1 VLC was carried out on $\mathrm{Al}_{2} \mathrm{O}_{3} ; \mathrm{VLC} \mathrm{I:} 108 \mathrm{~g} ; \mathrm{VLC}$ II: $20.8 \mathrm{~g}$

VLC I: cyclohexane- $\mathrm{CHCl}_{3}-\mathrm{MeOH}$ [50:50:0, 50:50:2, 50:50:5, 50:50:10, 50:50:20 and 50:50:50 (350 mL each)], volume of collected fractions: $35 \mathrm{~mL}$.

VLC II: $n \mathrm{Hex}-\mathrm{EtOAc-MeOH}[70: 30: 0,70: 30: 0.5,70: 30: 1,70: 30: 1.5,70: 30: 2,70: 30: 3$, and 70:30:5, (100 mL each)], volume of collected fractions: $10 \mathrm{~mL}$.

4.2.2 CC was performed on $\mathrm{Al}_{2} \mathrm{O}_{3} ; \mathrm{CC} \mathrm{I:} 1428.5 \mathrm{~g}$

CC I: cyclohexane-EtOAc-MeOH [70:30:0, 70:30:1, 70:30:1.5, 70:30:2, 70:30:3, 70:30:5, $70: 30: 7,70: 40: 10,60: 40: 20$ and 60:40:50 (3000, 6900, 2700, 1800, 3000, 2400, 2400, 1800, 2700 and $5100 \mathrm{~mL}$ )], volume of collected fractions: $300 \mathrm{~mL}$.

4.2.3 PLC was carried out on $\mathrm{Al}_{2} \mathrm{O}_{3}$. Separation was monitored in UV light at $254 \mathrm{~nm}$ or by spraying the border of the plates with Dragendorff's reagent. Compounds were eluted with $\mathrm{CHCl}_{3}-$ $\mathrm{MeOH}$ 1:1. Mobile phases:

PLC I: cyclohexane- $\mathrm{CHCl}_{3}-\mathrm{MeOH}$ 50:30:1

PLC II-V: To-acetone-EtOH-cc. $\mathrm{NH}_{3}$ 70:40:10:3

4.2.4 GFC was performed on Sephadex ${ }^{\circledR}$ LH-20; GFC I-IX: 5.0 g each. Number of collected fractions: 20. Volume of collected fractions: 1 and 20: $20 \mathrm{~mL}$ each, further fractions $1 \mathrm{~mL}$ each. Mobile phases:

GFC I-III, V-VIII: acetone

GFC IV, IX: $\mathrm{CHCl}_{3}-\mathrm{MeOH} 1: 1$

4.2.5 $\mathrm{CPC}$ was carried out with a Chromatotron ${ }^{\circledR}$ on manually prepared $\mathrm{Al}_{2} \mathrm{O}_{3}$ plates, thickness 1-4 $\mathrm{mm}$, flow rate $4-10 \mathrm{~mL} / \mathrm{min}$. Mobile phases:

CPC I: $\mathrm{CH}_{2} \mathrm{Cl}_{2}-\mathrm{MeOH}[98: 2,97: 3,95: 5,93: 7,90: 10$, and 80:20 (25, 45, 45, 45, $50,25 \mathrm{~mL}$, respectively)], volume of collected fractions: $5 \mathrm{~mL}$.

CPC II: $n \mathrm{Hex}-\mathrm{EtOAc}-\mathrm{MeOH}$ [70:30:3, 70:30:3.5, 70:30:4, 70:30:4.5, and 70:30:5, $(50 \mathrm{~mL}$ each)], volume of collected fractions: $5 \mathrm{~mL}$.

CPC III, VI: $n \mathrm{Hex}-\mathrm{CH}_{2} \mathrm{Cl}_{2}-\mathrm{MeOH}$ [70:30:1, 70:30:2, 70:30:3, 70:30:4, 70:30:5, and 70:30:7, (50 $\mathrm{mL}$ each)], volume of collected fractions: $5 \mathrm{~mL}$.

CPC IV-V: $n \mathrm{Hex}-\mathrm{CH}_{2} \mathrm{Cl}_{2}-\mathrm{MeOH}$ [70:30:3, 70:30:4, 70:30:5, and 70:30:7 (50 mL each)], volume of collected fractions: $5 \mathrm{~mL}$.

CPC VII: To-acetone-EtOH-cc. $\mathrm{NH}_{3}$ [70:40:10:1, and 70:40:10:2 (40 mL each)], volume of collected fractions: $2 \mathrm{~mL}$. 


\subsection{Semisynthesis of lipo-alkaloids}

The semisynthesis of aconitine-derived LAs was carried out according to the modified method of BAI et $a l^{159}$ as elaborated by CSUPOR et $a l^{31}{ }^{31}$ In brief the reaction mixtures were heated in an oil bath $\left(110{ }^{\circ} \mathrm{C}\right.$, except of esterification with eicosapentaenoic and docosahexaenoic acids, for which the temperature was lowered to $90^{\circ} \mathrm{C}$, due to the presumed higher heat-sensitivity of these compounds) for $3 \mathrm{~h}$ under vacuum (10 mbar). In the reactions $20 \mathrm{mg}$ aconitine (5) was esterified by $40 \mathrm{mg}$ lauric, myristic, stearic, palmitoleic, oleic, $\alpha$ - and $y$-linolenic, eicosanoic, 11Z-eicosenoic, 11Z,14Zeicosadienoic, 8Z,11Z,14Z-eicosatrienoic, eicosapentaenoic acids, and $25 \mathrm{mg}$ docosahexaenoic acid, respectively. All chemical substances used for the reactions were purchased as highly purified test reagents. Supplier for all compounds was Sigma-Aldrich Ltd., Hungary. For purity (catalogue number) of compounds see refs. ${ }^{19}$ and ${ }^{160}$. To obtain the pure LAs and the by-product, pyroaconitine (24), the reaction mixtures were successively purified by gelfiltration, preparative TLC and CPC as described in refs. ${ }^{160}$ and ${ }^{19}$. The identity and purity of the compounds were investigated by ${ }^{1} \mathrm{H}$ - and ${ }^{13} \mathrm{C}$-NMR spectroscopy.

\subsection{Characterisation and structure elucidation}

Optical rotations were determined in $\mathrm{CHCl}_{3}$ at room temperature with a Perkin-Elmer 341 polarimeter. NMR spectra were recorded in $\mathrm{CDCl}_{3}$ on a Bruker Avance DRX 500 spectrometer, at $500 \mathrm{MHz}\left({ }^{1} \mathrm{H}\right)$ and $125 \mathrm{MHz}\left({ }^{13} \mathrm{C}\right)$, with TMS as internal standard. Two-dimensional data were acquired and processed with standard Bruker software. In the ${ }^{1} \mathrm{H}-{ }^{1} \mathrm{H}$ COSY, HSQC and HMBC experiments, gradient-enhanced versions were used. HRMS measurements were performed on a Finnigan MAT $95 \mathrm{~S}$ and a VG ZAB SEQ hybrid mass spectrometer equipped with a Cs SIMS ion source. Melting points are uncorrected.

\subsection{Pharmacological tests carried out with isolated and semisynthesised alkaloids}

\subsubsection{Assays for COX-1, COX-2 and $\mathrm{LTB}_{4}$ formation inhibitory activity}

For detailed protocols of assays for COX-1, COX-2 and $\mathrm{LTB}_{4}$ formation inhibitory activities see ref. ${ }^{160}$ In the inhibition assays for COX-1 and COX-2 indomethacine (COX-1, IC $\left.\mathrm{C}_{50} 0.9 \mu \mathrm{M}\right)$ and NSB-398 (COX2, $\mathrm{IC}_{50} 2.6 \mu \mathrm{M}$ ) were used as positive controls. In the leucotriene $\mathrm{B}_{4}$ formation inhibition assay zileuton ( $\mathrm{IC}_{50} 5.0 \mu \mathrm{M}$, Sigma Aldrich) was used as positive control. ${ }^{160}$

\subsubsection{Alkaloids tested in the bioassays of $h E R G$ and $N a_{v} 1.2$ channels}

Semisynthetic preparations of 14-BzA-8-O-palmitate (48) and pyroaconitine (24), alike the isolation of acotoxicine (1), aconosine (49), dolaconine (50), delectinine (51), neolinine (52), neoline (53), acotoxinine (54), songoramine (55) and songorine (56) from A. toxicum; acovulparine (57) and septentriodine (58) from A. vulparia; delcosine (40), gigactonine (44), takaosamine (59) and 14- 
desacetyl-18-demethylpubescenine (60) from Consolida orientalis was described in ref. ${ }^{161}$ (for structures see Annex II). Aconitine (5) was purchased from Sigma-Aldrich. The purities of the compounds were investigated by means of ${ }^{1} \mathrm{H}-\mathrm{NMR}$ spectroscopy ${ }^{162}$, and all found to be $>95 \%$. In the hERG bioassay haloperidol was used as a positive control (Sigma).

Whole-cell patch clamp analysis of the effects on hERG channels

CHO cells stably expressing the transcript of hERG were investigated by the automated whole-cell patch clamp technique, using the QPatch-16 system (Sophion). For detailed protocol of hERG bioassay see ref. ${ }^{161}$

Whole-cell patch clamp analysis of current amplitude modulation

$\mathrm{CHO}$ cells stably expressing human $\mathrm{Na}_{v} 1.2$ sodium channels were investigated by the whole-cell patch clamp using the QPatch-16 automated patch clamp system. Cells were held at $-65 \mathrm{mV}$ and activated by a train consisting of 20 steps to $0 \mathrm{mV}$ for $8 \mathrm{~ms}$ at $10 \mathrm{~Hz}$. Train protocols were applied at 10-sintervals. The current traces were recorded, and the amplitude of peak current evoked by the last pulse within a train was measured as test parameter. The inhibition was calculated from the peak currents in the presence and absence of the test compound. The control solution contained the same concentration of the vehicle (DMSO or $\mathrm{HCl}$ ) as the solutions of the test compound. Solutions containing the test compounds were applied to the cells for 6-8 min.

\subsection{Determination of toxic alkaloid contents of processed Radix aconiti samples}

Processed Aconitum samples were obtained from different suppliers (Table 5). Unprocessed A. carmichaelii roots were obtained from a pharmacy in China. Aconitine, mesaconitine, and hypaconitine were purchased from PhytoLab $\mathrm{GmbH} .{ }^{82}$

For HPLC, an improved version of a recently reported method has been applied..$^{82}$ Peaks of mesaconitine, aconitine, and hypaconitine were identified by comparison of the HPLC-DAD chromatograms of the extracts of aconite roots with those of the reference solutions. Alkaloid content was calculated by comparison of the sum of the areas under curves (AUC) of mesaconitine, aconitine, and hypaconitine on the basis of the calibration curve established for aconitine. Calibration was established for aconitine based on five concentrations (with a range of $0.05-1.625 \mu \mathrm{g}$ ). ${ }^{82}$

Alkaloid titration was carried out according the method of the German Homeopathic Pharmacopoeia as published in ref. ${ }^{82}$ 


\section{RESULTS}

\subsection{Isolation of alkaloids}

\subsubsection{Isolation of alkaloids from A. anthora}

The dry herbal sample was $220 \mathrm{~g}$. The ground sample was percolated with $\mathrm{MeOH}$ (12 L) (Figure 3). After evaporation in vacuo, the concentrated extract $(370 \mathrm{~mL})$ was diluted with water $(130 \mathrm{~mL})$, and acidified with $4 \% \mathrm{H}_{2} \mathrm{SO}_{4}(250 \mathrm{~mL})$. After the removal of neutral materials with $\mathrm{CHCl}_{3}(5 \times 500 \mathrm{~mL})$, the acidic solution was adjusted to $\mathrm{pH} 9.0$ with $5 \% \mathrm{NaOH}$, and extracted with $\mathrm{CHCl}_{3}(5 \times 500 \mathrm{~mL})$ to yield the crude alkaloid fraction ( $3.09 \mathrm{~g}$ ). This crude fraction was first separated by VLC (VLC I). Fractions eluted with cyclohexane- $\mathrm{CHCl}_{3}-\mathrm{MeOH}$ (50:50:2) having similar composition (VLCl/6-10) were subjected to preparative LC (PLC I) yielding ANT-1 (12 mg, amorphous solid). Fractions obtained with cyclohexane- $\mathrm{CHCl}_{3}-\mathrm{MeOH} \quad(50: 50: 2)$ (VLC I/17-19) were subjected to repeated gel chromatography (GFC I and GFC II). The obtained compound was combined with the main alkaloid constituent obtained with consequent GFC (GFC III) of VLC I fractions 20-23, then further purified with and PLC (PLCII). This process afforded ANT-2, (8.2 mg, amorphous solid). The fractions obtained from VLC I with the solvent system cyclohexane- $\mathrm{CHCl}_{3}-\mathrm{MeOH}$ 50:50:5 (VLC I/24-27) were subjected to GFC (GFC IV). Upon standing, the alkaloid fraction of this separation furnished a crystalline material, which Figure 3. Isolation of alkaloids from $A$. anthora

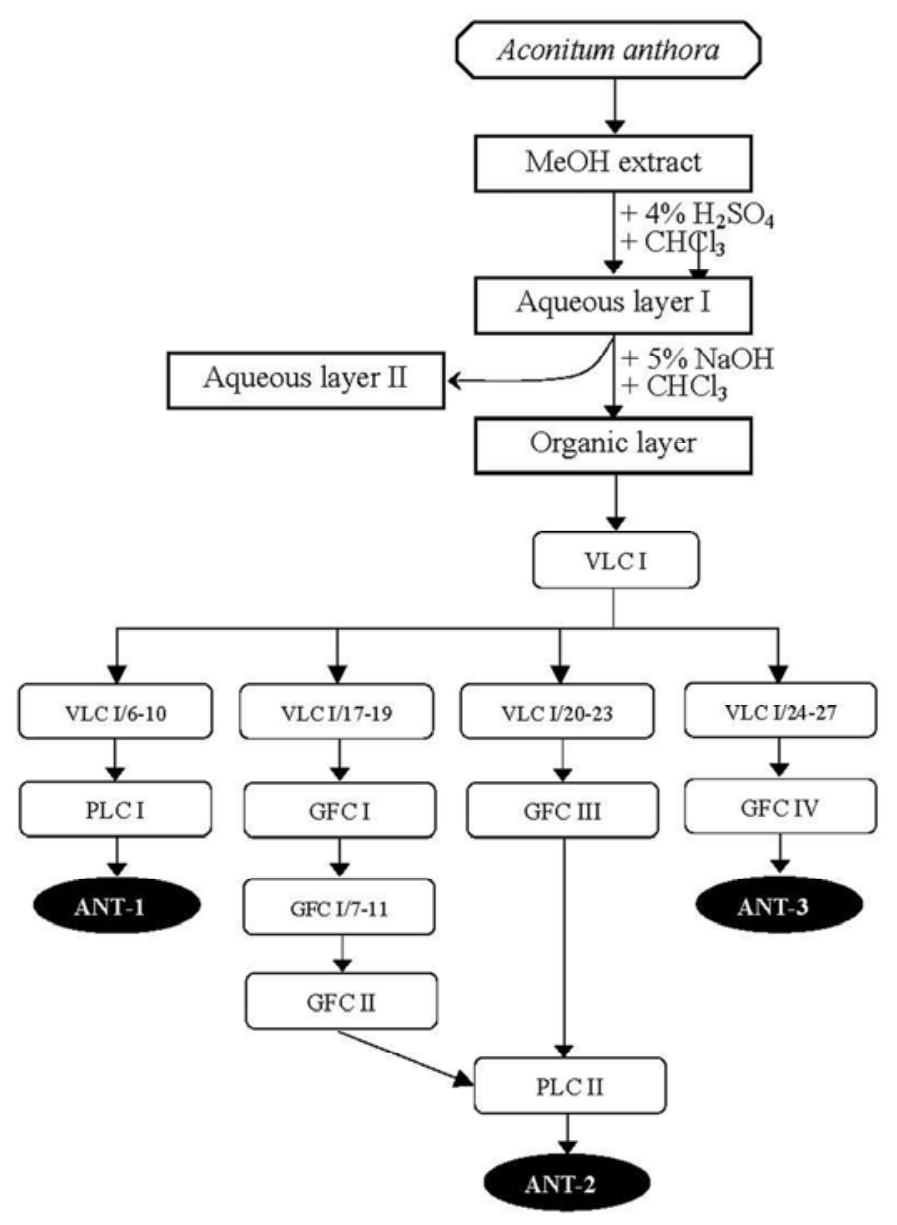
was recrystallised from $\mathrm{MeOH}$, yielding ANT-3 (23.0 mg, m.p. $283-5^{\circ} \mathrm{C}$ ) in pure form.

\subsubsection{Isolation of alkaloids from A. moldavicum}


The fresh sample mass was $1086 \mathrm{~g}$. The ground sample was percolated with $15.2 \mathrm{~L} \mathrm{MeOH}$ and, after evaporation in vacuo, the concentrated, dry residue was $40.6 \mathrm{~g}$. This residue was separated by CC (CC I) on $\mathrm{Al}_{2} \mathrm{O}_{3}(1428.5 \mathrm{~g})$, using a gradient system of cyclohexane-EtOAc-MeOH with increasing polarity (Figure 4). Crystalline material precipitated from fraction 10 (CC I/10) eluted with cyclohexane-EtOAc-MeOH (70:30:1). Recrystallisation was carried out using cyclohexane-EtOAc 7:3, yielding AMO-2 (122 mg, m.p. $136-9^{\circ} \mathrm{C}$ ) in pure form.

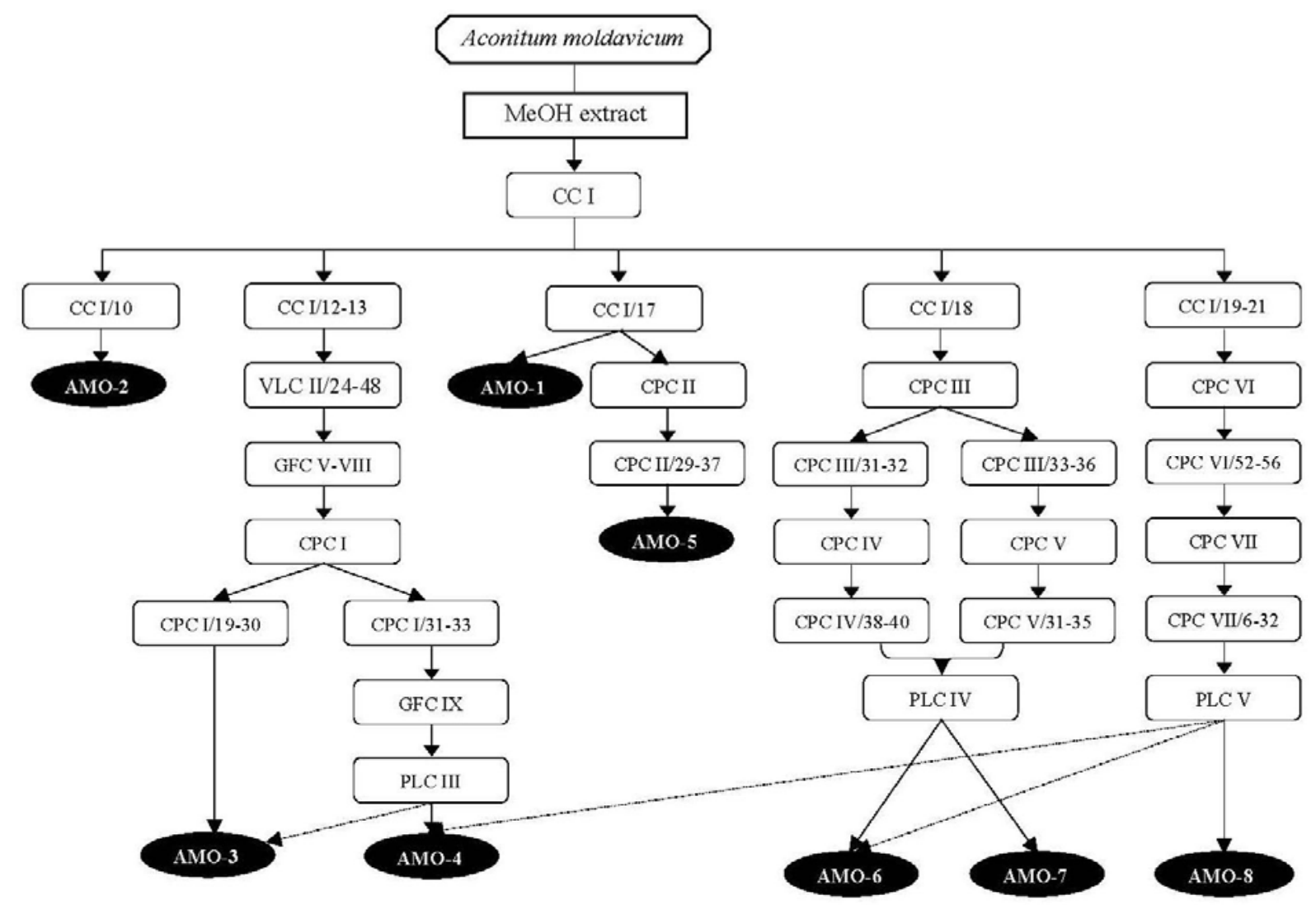

Figure 4. Isolation of alkaloids from A. moldavicum

Fractions eluted with cyclohexane-EtOAc-MeOH (70:30:1) having similar alkaloid composition (CC I/12-13) were combined and subjected to VLC (VLC II) using a gradient system of $n$ Hex-EtOAc-MeOH with increasing polarity. Fractions eluted with $n \mathrm{Hex}-\mathrm{EtOAc}-\mathrm{MeOH}$ (70:30:1, 70:30:1.5, and 70:30:2) (VLC II/24-48) were further purified with repeated gel chromatography (GFC V-VIII). The resulting fractions having similar composition were combined and further purified by $\mathrm{CPC}$ on $\mathrm{Al}_{2} \mathrm{O}_{3}$ stationary phase with a gradient system of $\mathrm{CH}_{2} \mathrm{Cl}_{2}-\mathrm{MeOH}$ with increasing polarity (CPC I). Fractions eluted from CPC I with $\mathrm{CH}_{2} \mathrm{Cl}_{2}-\mathrm{MeOH}$ 95:5 and 93:7 (CPC l/19-30) furnished crystalline AMO-3 (214 mg, m.p. 89$94{ }^{\circ} \mathrm{C}$ ) in pure form. Fractions eluted from $\mathrm{CPC}$ I with $\mathrm{CH}_{2} \mathrm{Cl}_{2}-\mathrm{MeOH}$ 93:7 (CPC I/31-33) were further purified with gel chromatography (GFC IX) followed by PLC (PLC III) to obtain AMO-4 (2.9 mg, amorphous solid) along with further amount of lycoctonine (AMO-3, $22.8 \mathrm{mg}$ ). Crystallisation was 
also observed in case of fraction 17 eluted from CC I with cyclohexane-EtOAc-MeOH (70:30:3) (CC I/17). The obtained material was recrystallised from cyclohexane-EtOAc 7:3 to yield AMO-1 (753 mg, m.p. $201-5^{\circ} \mathrm{C}$ ) in pure form. The mother liquor of this fraction was subjected to $\mathrm{CPC}$ on $\mathrm{Al}_{2} \mathrm{O}_{3}$ stationary phase with a gradient system of $n \mathrm{Hex}-\mathrm{EtOAc}-\mathrm{MeOH}$ with increasing polarity (CPC II). Fractions eluted from CPC II with $n \mathrm{Hex}-\mathrm{EtOAc}-\mathrm{MeOH}$ 70:30:4 and 70:30:4.5 (CPC II/29-37) furnished AMO-5 (27 mg, amorphous solid). Fraction eluted from CC I with cyclohexane-EtOAc-MeOH (70:30:3) (CC I/18) was further purified at first instance by $\mathrm{CPC}$ on $\mathrm{Al}_{2} \mathrm{O}_{3}$ stationary phase with a gradient system of $n \mathrm{Hex}-\mathrm{CH}_{2} \mathrm{Cl}_{2}-\mathrm{MeOH}$ with increasing polarity (CPC III). Subfractions eluted from CPC III with $n \mathrm{Hex}-\mathrm{CH}_{2} \mathrm{Cl}_{2}-\mathrm{MeOH}$ (70:30:4) (CPC III/31-32, CPC III/33-36) were parallely subjected to $\mathrm{CPC}$ on $\mathrm{Al}_{2} \mathrm{O}_{3}$ stationary phase with a gradient system of $n \mathrm{Hex}-\mathrm{CH}_{2} \mathrm{Cl}_{2}-\mathrm{MeOH}$ with increasing polarity (CPC IV and CPC V, respectively). Respective subfractions eluted with $n \mathrm{Hex}-\mathrm{CH}_{2} \mathrm{Cl}_{2}-\mathrm{MeOH}$ (70:30:7) (CPC IV/38-40, CPC V/31-35) were combined and then finally purified using PLC (PLC IV) to obtain AMO-6, (2 mg, amorphous solid) along with AMO-7 (3.6 mg, amorphous solid). Combined fractions eluted from CC I with cyclohexane-EtOAc-MeOH (70:30:5 and 70:30:7) (CC I/19-21) were purified by $\mathrm{CPC}$ on $\mathrm{Al}_{2} \mathrm{O}_{3}$ stationary phase with a gradient system of $n \mathrm{Hex}-\mathrm{CH}_{2} \mathrm{Cl}_{2}-\mathrm{MeOH}$ with increasing polarity (CPC VI). Subfractions eluted from CPC VI with $n \mathrm{Hex}-\mathrm{CH}_{2} \mathrm{Cl}_{2}-\mathrm{MeOH}$ (70:30:7) (CPC VI/52-56) were again subjected to $\mathrm{CPC}$ on $\mathrm{Al}_{2} \mathrm{O}_{3}$ stationary phase using now a two-step gradient of To-acetoneEtOH-cc. $\mathrm{NH}_{3}$ (CPC VII). Fractions obtained from this step (CPC VII/6-32) were combined and finally purified by using PLC (PLC V) to yield the new $\mathrm{C}_{19}$ DA AMO-8 (2 mg, amorphous solid) along with further amounts of AMO-4 (25.8 mg) and AMO-6 (7.4 mg)

\subsection{Structure elucidation of the isolated compounds}

\subsubsection{Alkaloids from A. anthora}

\section{ANT-2}

ANT-2 was isolated as amorphous solid; $[\alpha]_{D}{ }^{28}:-7$ (c $0.1, \mathrm{CHCl}_{3}$ ); for ${ }^{1} \mathrm{H}$ - and ${ }^{13} \mathrm{C}-\mathrm{NMR}$ data see Table A in Annex IV. The ESI-MS investigation demonstrated the presence of a molecular ion peak at $\mathrm{m} / \mathrm{z} 452.2994[\mathrm{M}+\mathrm{H}]^{+}\left(\mathrm{C}_{25} \mathrm{H}_{42} \mathrm{NO}_{6}\right)$, which afforded fragment ions at $\mathrm{m} / \mathrm{z} 420.2741\left[\mathrm{M}+\mathrm{H}-\mathrm{CH}_{3} \mathrm{OH}\right]^{+}$, $388.2476\left[\mathrm{M}+\mathrm{H}-2 \times \mathrm{CH}_{3} \mathrm{OH}\right]^{+}$and $370.2372\left[\mathrm{M}+\mathrm{H}-2 \times \mathrm{CH}_{3} \mathrm{OH}-\mathrm{H}_{2} \mathrm{O}\right]^{+}$. The ${ }^{1} \mathrm{H}-\mathrm{NMR}$ and JMOD spectra of ANT-2 showed signals at $\delta_{\mathrm{H}} 1.08 \mathrm{t}, 2.50 \mathrm{~m}$ and $2.41 \mathrm{dq}$ and $\delta_{\mathrm{C}} 49.4$ and 13.6, characteristic of an $\mathrm{N}$ ethyl group. Singlet signals at $\delta_{\mathrm{H}} 3.14,3.28,3.31$ and 3.37 (each $3 \mathrm{H}, s$ ) and carbon signals at $\delta_{\mathrm{C}} 48.2$, $56.0,56.4$ and 59.5 were indicative of the presence of four methoxy groups. In addition, the JMOD spectrum demonstrated that ANT-2 has a $\mathrm{C}_{19}$ norditerpene core, composed of four quaternary carbons, eight methines and seven methylenes (Table A in Annex IV). 
The HSQC experiments allowed the assignment of protons and protonated carbons. Interpretation of the proton-proton connectivities in the ${ }^{1} \mathrm{H}-{ }^{1} \mathrm{H} C O S Y$ spectrum led to the identification of three structural fragments: $-\mathrm{CH}_{-}-\mathrm{CH}_{2}-\mathrm{CH}_{2}$ (unit $\mathrm{A}, \mathrm{C}-1-\mathrm{C}-3$ ), $-\mathrm{CH}-\mathrm{CH}_{2}-\mathrm{CH}-\mathrm{CH}$ - (unit $\mathrm{B}$, $\mathrm{C}-5-\mathrm{C}-6-\mathrm{C}-7-\mathrm{C}-17$ ) and $-\mathrm{CH}-\mathrm{CH}(\mathrm{OR})-\mathrm{CH}\left(\mathrm{CH}_{2}-\right)-\mathrm{CH}(\mathrm{OR})-\mathrm{CH}_{2}$ ( unit $\left.\mathrm{C}, \mathrm{C}-9-\mathrm{C}-14-\mathrm{C}-13(\mathrm{C} 12)-\mathrm{C}-16-\mathrm{C}-15\right)$, two isolated methylenes $\left[\delta_{\mathrm{H}} 3.01 \mathrm{~d}, 3.13 \mathrm{~d}(\mathrm{C}-18)\right.$ and $\left.2.02 \mathrm{~d}, 2.54 \mathrm{~d}(\mathrm{C}-19)\right]$, and one $\mathrm{N}$-ethyl group. The long-range correlations form HMBC confirmed, that structural fragments $A-C$ and the two methylene groups (C-18 and C-19), together with the quaternary carbons $C-4, C-8, C-10$ and $C-11$, build up a norditerpene skeleton. Important two- and three-bond correlations were observed between the quaternary carbon at $\delta_{\mathrm{C}} 54.8(\mathrm{C}-11)$ and the protons at $\delta_{\mathrm{H}} 3.75(\mathrm{H}-1), 2.41(\mathrm{H}-7), 2.66(\mathrm{H}-$ 12a) and $2.87(\mathrm{H}-17)$, and between the carbon at $\delta_{\mathrm{C}} 38.4(\mathrm{C}-4)$ and the protons at $\delta_{\mathrm{H}} 1.75(\mathrm{H}-3 \mathrm{a}), 1.42$ (H-3b), $1.84(\mathrm{H}-5), 3.13(\mathrm{H}-18 \mathrm{a}), 3.01(\mathrm{H}-18 \mathrm{~b}), 2.54(\mathrm{H}-19 \mathrm{a})$ and $2.02(\mathrm{H}-19 \mathrm{~b})$, indicating that fragment $A$ and the quaternary carbons C-4 and C-11 form a six-membered ring. The correlations of the quaternary carbon at $\delta_{\mathrm{C}} 77.0(\mathrm{C}-8)$ with the protons at $\delta_{\mathrm{H}} 1.82(\mathrm{H}-6 \mathrm{a}), 1.47(\mathrm{H}-6 \mathrm{~b}), 2.41(\mathrm{H}-7), 1.99(\mathrm{H}-$ 9), $2.19(\mathrm{H}-15 \mathrm{a})$ and $2.10(\mathrm{H}-15 \mathrm{~b})$, and of the carbon at $\delta_{\mathrm{C}} 81.1(\mathrm{C}-10)$ with the protons at $\delta_{\mathrm{H}} 3.75(\mathrm{H}-$ 1), $1.99(\mathrm{H}-9), 2.66(\mathrm{H}-12 \mathrm{a}), 1.71(\mathrm{H}-12 \mathrm{~b}), 2.50(\mathrm{H}-13)$ and $2.87(\mathrm{H}-17)$ proved the linkage of structural parts $C$ and $B$ as in the aconitane skeleton with six oxygen functions. The HMBC spectrum also provided information on the locations of the four methoxy groups. The long-range correlations of C$1, \mathrm{C}-8, \mathrm{C}-16$ and $\mathrm{C}-18$ with the protons at $\delta_{\mathrm{H}} 3.28,3.14,3.37$ and 3.31 (each $3 \mathrm{H}$ ) revealed the positions of methoxy groups at C-1, C-8, C-16 and C-18, respectively. The 8-OMe group displayed an unusual high-field carbon resonance $\left(\delta_{\mathrm{C}} 48.2\right)$, similarly as observed for other 8-methoxy-substituted NDAs. ${ }^{163}$ The two hydroxy groups in ANT-2, which were evident from the molecular mass and the carbon resonances at $\delta_{\mathrm{C}} 73.3$ and 81.1, were located of necessity on C-10 and C-14.

The relative stereochemistry of ANT-2 was elucidated by analysing the NOESY spectrum. As starting point, the stereochemistry of $\mathrm{H}-5$ was considered to be $\beta$, as characteristic for NDAs. The Overhauser effects between $\mathrm{H}-5$ and $\mathrm{H}-1$, and between $\mathrm{H}-5$ and $\mathrm{H}-18 \mathrm{a}$, were indicative of the $\beta$ position of $\mathrm{H}-1$ and the 18-methylene group. The NOESY correlations between $\mathrm{H}-19$ and $\mathrm{H}-17, \mathrm{H}-19$ and $\mathrm{H}-21, \mathrm{H}-17$ and $\mathrm{H}-16$, and $\mathrm{H}-17$ and $\mathrm{H}-12 \alpha$ pointed to $\alpha$-oriented protons, and corroborated that the $\mathrm{N}$-containing bridge, between $\mathrm{C}-19$ and $\mathrm{C}-17$, including the $\mathrm{N}$-ethyl group, is below the plane of the six-membered ring. Further important NOEs were detected between $\mathrm{H}-9$ and $\mathrm{H}-14, \mathrm{H}-13$ and $\mathrm{H}-$ 14, $\mathrm{H}-12 \beta$ and $\mathrm{H}-13, \mathrm{H}-12 \beta$ and $\mathrm{H}-14, \mathrm{H}-13$ and $16-\mathrm{OMe}$, and $\mathrm{H}-15 \beta$ and 8-OMe, which confirmed the $\beta$ orientation of all of these protons and groups. Furthermore, some NOESY correlations were suitable for the steric differentiation of methylene protons $\left(\mathrm{H}_{2}-2\right.$, $H_{2}-3, H_{2}-6, H_{2}-12$ and $\left.H_{2}-15\right)$. Such correlations were observed

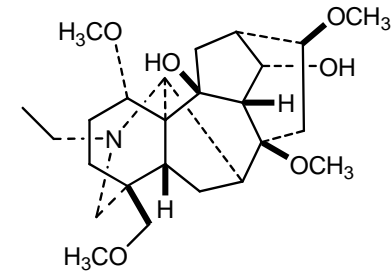

10-hydroxy-8-O-methyltalatizamine (ANT-2) 
between $\mathrm{H}-1$ and $\mathrm{H}-2 \beta ; \mathrm{H}-1$ and $\mathrm{H}-3 \beta ; \mathrm{H}-2 \alpha$ and $\mathrm{H}-3 \alpha ; \mathrm{H}-9$ and $\mathrm{H}-6 \beta ; \mathrm{H}-16$ and $\mathrm{H}-12 \alpha ; \mathrm{H}-16$ and $\mathrm{H}-$ $15 \alpha ; \mathrm{H}-17$ and $\mathrm{H}-15 \alpha ; \mathrm{H}-15 \beta$ and 8-OMe; $\mathrm{H}-13$ and $\mathrm{H}-12 \beta$; and $\mathrm{H}-14$ and $\mathrm{H}-12 \beta$. All of the above evidence confirmed the structure of ANT-2 as 10-hydroxy-8-O-methyltalatizamine.

\section{ANT-1}

The ${ }^{1} \mathrm{H}-\mathrm{NMR}$ spectrum of ANT-1 showed the presence of two methoxy [ $\delta 3.32$ and $3.34 \mathrm{ppm}(2 \times 3 \mathrm{H}$, $2 \times s)]$ and one $N$-ethyl groups [ $\delta 1.12 \mathrm{ppm}(3 \mathrm{H}, \mathrm{t}, J=7,0 \mathrm{~Hz})]$. The JMOD spectrum of this compound proved the presence of two methoxy groups $(\delta 56.3,59.4 \mathrm{ppm})$ and an $N$-ethyl substituent $(\delta 48.5$, $13.0 \mathrm{ppm})$. In addition, it indicated further 19 carbon atoms, namely a norditerpenoid core. The carbon skeleton is built up by 9 methine and 10 methylene+quaternary carbon atoms, distinguished them on the basis of the ${ }^{13} \mathrm{C}$ resonance signals. Such structure corresponds to isotalatizidine (20). The spectral data were compared, and it was concluded that NMR data of the isolated compound and of isotalatizidine (Table C in Annex IV) showed good correlation, thus, ANT-1 is identical with isotalatizidine (20).

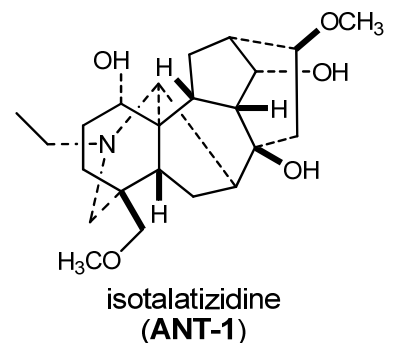

This compound was reported earlier from a Turkish population of $A$. anthora by MERIÇLI et al. ${ }^{40}$ We found ${ }^{13} \mathrm{C}-\mathrm{NMR}$ chemical shifts identical to those described earlier, ${ }^{164}$ but our 2D NMR investigations, including ${ }^{1} \mathrm{H}-{ }^{1} \mathrm{H} C O S Y, H S Q C$ and $\mathrm{HMBC}$ experiments, permitted some revised ${ }^{13} \mathrm{C}$ assignments and complete chemical shift assignments for all protons of $\mathbf{2 0}$ (Table $\mathbf{C}$ in Annex IV). The HMBC correlations between C-3/H-1, C-2/H $-3, \mathrm{C}-3 / \mathrm{H}_{2}-18, \mathrm{C}-3 / \mathrm{H}_{2}-19, \mathrm{C}-10 / \mathrm{H}-1, \mathrm{C}-10 / \mathrm{H}-5, \mathrm{C}-10 / \mathrm{H}-9$, C-10/H $2-12, \mathrm{C}-10 / \mathrm{H}-13, \mathrm{C}-10 / \mathrm{H}-17, \mathrm{C}-12 / \mathrm{H}-9, \mathrm{C}-12 / \mathrm{H}-10, \mathrm{C}-12 / \mathrm{H}-16, \mathrm{C}-13 / \mathrm{H}-9, \mathrm{C}-13 / \mathrm{H}-12, \mathrm{C}-13 / \mathrm{H}-14$, $\mathrm{C}-13 / \mathrm{H}-15$, and $\mathrm{C}-13 / \mathrm{H}-16$ indicated the ${ }^{13} \mathrm{C}$ reassignments of $\mathrm{C}-2, \mathrm{C}-3, \mathrm{C}-10, \mathrm{C}-12$ and $\mathrm{C}-13$, as listed in Table C in Annex IV.

\section{ANT-3}

ANT-3 was isolated as white crystals (m.p. $283-5^{\circ} \mathrm{C}$ ). Its JMOD spectrum contained signals of 20 carbon atoms, which allows to conclude a $C_{20}$ diterpenoid structure. Signals at 145.3 and $108.1 \mathrm{ppm}$ were indicative to an exomethylene group in the molecule, which is common in the $C_{20}$ diterpenoid alkaloids isolated from Aconitum species. Additional ${ }^{13} \mathrm{C}-\mathrm{NMR}$

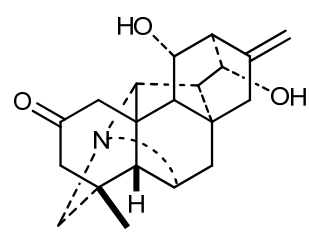

hetisinone (ANT-3) signals showed the presence of 9 secondary+quaternary, 8 methine and 1 methyl groups. The carbon signal at $212.9 \mathrm{ppm}$ refers to a keto group. In the ${ }^{1} \mathrm{H}-\mathrm{NMR}$ spectrum of ANT-3 1 methyl signal connectioned to a quaternary carbon atom was identified $(\delta 1.14 \mathrm{~s}, 3 \mathrm{H})$. Additionally, hydrogens of the exomethylene group could be detected at $\delta 4.86(\mathrm{~s})$ and $4.68(\mathrm{~s}) \mathrm{ppm}$. It was found that the ${ }^{1} \mathrm{H}$ and ${ }^{13} \mathrm{C}$ chemical shifts of ANT-3 are in good agreement with the data of hetisinone (39) published by 
DE LA FUENTE et al. The ${ }^{13} \mathrm{C}$ chemical shifts correlated well with the data published by GonZALEZ et al. The above evidence indicated that ANT-3 is identical with hetisinone (39). ${ }^{165,166}$

\subsubsection{Alkaloids from A. moldavicum}

\section{AMO-8}

AMO-8 was isolated as amorphous solid; $[\alpha]_{D}{ }^{28}:+22$ (c $0.1, \mathrm{CHCl}_{3}$ ); for ${ }^{1} \mathrm{H}$ - and ${ }^{13} \mathrm{C}$-NMR data see Table B in Annex IV. It was shown by HRESIMS to have the molecular formula of $\mathrm{C}_{24} \mathrm{H}_{39} \mathrm{NO}_{8}$ according to the quasimolecular ion peak at $\mathrm{m} / \mathrm{z} 470.2761[\mathrm{M}+\mathrm{H}]^{+}$(calcd. for $\mathrm{C}_{24} \mathrm{H}_{40} \mathrm{O}_{8} 470.2754$ ), which afforded fragment ions at $\mathrm{m} / \mathrm{z} 452\left[\mathrm{M}+\mathrm{H}-\mathrm{H}_{2} \mathrm{O}\right]^{+}$and $320\left[\mathrm{M}+\mathrm{H}-\mathrm{CH}_{3} \mathrm{OH}\right]^{+}$. The ${ }^{1} \mathrm{H}$ and ${ }^{13} \mathrm{C} \mathrm{JMOD}$ spectra of AMO-8 indicated the presence of an $N$-ethyl group $\left(\delta_{\mathrm{H}} 1.11 \mathrm{t}, 2.97 \mathrm{~m}\right.$ and $2.85 \mathrm{dq} ; \delta_{\mathrm{C}} 50.3$ and 14.0). Singlet signals at $\delta_{\mathrm{H}} 3.35,3.43$ and 3.45 (each $3 \mathrm{H}, s$ ) and carbon signals at $\delta_{\mathrm{C}} 56.3,57.8$ and 58.0 demonstrated the presence of three methoxy groups. Further, the JMOD spectrum suggested that the skeleton consists of 19 carbons, including six methylenes, eight methines and five quaternary carbons (Table B in Annex IV). From the HSQC spectrum, the chemical shifts of the protonated carbons were assigned, and the proton-proton connectivities were then studied. The ${ }^{1} \mathrm{H}$ ${ }^{1} \mathrm{H}$ COSY spectrum defined structural fragments with correlated protons: $-\mathrm{CHR}^{-} \mathrm{CH}_{2}-\mathrm{CH}_{2}-$ (unit $\mathrm{A}, \mathrm{C}-$ $1-\mathrm{C}-3)\left(\delta_{\mathrm{H}} 4.06 \mathrm{brs}, 1.72 \mathrm{~m}, 1.68 \mathrm{~m}, 1.98 \mathrm{~m}\right.$ and $1.47 \mathrm{~m}$ ), $-\mathrm{CH}-\mathrm{CHR}-$ (unit B, C-5-C-6) $\left(\delta_{\mathrm{H}} 2.15 \mathrm{~s}, 4.03\right.$ s), $-\mathrm{CH}-\mathrm{CHR}-\mathrm{CH}-\mathrm{CH}_{2}-$ (unit C, C-9-C-14-C-13-C-12) ( $\delta_{\mathrm{H}} 2.83 \mathrm{~d}, 4.11 \mathrm{t}, 2.58 \mathrm{dd}, 2.34 \mathrm{~d}$ and $1.95 \mathrm{dd}$ ), $-\mathrm{CH}_{2}-\mathrm{CH}-$ (unit D, C-15-C-16) $\left(\delta_{\mathrm{H}} 2.63 \mathrm{dd}, 1.80 \mathrm{dd}\right.$ and $3.26 \mathrm{dd}$ ), two isolated methylenes $\left[\delta_{\mathrm{H}} 3.40 \mathrm{~d}\right.$, $3.70 \mathrm{~d}(\mathrm{C}-18)$ and $2.45 \mathrm{~d}, 2.49 \mathrm{~d}(\mathrm{C}-19)$ ], and one $\mathrm{N}$-ethyl group. The long-range correlations detected in the HMBC spectrum proved, that structural elements A-D and the two methylene groups (C-18 and $\mathrm{C}-19)$, together with the quaternary carbons $\mathrm{C}-4, \mathrm{C}-7, \mathrm{C}-8, \mathrm{C}-10$ and $\mathrm{C}-11$, build up an aconitane diterpene substituted in C-1, 6, 7, 8, 10, 14, 16, 18 positions (Table B in Annex IV). The location of the methoxy groups were established via HMBC experiments. The long-range correlations of C-6, C-14 and $\mathrm{C}-16$ with the protons at $\delta_{\mathrm{H}} 4.03 \mathrm{~s}, 4.11 \mathrm{t}$ and $3.26 \mathrm{dd}$ demonstrated the presence of methoxy groups at C-6, C-14 and C-16, respectively. The four hydroxy groups in AMO-8 were located of necessity on C-1, C-7, C-8, C-10 and C-18. The stereochemistry and relative configuration of AMO-8 were studied by means of a NOESY experiment (Table B in Annex IV). As reference point, the $\beta$ stereochemistry of H-5 was used, which is characteristic for NDAs. The Overhauser effects between H-5/H-9, H-5/H-3ß, H-3ß/H-1, H-9/H-14, H-9/8-OH, H-14/13, H-13/H$12 \beta, \mathrm{H}-12 \beta / \mathrm{H}-14$ and $8-\mathrm{OH} / \mathrm{H}-6$ were indicative of the $\beta$ position of these protons and $8-\mathrm{OH}$ group. On the other hand, NOE effects observed between $\mathrm{H}-6 / \mathrm{H}-19, \mathrm{H}-17 / \mathrm{H}-16, \mathrm{H}-17 / \mathrm{H}-20, \mathrm{H}-16 / \mathrm{H}-12 \alpha, \mathrm{H}-$ $16 / \mathrm{H}-15 \alpha$ exhibited the $\alpha$-orientation of $\mathrm{H}-6, \mathrm{H}-16$ and corroborated

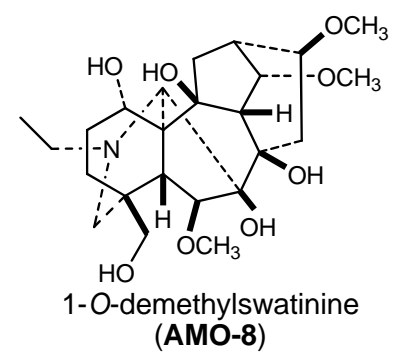


that the $\mathrm{N}$-containing bridge, between $\mathrm{C}-19$ and $\mathrm{C}-17$, including the $\mathrm{N}$-ethyl group, is below the plane of ring A. All of the above evidence was used to propose the structure of this compound as new alkaloid, 1-O-demethylswatinine (47).

Further compounds isolated from A. moldavicum were identified as delcosine (40, AMO-1), ajacine (41, AMO-2), lycoctonine (42, AMO-3), gigactonine (44, AMO-5), and cammaconine (45, AMO-6) by comparing their spectral data with those reported in the literature. ${ }^{167,168169}$ Swatinine (43, AMO-4) and columbianine (46, AMO-7) are known compounds of the Aconitum genus (found in A. laeve, $A$. ferox and $A$. lamarckii) ${ }^{91,171}$, but our $2 \mathrm{D}$ NMR studies provided the complete ${ }^{1} \mathrm{H}$ assignments for these alkaloids for the first time (Table D in Annex IV).

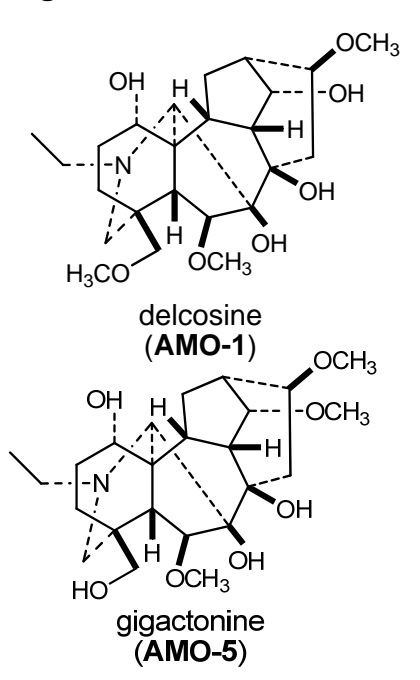

\subsection{Semisynthesis of lipo-alkaloids}

As a result of the semisynthesis the following transesterified compounds were obtained: 14-BzA-8-Olaurate (25), 14-BzA-8-O-myristate (26), 14-BzA-8-O-stearate (27), 14-BzA-8-O-palmitoleate (28), 14 BzA-8-O-oleate (29), 14-BzA-8-O- $\alpha$-linolenate (30), 14-BzA-8-O- - -linolenate (31), 14-BzA-8-Oeicosanoate (32), 14-BzA-8-O-eicosa-11Z-enoate (33) 14-BzA-8-O-eicosa-11Z,14Z-dienoate (34), 14-BzA-8-O-eicosa-8Z,11Z,14Z-trienoate (35) 14-BzA-8-O-eicosapentaenoate (36), 14-BzA-8-Odocosahexaenoate (37).

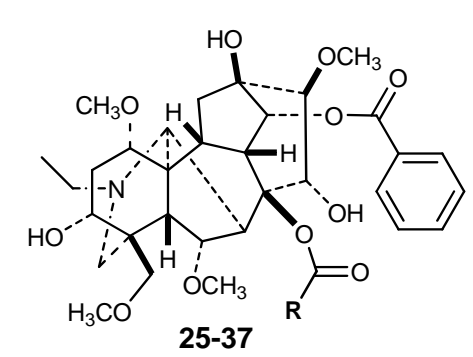

R: esterifying fatty acid

\begin{tabular}{|c|c|c|}
\hline $\begin{array}{l}\text { Comp. } \\
\text { No. }\end{array}$ & Esterifying fatty acid & $\begin{array}{l}\text { Corresponding lipo-alkaloid } \\
\text { (BzA = benzoylaconine) }\end{array}$ \\
\hline 25 & lauric & 14-BzA-8-O-laurate \\
\hline 26 & myristic & 14-BzA-8-O-myristate \\
\hline 27 & stearic & 14-BzA-8-O-stearate \\
\hline 28 & palmitoleic & 14-BzA-8-O-palmitoleate \\
\hline 29 & oleic & 14-BzA-8-O-oleate \\
\hline 30 & $\alpha$-linolenic & 14-BzA-8-O- $\alpha$-linolenate \\
\hline 31 & $y$-linolenic & 14-BzA-8-O- - -linolenate \\
\hline 32 & eicosanoic & 14-BzA-8-O-eicosanoate \\
\hline 33 & 11Z-eicosenoic & 14-BzA-8-O-eicosa-11Z-enoate \\
\hline 34 & $11 Z, 14 Z$ - eicosadienoic & 14-BzA-8-O-eicosa-11Z,14Z-dienoate \\
\hline 35 & $8 Z, 11 Z, 14 Z$-eicosatrienoic & 14-BzA-8-O-eicosa-8Z,11Z,14Z-trienoate \\
\hline 36 & eicosapentaenoic & 14-BzA-8-O-eicosapentaenoate \\
\hline 37 & docosahexaenoic & 14-BzA-8-O-docosahexaenoate \\
\hline
\end{tabular}




\subsection{Pharmacological tests with the isolated and semisynthesised alkaloids}

\subsubsection{Assays for COX-1, COX-2 and $\mathrm{LTB}_{4}$ formation inhibitory activity}

The aim of the semisynthetic preparation of a LA series was to gain information about the pharmacology of these compounds and to conclude some structure-activity relationships concerning the nature of esterifying fatty acids. ${ }^{160}$ In vitro anti-inflammatory activities of altogether thirteen LAs (25-37) were evaluated by COX-1, COX-2 and $\mathrm{LTB}_{4}$ formation inhibitory assays (Table 2).

Table 2: In vitro anti-inflammatory activities of semisynthetic LAs

\begin{tabular}{|c|c|c|c|}
\hline \multirow{2}{*}{ Compound } & \multicolumn{3}{|c|}{ Inhibition $\% \pm$ SD* } \\
\hline & COX-1 & COX-2 & LTB $_{4}$ formation \\
\hline 14-BzA-8-O-laurate (25) & $-29.8 \pm 5.7$ & $-8.0 \pm 5.6$ & $33.5 \pm 11.2$ \\
\hline 14-BzA-8-O-myristate (26) & $-25.3 \pm 21.6$ & $-4.0 \pm 15.1$ & $35.9 \pm 9.8$ \\
\hline 14-BzA-8-O-stearate (27) & $-33.5 \pm 39.3$ & $-3.5 \pm 10.2$ & $52.5 \pm 5.9$ \\
\hline 14-BzA-8-O-palmitoleate (28) & $-18.8 \pm 8.7$ & $17.1 \pm 9.0$ & $34.5 \pm 6.5$ \\
\hline 14-BzA-8-O-oleate (29) & $-24.3 \pm 17.0$ & $15.3 \pm 28.9$ & $45.5 \pm 4.6$ \\
\hline 14-BzA-8-O- $\alpha$-linolenate (30) & $-5.9 \pm 20.7$ & $22.0 \pm 7.8$ & $48.0 \pm 1.9$ \\
\hline 14-BzA-8-O- - -linolenate (31) & $-11.8 \pm 22.8$ & $12.7 \pm 4.9$ & $34.7 \pm 1.7$ \\
\hline 14-BzA-8-O-eicosanoate (32) & $25.7 \pm 6.5$ & $-1.8 \pm 22.1$ & $30.9 \pm 11.8$ \\
\hline 14-BzA-8-O-eicosa-11Z-enoate (33) & $25.1 \pm 2.2$ & $-19.7 \pm 9.1$ & $25.7 \pm 6.5$ \\
\hline 14-BzA-8-O-eicosa-11Z,14Z-dienoate (34) & $26.3 \pm 10.8$ & $34.7 \pm 17.5$ & $25.1 \pm 2.2$ \\
\hline 14-BzA-8-O-eicosa-8Z,11Z,14Z-trienoate (35) & $29.9 \pm 2.3$ & no data available & $26.3 \pm 10.8$ \\
\hline 14-BzA-8-O-eicosapentaenoate (36) & $54.5 \pm 24.4$ & $66.1 \pm 3.5$ & $46.0 \pm 3.3$ \\
\hline 14-BzA-8-O-docosahexaenoate (37) & $15.1 \pm 24.2$ & $40.2 \pm 8.8$ & $61.0 \pm 7.9$ \\
\hline
\end{tabular}

* average of 2 tests in duplicate, the compounds were tested at $50 \mu \mathrm{M}$ concentration.

$\mathrm{IC}_{50}$ values of positive controls: indomethacine (COX-1): $0.9 \mu \mathrm{M}$; NSB-398 (COX-2): $2.6 \mu \mathrm{M}$; and zileuton ( $\mathrm{LTB}_{4}$ formation inhibition) $5.0 \mu \mathrm{M}$

In the COX-1 inhibition assay 14-BzA-8-O-eicosapentaenoate (36) exhibited the highest activity with $54.5 \%$ inhibition at $50 \mu \mathrm{M}$. Besides this compound, 14-BzA-8-O-eicosanoate (32), 14-BzA-8-O-eicosa11Z-enoate (33) 14-BzA-8-O-eicosa-11Z,14Z-dienoate (34), 14-BzA-8-O-eicosa-8Z,11Z,14Z-trienoate (35), and 14-BzA-8-O-docosahexaenoate (37) showed moderate inhibitory activities, all other LAs (25-31) were inactive against the COX-1 enzyme.

In the COX-2 inhibition assay, also 14-BzA-8-O-eicosapentaenoate (36) demonstrated remarkable activity (66.1\% inhibition at $50 \mu \mathrm{M})$, which was followed by the moderately effective 14BzA-8-O-eicosa-11Z,14Z-dienoate (34) and 14-BzA-8-O-docosahexaenoate (37). Compounds (28-31 and 34), which contain fatty acid side chains with 1-3 double bonds also showed low inhibitory activities with the exception of 14-BzA-8-O-eicosa-11Z-enoate (33), which contained a relatively long carbon side chain. Compounds with saturated acyl groups $(\mathbf{2 5 - 2 7}, \mathbf{3 2})$ were inactive against COX-2 enzyme.

In the $\mathrm{LTB}_{4}$ formation inhibitory assay all tested compounds showed activity to a certain extent. The highest activity was measured in case of 14-BzA-8-O-docosahexaenoate (37, 61.0\% 
inhibition at $50 \mu \mathrm{M})$. All other LAs (25-36) expressed significant, but lower potency in 5-LOX mediated formation of $\mathrm{LTB}_{4}$.

\subsubsection{Assessment of the $h E R G$-inhibiting ability of Aconitum alkaloids}

The tested series of compounds represent a diversity of structural types, including bisnor- $\left(\mathrm{C}_{18}\right)$, nor$\left(C_{19}\right)$ and diterpene $\left(C_{20}\right)$ alkaloids substituted with hydroxy, methoxy, keto, acetyl and various aromatic ester groups. All the compounds are $\mathrm{N}$-ethyl-substituted with the exception of acovulparine (57), which contains an azomethine group. Table 3 shows the measured hERG current inhibitions exerted by the compounds.

Table 3. Inhibition of hERG current by selected compounds at nominal concentration of $10 \mu \mathrm{M}$

\begin{tabular}{llll}
\hline Compound & Inhibition (\%) & sem & $\mathbf{n}$ \\
\hline acotoxicine (1) & 17.3 & 3.3 & 5 \\
aconitine (5) & 44.9 & 7.4 & 5 \\
isotalatizidine (20) & 19.1 & 3.2 & 5 \\
pyroaconitine (24) & 18.7 & 1.6 & 4 \\
10-hydroxy-8-O-methyltalatizamine (38) & 15.8 & 1.1 & 8 \\
hetisinone (39) & 14.3 & 3.9 & 3 \\
delcosine (40) & 17.9 & 2.4 & 5 \\
ajacine (41) & 13.0 & 1.7 & 7 \\
lycoctonine (42) & 13.7 & 3.3 & 6 \\
swatinine (43) & 8.9 & 1.6 & 5 \\
gigactonine (44) & 38.0 & 7.4 & 5 \\
14-BzA-8-O-palmitate (48) & 39.6 & 5.6 & 7 \\
aconosine (49) & 15.3 & 3.5 & 6 \\
dolaconine (50) & 8.3 & 1.4 & 7 \\
delectinine (51) & 7.7 & 2.3 & 6 \\
neolinine (52) & 35.8 & 4.7 & 5 \\
neoline (53) & 14.4 & 3.7 & 5 \\
acotoxinine (54) & 6.5 & 2.2 & 6 \\
songoramine (55) & 36.4 & 5.4 & 4 \\
songorine (56) & 13.2 & 1.8 & 15 \\
acovulparine (57) & 10.8 & 2.3 & 8 \\
septentriodine (58) & 20.9 & 1.0 & 9 \\
takaosamine (59) & 12.5 & 2.9 & 6 \\
14-desacetyl-18-demethylpubescenine (60) & 6.5 & 1.9 & 6 \\
haloperidol (at 1 $\mu \mathrm{M})$ & 94.6 & 1.3 & 19 \\
\hline
\end{tabular}

The highest hERG blockade activity was observed for the norditerpene diesters aconitine (5) and 14BzA-8-O-palmitate (48), which exerted a 44.9 and a $39.6 \%$ inhibitory effect, respectively. The structurally similar pyroaconitine (24), with only one ester substituent, is a much less potent hERG channel inhibitor, with an $18.7 \%$ inhibitory effect. The further monoesters septentriodine (58), ajacine (41), acotoxinine (54) and dolaconine (50) also revealed only moderate $\mathrm{K}^{+}$channel potency, with 20.9, 13.0, 6.5 and $8.3 \%$ inhibition, respectively. Our results indicate that the substitution with two ester groups is an important structural feature for the $\mathrm{K}^{+}$channel activity. However, it can not be 
stated that the presence of an aryl ester group is required for the exertion of hERG activity, since ajacine (41) and acotoxinine (54) containing aromatic ester functionalities, do not possess high potency. As concerns the other non-esterified compounds based on the aconitane skeleton, gigactonine (44) and neolinine (52) exhibited marked hERG-inhibiting ability with 38.0 and $35.8 \%$ inhibitory activity, respectively. In the $C_{20}$ alkaloid group, songoramine (55) (36.4\% inhibition) was similarly as active as aconitine (5). Its close analogue, songorine (56), containing a 1-hydroxy group instead of 1,19-ether bridge, revealed only a low inhibitory potential on the hERG channel $(13.2 \%$ inhibition).

\subsubsection{Assessment of $\mathrm{Na}_{v} 1.2$ sodium channel activity of Aconitum alkaloids}

This series of alkaloidal compounds represents diverse structural types as it is described in section 5.4.2. Table 4 shows the measured $\mathrm{Na}_{v} 1.2$ inhibitions exerted by the compounds.

Table 4. Inhibition of $\mathrm{Na}_{\mathrm{v}} 1.2$ channels by selected compounds at nominal concentration of $10 \mu \mathrm{M}$

\begin{tabular}{llll}
\hline Compound & Inhibition (\%) & sem & $\boldsymbol{n}$ \\
\hline acotoxicine (1) & 28 & 3. & 8 \\
aconitine (5) & 25 & 3 & 8 \\
isotalatizidine (20) & 18 & 5 & 5 \\
pyroaconitine (24) & 57 & 2 & 7 \\
10-hydroxy-8-O-methyltalatizamine (38) & 16 & 7 & 8 \\
hetisinone (39) & 28 & 3 & 4 \\
delcosine (40) & 13 & 4 & 8 \\
ajacine (41) & 44 & 5 & 8 \\
lycoctonine (42) & 22 & 5 & 7 \\
swatinine (43) & 10 & 4 & 5 \\
gigactonine (44) & 2 & 4 & 7 \\
aconosine (49) & 18 & 6 & 5 \\
dolaconine (50) & 6 & 5 & 7 \\
delectinine (51) & 42 & 5 & 8 \\
14-BzA-8-O-palmitate (48) & 27 & 2 & 9 \\
neolinine (52) & 16 & 6 & 4 \\
neoline (53) & 15 & 4 & 7 \\
acotoxinine (54) & 14 & 4 & 4 \\
songoramine (55) & 15 & 3 & 8 \\
songorine (56) & 18 & 6 & 7 \\
acovulparine (57) & 30 & 4 & 6 \\
septentriodine (58) & 43 & 6. & 7 \\
takaosamine (59) & 3 & 2 & 4 \\
14-desacetyl-18-demethylpubescenine (60) & 19 & 3 & 8 \\
\hline & & &
\end{tabular}

Pyroaconitine (24) exerted the highest inhibitory activity, for which the $I C_{50}$ value was also determined $(7.3 \pm 1.5 \mu \mathrm{M})$. Furthermore, ajacine (41), septentriodine (58), and delectinine (51) also demonstrated significant $\mathrm{Na}_{\mathrm{v}} 1.2$ channel inhibition (44-42\%) at $10 \mu \mathrm{M}$; several other compounds (acovulparine (57), acotoxicine (1), hetisinone (39), 14-BzA-8-O-palmitate (48), aconitine (5), and 
lycoctonine (42)) exerted moderate inhibitory activity $(30-22 \%)$, while the rest of the tested alkaloids were considered to be inactive.

\subsection{Determination of toxic alkaloid contents of processed Radix aconiti}

The content of mesaconitine, aconitine, and hypaconitine has been determined in 16 commercial samples of processed aconite roots by HPLC and alkaloid titration (Table 5). These samples provide a near representative spectrum of processed TCM aconite drugs being available at Chinese and German markets.

Table 5. Origin of investigated aconite root samples and their alkaloid contents determined by HPLC analysis of toxic alkaloids (sum of mesaconitine, aconitine and hypaconitine) and by titration

\begin{tabular}{|c|c|c|c|}
\hline Code & Simplified code for HPLC analyses & HPLC (\%) & Titration (\%) \\
\hline \multicolumn{4}{|c|}{ Zhicaowu - Aconiti kusnezoffi praeparata } \\
\hline 37951 & B3 (EDQM) & not detectable & 0.065 \\
\hline 37747 & B4 (EDQM) & 0.007 & 0.013 \\
\hline- & B6 (Hong Kong Baptist University) & not detectable & 0.194 \\
\hline \multicolumn{4}{|c|}{ Zhichuanwu (Shanxi) - Aconiti praeparata (radix) } \\
\hline 32969 & D1 (EDQM) & 0.054 & 0.207 \\
\hline- & D2 (Hong Kong Baptist University) & not detectable & 0.120 \\
\hline \multicolumn{4}{|c|}{ Aconiti carmichaelii radix praeparata/Aconiti radix praeparata } \\
\hline 28479 & E1 (EDQM) & 0.013 & 0.062 \\
\hline 36890 & E2 (EDQM) & 0.162 & 0.433 \\
\hline \multicolumn{4}{|c|}{ Shanghai market - Aconiti radix praeparata/Aconiti radix lateralis praeparata } \\
\hline 37271 & $F 2-2003$ & not detectable & 0.045 \\
\hline 37270 & F3 - 2004 & not detectable & 0.103 \\
\hline 37269 & F4 - 2005 & not detectable & 0.123 \\
\hline 37275 & $F 5-2008$ & 0.125 & 0.342 \\
\hline 37272 & F6 - 2009 & not detectable & 0.070 \\
\hline \multicolumn{4}{|c|}{ German market - Aconiti radix praeparata/Aconiti radix lateralis praeparata } \\
\hline 37276 & G1 - 2004 & 0.003 & 0.113 \\
\hline 37265 & $G 2-2004$ & 0.026 & 0.129 \\
\hline 37263 & G4 - 2007 & 0.043 & 0.097 \\
\hline 37266 & G5 - 2007 & 0.011 & 0.116 \\
\hline
\end{tabular}

The HPLC method developed by $u s^{82}$ provides good separation of the main toxic alkaloids (Figure 5) and therefore serves as basis for reliable quantitative analysis. 


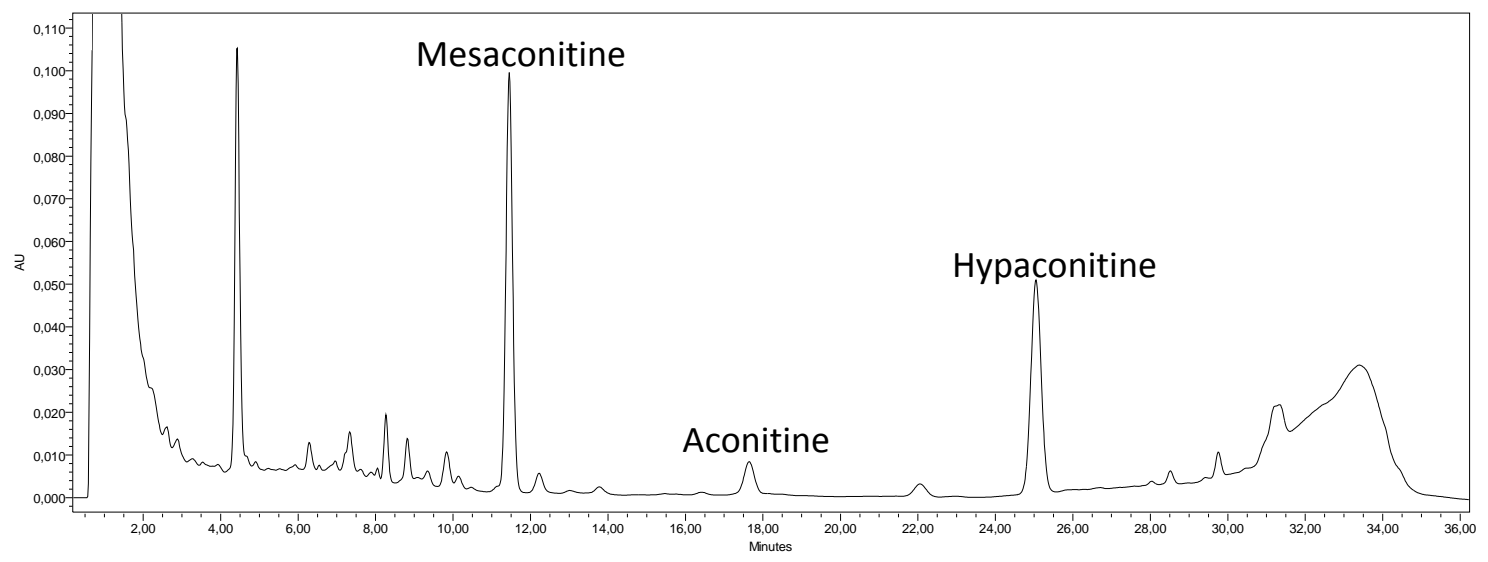

Figure 5. HPLC chromatogram of the extract prepared from a crude aconite root sample

For quantitative determination, linear regression analysis for aconitine was performed by the external standard method. The regression equation for aconitine was $y=2999256695.1674 x+66$ 930.4245 ( $x$ stands for the amount of injected alkaloid in $\mathrm{mg}, y$ denotes the area under the curve). The correlation coefficient $\left(R^{2}\right)$ was 0.9994 . Using the HPLC method, in most of the samples no toxic alkaloids or only traces could be detected (Table 5). However, in four samples (D1, E2, F5, G4), $>0.04 \%$ of aconitine, hypaconitine, and mesaconitine, the highest with a content of $0.162 \%$ (E2), were quantified. The alkaloid content determined by titration was considerably higher than determined by HPLC (Figure 6).

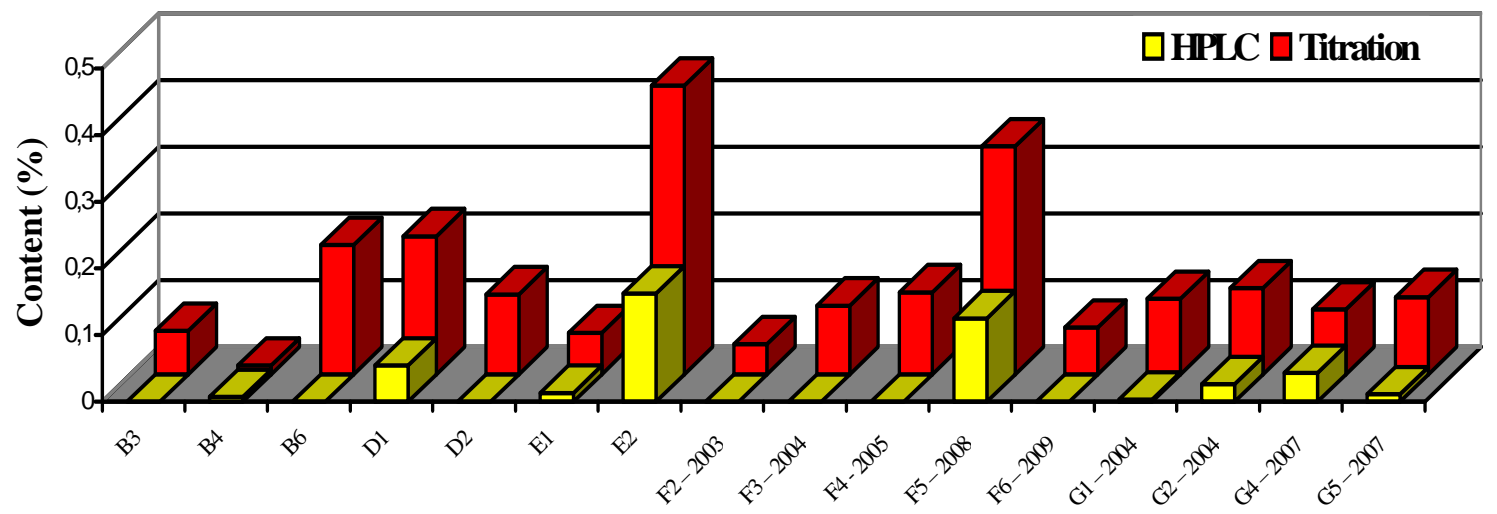

Figure 6. Comparison of content (\%) of alkaloidal compounds measured by HPLC and titration.

Samples, in which toxic alkaloids were not detectable by HPLC, still contained up to $0.2 \%$ alkaloids according to titration. Careful processing obviously degrades the toxic alkaloids but does not remove all alkaloids. Total alkaloid titration determines not only the toxic diester alkaloids but also the monoester, unesterified, and LAs. There was no correlation between the low values $(<0.02 \% \mathrm{HPLC})$, but there was a correlation in high values of alkaloid contents determined by the two methods (Figure 7). When taking into consideration only samples with measurable alkaloid content by HPLC, a correlation coefficient of 0.91 was found between the results of the two methods. 


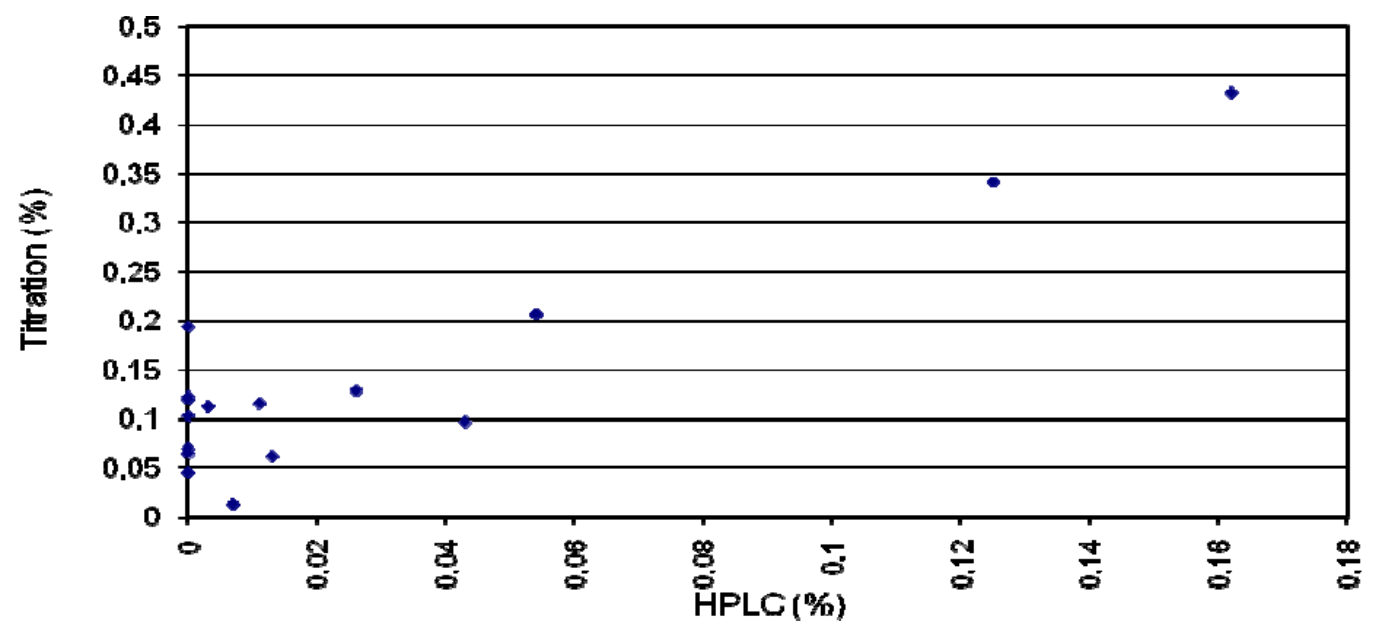

Figure 7. Correlation of the alkaloid contents by HPLC quantification and titration

\section{DISCUSSION}

DAs accumulated by Aconitum species have been in the focus of attention for several reasons. Amassed from classical and highly instrumentalised phytochemical studies the pieces of chemical information regarding the interesting, complex and variable structures of these compounds represent a body of information that by now literally surpassed the limits of encyclopaedic knowledge. Contrasting with this it should be noted that there is still no sufficient information on the pharmacology and toxicology of these alkaloids. These considerations and the fact that rare and/or endemic Aconitum species are partially or completely unexplored provided the primary motivation for the research group of HOHMANN et al. (Department of Pharmacognosy, University of Szeged) to start a research programme in 2001 dealing with Aconitum species native to the Carpatian Basin. In continuation of the work accomplished by CSUPOR et al. on A. toxicum and A. vulparia, and by HOHMANN and HAJDÚ et al. on C. orientalis, my work principally targeted the detailed phytochemical investigation of further two native monkshood species, $A$. anthora. and A. moldavicum.

\section{Isolation of alkaloids from A. anthora and A. moldavicum}

The phytochemical work was started with the screening of the alkaloid contents of the roots and above-ground parts of $A$. anthora and of the roots of $A$. moldavicum.

Taking into consideration the limited amount of the plant material, the above-ground parts and roots of $A$. anthora were examined together. In case of $A$. moldavicum the roots were processed. The plant materials were extracted with the amphipolar solvent, $\mathrm{MeOH}$. In the case of $A$. anthora, a classical alkaloid isolation methodology based on solvent-solvent partitioning was applied. This method aims at the separation of alkaloids from neutral compounds. Further multiple-step chromatographic separation (including CC, VLC, GFC, PLC and CPC) on $\mathrm{Al}_{2} \mathrm{O}_{3}$ and Sephadex ${ }^{\circledR} \mathrm{LH}-20$ stationary phases resulted in the isolation of 3 pure compounds (ANT-1-3). 
In the case of $A$. moldavicum, an isolation procedure in neutral medium was proposed to obtain the alkaloids. Reasons for the choice of this method were the facts that the extract of the roots did not contain chlorophyll; moreover, in neutral medium the risk of acidic or alkaline hydrolysis can be minimized. Initially, $\mathrm{CC}$ using an $\mathrm{Al}_{2} \mathrm{O}_{3}$ stationary phase was applied to remove polyphenolic compounds. After extensive chromatographic purification (including CC, VLC, GFC, PLC and $\mathrm{CPC}$ ) with the use of $\mathrm{Al}_{2} \mathrm{O}_{3}$ and $\mathrm{Sephadex}^{\circledR} \mathrm{LH}-20$ and different solvent systems, 8 pure compounds were isolated (AMO-1-8).

\section{Structure elucidation of isolated compounds}

The structure determination of the isolated compounds was carried out by means of spectroscopic experiments. The most useful data regarding the structures originated from the $1 \mathrm{D}$ and $2 \mathrm{D}$ NMR $\left({ }^{1} \mathrm{H}-\right.$ NMR, JMOD, ${ }^{1} \mathrm{H}^{1}{ }^{1} \mathrm{H}$ COSY, HSQC, HMBC and NOESY) measurements. The already known compounds were identified by comparing their NMR data with those in the literature. The constitutions of the new compounds were elucidated by detailed analysis of the NMR spectra, supplemented with mass spectrometric experiments. The relative configurations were determined with the aid of NOESY experiments. As starting point, the stereochemistry of $\mathrm{H}-5$ was considered to be $\beta$, as characteristic for DAs. Complete ${ }^{1} \mathrm{H}$ - and ${ }^{13} \mathrm{C}$-NMR chemical shift assignments were made for the new compounds, and also to supplement or revise missing or incorrect data on the known compounds.

From $A$. anthora, 1 hetisane-type $C_{20}$ [hetisinone $\left(39\right.$, ANT-3)] and 2 aconitane-type $C_{19}$ DAs [isotalatizidine (20, ANT-1) and 10-hydroxy-8-O-methyltalatizamine (38, ANT-2)] were identified (Annex III). The structure and relative configuration of the new alkaloid, 10-hydroxy-8-Omethyltalatizamine $\left(\mathbf{3 8}\right.$, ANT-2) were elucidated. ${ }^{1} \mathrm{H}$ - and ${ }^{13} \mathrm{C}-\mathrm{NMR}$ chemical shift assignments were determined for this compound for the first time, with a corrected or supplemented assignment in the case of isotalatizidine (20, ANT-1). Hetisinone (39, ANT-3) was identified on the basis of the good agreement of measured and previously reported NMR data.

From A. moldavicum, 8 aconitane-type $C_{19}$ DAs [delcosine (40, AMO-1), ajacine (41, AMO-2), lycoctonine (42, AMO-3), swatinine (43, AMO-4), gigactonine (44, AMO-5), cammaconine (45, AMO6), and columbianine (46, AMO7)] were identified (Annex III). The complete structure and relative stereochemistry of the new alkaloid, 1-O-demethylswatinine (47, AMO-11) were determined. ${ }^{1} \mathrm{H}$ - and

${ }^{13} \mathrm{C}$-NMR chemical shift assignments were determined for this compound for the first time; while for ajacine (41, AMO-2), and swatinine (43, AMO-4), complete ${ }^{1} \mathrm{H}$ chemical shift assignments were also carried out. All other alkaloids, namely delcosine (40, AMO-1), lycoctonine (42, AMO-3) gigactonine (44, AMO-5), cammaconine (45, AMO-6), and columbianine (46, AMO-7) were identified on the basis of the comparison of the measured and literature NMR data. 


\section{LAs: Semisynthesis and antiphlogistic activity testing}

Processed aconite roots are widely used in Eastern medicinal systems, especially in TCM as painkillers and antirheumatic agents. ${ }^{4}$ As long as aconitine-type DAs found in unprocessed roots are known to exhibit a broad spectrum of pharmacological activities, including antinociceptive and antiinflammatory effects in vitro, ${ }^{1,172}$ it is noteworthy that LAs are characteristic compounds of both processed and unprocessed aconite drugs. Their amount significantly increases in the course of the traditional processing of the drugs. Aconitine-type alkaloids (e.g. aconitine, hypaconitine, mesaconitine) are highly toxic, in contrast to LAs, which possess significantly less toxicity due to the presence of a long chain fatty acid moiety in the molecules at $\mathrm{C}-8 .{ }^{31}$ In the last decade several analytical aspects of these compounds and processed aconite drugs $s^{20,22,24,26,85,173}$ have been reported, but no detailed pharmacological studies were conducted in connection with their therapeutic relevance; and this phenomenon also means that less attention has been paid so far to the potential role of LAs in the pharmacological effects of processed aconite drugs.

A previous work carried out by CSUPOR et al. demonstrated that processing (usually boiling) of crude aconite roots decreases the amount of toxic alkaloids and increases the concentration of LAs. Therefore, toxic aconite alkaloids cannot be responsible for activity, but LAs may be. ${ }^{31}$ The fact that the long chain fatty acid residues can reduce the high toxicity of DDAs, while still retaining the otherwise desirable antinociceptive and anti-inflammatory activities is of great importance. However, because the close structural similarities of compounds substituted with lipoid chains, these alkaloids have not been isolated to date in pure form from natural sources.

With the aim to evaluate the antiphlogistic potential of fatty acid substituted NDAs, a series of 13 aconitine derived LAs (25-37) as model substances were prepared semisynthetically, and subjected to in vitro anti-inflammatory assays, using the COX-1, COX-2 and LTB ${ }_{4}$ formation inhibition models. The aim of this work was to gain information about the pharmacology of LAs and to conclude some structure-activity relationships concerning the nature of the esterifying fatty acids. ${ }^{22}$

In the reactions aconitine was transesterified by 13 different saturated and unsaturated fatty acids resulting the corresponding 14-BzA-8-O-esters and pyroaconitine. The COX-1, COX-2 and $\mathrm{LTB}_{4}$ formation inhibitory activities of the compounds were investigated. In the COX-1 assay only compounds substituted with $\mathrm{C}_{20}$ and $\mathrm{C}_{22}$ fatty acid moiety (32-37) exhibited moderate activity, while all other LAs (25-31) were inactive on the COX-1 enzyme independently to the unsaturation and the length of the substituting fatty acid chain. In the COX-2 inhibition assay a correlation between the grade of unsaturation in the ester group and the enzyme inhibitory activity may be presumed, while regarding the 5-LOX assay a weak correlation could be noted between the activity and the length of the fatty acid chain (for graphical illustration of the activities of certain LAs see Figure 8). 
These results demonstrating that LAs are not just by-products of a traditional drug processing method put further emphasis on analytical work, because without proper analytical mapping and quantitation neither the safety nor the efficacy of drugs of human use can be determined. It should be noted that currently no unambiguous pharmacological results are available studying concomitantly all the main alkaloid-type compounds of crude and processed aconite roots (DDAs, MAs, LAs and pyrolysates) in the same test system. Such work may be able to clearly distinguish the real roles of these compounds.

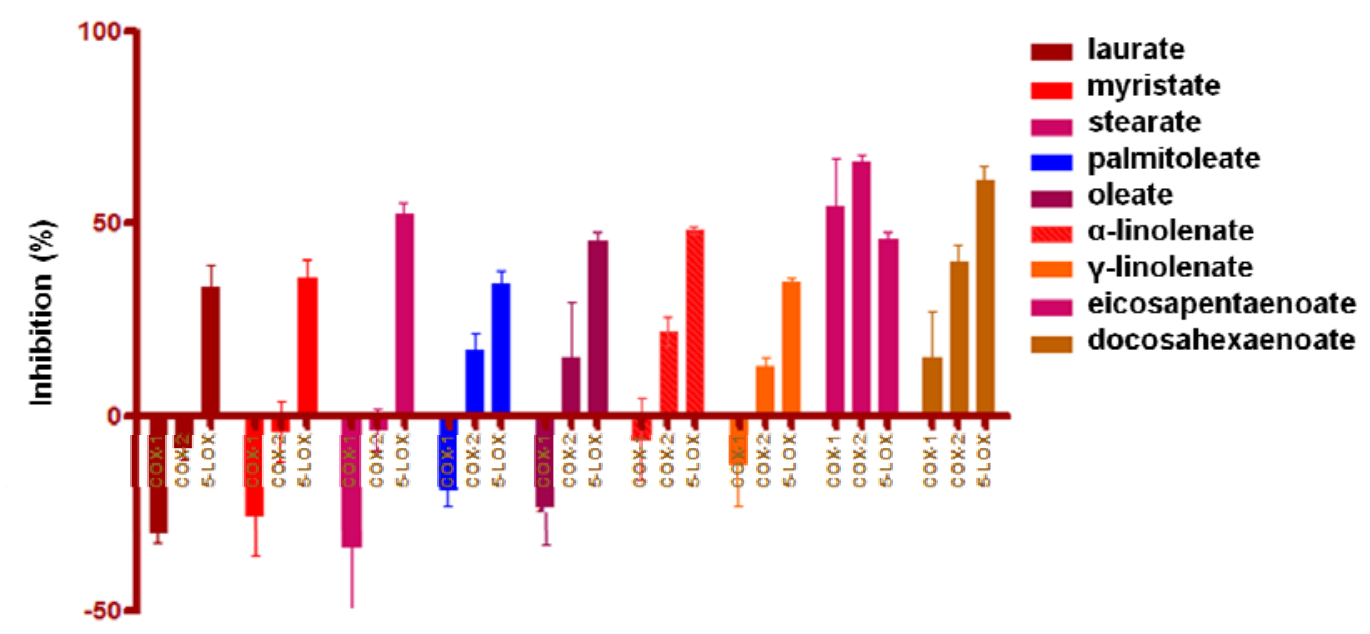

Figure 8. Anti-inflammatory activities of LAs

\section{Investigation of ion channel inhibitory activities of selected compounds}

Pharmacons that exhibit a use-dependent blockade of ion channels, have long been used, for example in the treatment of chronic neuropathic or inflammatory pain states, epilepsies, migraine and neurodegeneration related to ischaemia. ${ }^{174,175}$ Because of the fact that in contrast with the exorbitant body of chemical information the common pharmacological knowledge on DAs can still be considered as rather poor, co-operative research programmes to gain further data on the pharmacological characteristics of DAs were initiated. Within the framework of this a selection of DA compounds was subjected to hERG and $\mathrm{Na}_{\mathrm{v}} 1.2$ channel inhibitory assays.

Although most of the cardiovascular and neurologic effects and poisoning with Aconitum products are explained by the activation of $\mathrm{Na}^{+}$channels, the involvement of the $\mathrm{K}^{+}$channels in the pharmacological effects of DAs is not explored systematically. The human ether-à-go-go-related gene ( $h E R G$ ) encodes a cardiac voltage-gated $\mathrm{K}^{+}$channel (Kv11.1) that provides the major repolarising current (IKr) in phase 3 of the cardiac action potential. Most drugs that have been shown to increase the QT interval of the ECG at therapeutic doses incorporate IKr inhibition in their spectrum of effects. Prolongation of the QT interval can lead in rare cases to the polymorphic ventricular dysrhythmia 
called torsade de pointes (TdP) and sudden death. ${ }^{176,177}$ Only one previous study has been reported the hERG channel inhibitory effect of the most commonly available DA, aconitine (5). ${ }^{92}$

Our data suggest that some structurally and functionally unrelated diterpene and NDAs may block the hERG $\mathrm{K}^{+}$channel, and may therefore act in cardiac action potential repolarisation, with prolongation of the QT interval, and increase of the risk of potentially fatal ventricular arrhythmias. ${ }^{161}$ The toxic plasma concentration of aconitine (5) is 30-1000 times lower than its $I_{50}$ value on hERG channels, and its serious cardiac side effects are generally believed to be a result of $\mathrm{Na}^{+}$channel modulation. ${ }^{178,179}$ However, for the other hERG-active alkaloids, the above difference in concentration is potentially small enough to exert their hERG effect during the therapeutic application of aconite drugs, which could result in adverse cardiovascular effects. The results obtained in this experiment do not allow establishment of a correlation between the structure and hERG channel activity of the alkaloids, but call the attention to the fact that relatively minor structural differences may cause considerable differences in efficacy ${ }^{161}$; and more importantly clearly indicate that the cardiovascular safety profile of Aconitum drugs should be evaluated taking into account the possible effect of DAs on hERG channels.

Developing subtype selective pharmacons that only block the channel isoforms specifically involved in the disease to be treated is a widely used strategy in modern drug research. ${ }^{174}$ Theoretically, such compounds offer a relatively good side-effect profile, by leaving the channel subtypes involved in important physiological functions, such as the heart type Nav1.5, untouched. Unfortunately, sodium channel blockers currently applied with different therapeutic indications discriminate poorly between $\mathrm{Na}_{v} 1 . x$ subtypes and their tolerable therapeutic indices are rather the consequence of their use-dependent properties. Another important aspect is that compounds used therapeutically should devoid or have the least minimal activity against the hERG cardiac $\mathrm{K}^{+}$channel being involved in cardiac toxicity. ${ }^{180,181}$

Concerning the relationship between the structural features and the $\mathrm{Na}_{v} 1.2$ inhibiting activity of the studied alkaloids it seems relevant that the concomitant presence of a methoxy function at C1 , the presence of an oxygen-containing functionality at $\mathrm{C}-8$, and the presence of a (substituted) aroyl function either at C-14 or at C-18 is necessary, with the parallel requirement that the number of oxygen functionalities in the molecule should be at least 4 . Satisfaction of these stipulations can be seen in the case of all significantly $(\mathbf{4 1}, \mathbf{5 1}, \mathbf{5 8}, \mathbf{2 4})$ and moderately active compounds $(\mathbf{4 2}, \mathbf{1}, \mathbf{5 7}, \mathbf{5}$, 24). When C-1 methoxy is changed to hydroxyl, the inhibitory effects of the compounds decrease as it can be seen in the case of delectinine (51) (42\% inhibition) and takaosamine (59) (3\% inhibition). The only, nonetheless very interesting outlier compound is swatinine (43) (10\% inhibition), which has a methoxy group at C-1; however, it is substituted with an unusual, extra hydroxyl at C-10. Without this latter substituent, the compounds substitution pattern is identical with acovulparine (57) (with 
the only structural difference occurring on the $N$ atom) (30\% inhibition). This surprising, and rather large activity difference allows to hypothesise the importance of hydroxy substitution at C-10 that may pose some kind of steric hindrance for the molecule when interacting with the channel receptor. However, it cannot be excluded that differences in the substitution of $N$ atom may also be of importance regarding this difference in activity. Influence of the position of the aroyl functionality on the inhibitory activity is illustrated by the example of acotoxinine (1), which was found to be inactive, in spite of the fact that it has an aroyl functionality in the molecule, but it is positioned at C-8, not at $\mathrm{C}-14$ or $\mathrm{C}-18$, as it has been described above. These stipulations seem to be supported by a detailed QSAR analysis of 12 DAs, which revealed that the position of the aroyl/aroyloxy groups at C-4 or C-14 is the major determinant of the analgesic activity. Alkaloids with an aroyl or an aroyloxy group at C14 exhibited an analgesic potency approximately 30 times higher than that of alkaloids with an aroyloxy group at C-4 in a model of acetic acid-induced writhing in rats. ${ }^{182^{\dagger}}$ Previously it has also been proven that alkaloids with low affinity for the neurotoxin receptor site $2 \mathrm{of}^{+}$channels lack antinociceptive action. ${ }^{183^{\dagger}}$ As regards the three $C_{20}$ DAs involved in this study only one (hetisinone, 39) has been found to exert moderate activity, therefore no relevant deductions may be made concerning the structure-activity relationship of these compounds. It is noteworthy, though to mention that songorine (56) was found practically inactive, which is in line with the previous results of FRIESE et al. when observing that this compound has failed to modulate $\mathrm{Na}^{+}$channels. ${ }^{87+}$ However, in their study no exact subtype specification was provided on the examined $\mathrm{Na}^{+}$channels. Further two aspects to be emphasised are that amongst the four most active compounds only one, delectinine (51) is not esterified (although satisfying all other presumably necessary conditions), and that both diester-type compounds (14-BzA-8-O-palmitate (48) and aconitine (5)) have been found to exert only moderate inhibitory activity on the studied particular channel subtype.

Considering our herein results, especially in light of our previously reported results on the hERG $\mathrm{K}^{+}$channel inhibitory activity of these DAs ${ }^{161}$ it can be observed that certain compounds (14BzA-8-O-palmitate (48), aconitine (5), gigactonine (44)) exerted noteworthy activity in both pharmacological tests, thus despite their promising $\mathrm{Na}_{\mathrm{v}} 1.2$ inhibitory activity these compounds should be considered as potentially harmful by causing adverse cardiovascular effects through their hERG effect, nevertheless, some of these compounds show some selectivity over hERG channels. Their potential cardiovascular safety risk should be evaluated based on their hERG $\mathrm{IC}_{50}$ value and in vivo efficient free plasma concentration. Among the studied active alkaloids particularly those should be further pursued as model substances for pharmacological lead compounds as selective $\mathrm{Na}_{\mathbf{v}} 1.2$ inhibitors, which exert minor or no hERG activity ${ }^{161}$, i.e. ajacine (41) and delectinine (51). 


\section{Analysis of processed TCM aconite drugs for DA content}

Traditional processing, which is a generally applied approach in the Far Eastern traditional medicinal systems, provides aconite drugs for human therapeutic use. Practically all analytical works on the topic demonstrated that cautious processing (usually boiling) of crude aconite roots decreases the amount of normal DAs and increases the concentration of LAs resulting in the reduction of toxicity of the drugs. Quality control criteria of pharmacopoeias are not always sufficient to warrant safety. In case of Radix aconiti and Radix aconiti kusnezoffii, the DA content is not limited in the PhPRC and the warning it stipulates ("be cautious about the unprocessed root taken orally") is not commensurable to the danger of toxicity. In the Radix aconiti praeparata and Radix aconiti kusnezoffii praeparata monographs, a colorimetric assay is used for the determination of DDAs (required content level should not be $>0.15 \%$ ), and a titrimetric assay for the determination of the total alkaloid content (required level should not be $<0.20 \%$ of alkaloids, calculated as aconitine). The dosage of these two drugs is $1.5-3 \mathrm{~g}$, which may contain as much as $4.5 \mathrm{mg}$ DDAs. ${ }^{84}$ Moreover, for Radix aconiti lateralis praeparata, the dose of which is $3-15 \mathrm{~g}$, only the TLC analysis of aconitine is specified. ${ }^{84}$ Taking into account that the minimum lethal dose of aconitine is $3-6 \mathrm{mg}^{184}$, it is obvious that only careful processing and quality control may warrant the safety of aconite containing medicinal products. Several homeopathic pharmacopoeias contain a monograph on A. napellus, and the essence of methods used for the qualification of its drugs, as demonstrated in the most prominent homeopathic pharmacopoeia, the German Homeopathic Pharmacopoeia, is the titrimetric determination of the total alkaloid content. ${ }^{185}$ Since the titrimetric determination provides no direct information on the toxic DDA content of aconite roots, more reliable methods are required for the quality control of processed plant material. Therefore the aim of our work was to develop a quick and simple HPLC method for the quality control of aconite roots with comparable or better reliability to those of the previously published methods ${ }^{186-189}$, to compare the results of titration method with HPLC analysis of the toxic alkaloids. ${ }^{82}$

In most of the commercial samples, toxic alkaloids were undetectable, or only traces were found by the applied HPLC method. However, the fact that in four samples (D1, E2, F5, G4), toxic aconite alkaloid levels could be detected above $0.04 \%$, highlights the consideration that these alkaloid contents are high enough to question the safety of the samples concerned. Samples with mesaconitine, aconitine, and hypaconitine content below the HPLC detection limit still contained up to $0.2 \%$ alkaloids determined by titration. With this comparison of results of HPLC and titrimetric analyses no correlation was found between the two methods. ${ }^{82}$ The sample preparation and HPLC analysis method developed by us offers a quick and reliable possibility to determine the quantity of the most important toxic alkaloids of $A$. carmichaelii and $A$. kusnezoffii and was developed with the aim of providing a proper analytical tool for pharmacopoeial aconite drug analysis. 


\section{SUMMARY}

Within the frame of the research programme of the Department of Pharmacognosy the present doctoral thesis targeted the thorough phytochemical examination of samples (collected from Hungarian populations) of $A$. anthora and $A$. moldavicum resulting in the isolation and structure elucidation of 2 new, and 9 known DAs. One new compound, 10-hydroxy-8-O-methyltalatizamine (ANT-2, 38), together with the known compounds, isotalatizidine (ANT-1, 20) and hetisinone (ANT-3, 39) were obtained from A. anthora; while another new alkaloid, 1-O-demethylswatinine (AMO-8, 47), together with seven known compounds, delcosine (AMO-1, 40), ajacine (AMO-2, 41), lycoctonine (AMO-3, 42), swatinine (AMO-4, 43), gigactonine (AMO-5, 44), cammaconine (AMO-6, 45), and columbianine (AMO-7, 46) were isolated from A. moldavicum. With the exception of isotalatizidine (ANT-1, 20) all alkaloids were reported from the investigated taxa for the first time.

The structures were established by means of HRESIMS, 1D and 2D NMR spectroscopy, including ${ }^{1} \mathrm{H}-{ }^{1} \mathrm{H}$ COSY, NOESY, HSQC and HMBC experiments, resulting in complete and unambiguous ${ }^{1} \mathrm{H}$ and ${ }^{13} \mathrm{C}$ assignments for all isolated compounds, and the reassignment, supplementation or revision of missing or incorrect data on the known compounds, isotalatizidine (ANT-1, 20), ajacine (AMO-2, 41), and swatinine (AMO-4, 43).

To ensure the availability of LAs for pharmacological studies, a formerly published semisynthetic approach using aconitine and fatty acids as synthons of natural origin have been applied in a refined form. As a result, a series of 13 aconitine derived LAs (25-37) were prepared semisynthetically, purified by using a variety of chromatographic methods, and in the frame of cooperation, subjected to in vitro anti-inflammatory assays, using the COX-1, COX-2 and $\mathrm{LTB}_{4}$ formation inhibition models. Results obtained from these assays reinforced the presumption that LAs may play a role in the anti-inflammatory effect of processed aconite roots. The production and antiphlogistic testing of these LAs were reported for the first time and certain structure-activity relationships concerning the nature of esterifying fatty acids on the anti-inflammatory activity has also been proposed for the first time.

Within the framework of co-operations, twenty-four $C_{19}$ and $C_{20}$ DAs representing the structural diversity (different skeletal types and substitution patterns) of Aconitum alkaloids (including several of those obtained from the herein discussed 2 taxa) were subjected to measure their hERG and $\mathrm{Na}_{v} 1.2$ channel inhibitory effects by whole-cell patch clamp technique. Although the results obtained in the hERG-inhibiting ability assay do not allow establishment of a correlation between the structure and hERG channel activity of the alkaloids, but clearly indicate that the cardiovascular safety profile of Aconitum drugs should be evaluated taking into account the possible effect of DAs on hERG $\mathrm{K}^{+}$channels. 
On the contrary, our results obtained in the $\mathrm{Na}_{v} 1.2$ channel inhibitory activity assay made possible to propose certain structure-activity relationships regarding the structural features that may influence the channel activity of DAs. These observations may open new perspectives in the research of channel subtype specific compounds, especially when considering that DAs comprise large and chemically diverse and biologically remarkably active compound repertory. The herein reported specific inhibitory activity of certain DAs on $\mathrm{Na}_{v} 1.2$ channel is intriguing especially in light of the facts that in different geographical regions of the world some DA containing Delphinium and Aconitum species have long been used as both unprocessed and processed drugs of folk and traditional medicine for the same analgetic and antiepileptic indications ${ }^{4,190}$ as those $\mathrm{Na}_{\mathrm{v}} 1.2$ inhibitory drug candidate compounds. ${ }^{174}$ In conclusion, it can be stated that distinctly minor substitutional changes seem to have rather firm impact on the inhibitory activity of DAs both on hERG and $\mathrm{Na}_{\mathrm{v}} 1.2$ channels. It should be noted that experimental pharmacological results obtained in relation to the inhibitory activities of DAs on both the hERG $\mathrm{K}^{+}$channel and the specific $\mathrm{Na}^{+}$channel subtype, $\mathrm{Na}_{\mathrm{v}} 1.2$, were reported for the first time.

As consequence of the harmonization of TCM and modern medicinal systems aconite preparations are also attracting increasing interest of today's Western medicine, which is strikingly illustrated by the fact that despite the potentially hazardous nature of these drugs their incorporation into the Ph. Eur. is currently in progress. In order to contribute to the improvement of quality control of these drugs, we have developed a simple, quick and reliable HPLC method to measure the toxic DA in aconite drugs and validated the method by quantifying 16 commercial samples of processed $A$. carmichaelii and $A$. kusnezofii drugs. The results obtained with the HPLC assessment were compared with a titrimetric analysis of the total alkaloid contents and the conclusion has been drawn that our HPLC method may be considered as proper tool for purity and quality test in pharmacopoeial monographs.

To sum up all these phytochemical and pharmacological results from a pharmacognostic point of view it should be emphasised that DAs expressing notable bioactivities should be regarded as valuable lead compounds worthy of further research and development; and with regard to natural sources all plant species being able to "economically" produce these exceptional substances should be attributed distinct importance and attention to ensure protection and detailed scientific investigation. 


\section{Novel scientific results - résumé:}

1. Phytochemical investigation of $A$. anthora and $A$. moldavicum resulted in the isolation of 2 new [1-O-demethylswatinine (11, AMO-8) and 10-hydroxy-8-O-methyltalatizamine (2, ANT-2)], and 9 known DAs [hetisinone (3, ANT-3), isotalatizidine (1, ANT-1), delcosine (4, AMO-1), ajacine (5, AMO-2), lycoctonine (6, AMO-3), swatinine (7, AMO-4), gigactonine (8, AMO-5), cammaconine $(9$, AMO-6) and columbianine (10, AMO-7)], which - with the exception of one compound - was isolated from these species for the first time; the latter taxon was investigated chemically for the first time;

2. Through extensive 1D and 2D NMR studies structure elucidation and complete and unambiguous ${ }^{1} \mathrm{H}$ and ${ }^{13} \mathrm{C}$ assignments was carried out for all isolated compounds; reassignment, supplementation or revision of missing or incorrect data was performed for the already known compounds;

3. 13 Aconitine-derived LAs were prepared semisynthetically and purified chromatographically by a methodology developed by us;

4. Anti-inflammatory assays with the semisynthetic LAs were carried out on the COX-1, COX-2 and $\mathrm{LTB}_{4}$ formation inhibition models to establish for the first time certain antiphlogistic structureactivity relationships concerning the effect of the nature of the esterifying fatty acid moiety;

5. Pharmacological bioassays on the hERG and $\mathrm{Na}_{v} 1.2$ channels were carried out by using a selected series of DAs to establish for the first time certain structure-activity relationships concerning the effect of the tested DAs on these channels;

6. As a result of these pharmacological assays ajacine (AMO-2) and delectinine, which are selective $\mathrm{Na}_{v} 1.2$ inhibitors, and at the same time exert minor or no hERG activity were identified as perspective compounds for further pharmacological analyses and as potential lead compounds. Determination of the toxic DA content in 16 authentic processed Radix aconiti samples was performed by a HPLC method developed by us, 4 potentially toxic commercial samples were identified; comparison of our results with the widely applied titrimetry revealed the superiority of our method in terms of accuracy and therapeutic relevance. 


\section{REFERENCES}

2 Fan ZC, Zhang ZQ J Chem Crystallogr 2008; 38:895-899

3 Csupor D Investigation of the diterpene alkaloids of Aconitum species native to the Carpathian Basin, In: Annals of Albert Szent-Györgyi Medical \& Pharmaceutical Center (ed. Fülöp F), Vol. 143, JATEPress, Szeged, 2007.

4 Singhuber J, Zhu M, Prinz S, Kopp B J Ethnopharmacol 2009; 126:18-30

5 Borhidi A A zárvatermők fejlődéstörténeti rendszertana, Nemzeti Tankönyvkiadó, Budapest, 1995. p 169

6 Jabbour F, Renner S Mol Phylogenet Evol 2012; 62:928-942

7 Utelli AB, Roy BA, Baltisberger M Plant Syst Evol 2000; 224:195-212

8 Tutin TG, Burges NA, Chater AO, Edmondson JR, Heywood VH, Moore DM, Valentine DH, Walters SM, Webb DA, eds., Flora Europaea Vol. 1., Cambridge University Press, Cambridge, 1993. pp 254-256 59, , Academic Press, 2002. pp 61-65

Farkas G, ed., Magyarország védett növényei, Mezőgazda Kiadó, Budapest, 1999. pp 106-107

Soó R A magyar flóra és vegetáció rendszertani, növényföldrajzi kézikönyve Il., Akadémiai Kiadó, Budapest, 1966. p 41

Liu H, Katz A J Nat Prod 1996; 59:135-138

Csupor D, Forgo P, Wenzig EM, Bauer R, Hohmann J J Nat Prod 2008; 71:1779-1782

Kolak U, Öztürk M, Özgökçe F, Ulubelen A Phytochemistry 2006; 67:2170-2175

Dalton DR The Alkaloids: The Fundamental Chemistry - A Biogenetic Approach, in Studies in Organic Chemistry (ed. Gassman PG), Vol. 7, Marcel Dekker, New York, 1979.

Southon LW, Buckingham J Dictionary of Alkaloids, Chapman and Hall, London, New York, 1989.

Wang FP, Liang XT $\mathrm{C}_{20}$-diterpenoid alkaloids In: The Alkaloids: Chemistry and Biology (ed. Cordell GA), Vol.

Kitagawa I, Yoshikawa M, Chen ZL, Kobayashi K Chem Pharm Bull 1982; 30:758-761

Wang FP, Chen QH, Liu XY Nat Prod Rep 2010; 27:529-570

Borcsa B, Dezső Cs, Forgo P, Widowitz U, Bauer R, Hohmann J Nat Prod Commun 2011; 6:527-536

Xu Q, Wang Y, Liu C, Liu Z, Liu S Anal Sci 2003; 19:1599-1603

Hanuman JB, Katz A J Nat Prod 1994; 57:105-115

Sun W, Song F, Cui M, Liu S Planta Med 1999; 65:432-436

Sun WX, Liu SY, Liu ZQ, Song, FR Fang SP Rapid Commun Mass Spectrom 1998; 12:821-824

Shim SH, Lee SY, Kim JS, Son KH, Kang SS Arch Pharm Res 2005; 28:1239-1243

Shim SH, Kim JS, Kang SS Chem Pharm Bull 2003; 51:999-1002

Yue H, Pi Z, Song F, Liu Z, Cai Z, Liu S Talanta 2009; 77:1800-1807

Wang Y, Liu ZQ, Song FR, Liu SY Rapid Commun Mass Spectrom 2002; 16:2075-2082

Wang Y, Song FR, Xu QX, Liu ZQ, Liu SY J Mass Spectrom 2003; 38:962-970 
Wang J, van der Heijden R, Spijksma G, Reijmers T, Wang M, Xu G, Hankemeier T, van der Greef J J Chromatogr A 2009; 1216:2169-2178 J Ethnopharmacol 2011; 137:730-742 Ethnopharmacol 2010; 130:559-562 550

45:287-289 2000; 55:696-698 SM Chem Nat Compd 2012; 47:1032-1034 Chem 2005; 13:6493-6501

Shrestha PM, Katz A J Nat Prod 2000; 63:2-5

Wu W, Liang ZT, Zhao ZZ, Z.W. Cai ZW J Mass Spectrom 2007; 42:58-69

Csupor D, Wenzig EM, Zupkó I, Wölkart K, Hohmann J, Bauer R J Chromatogr A 2009; 1216:2079-2086

Schmitz G, Ecker J Prog Lipid Res 2008; 47:147-155

Wang Y, Shi L, Song FR, Liu ZQ, Liu SY Rapid Commun Mass Spectrom 2003; 17:279-284

Zhang S, Zhao G, Lin G Phytochemistry 1999; 51:333-336

Díaz JG, Ruiz JG, Herz W Phytochemistry 2004; 65:2123-2127

Xiong L, Peng C, Xie XF, Guo L, He CJ, Geng Z, Wan F, Dai O, Zhou QM Molecules 2012; 17:9939-9946

Shim SH, Kim JS, Son KH, Bae KH, Kang SS J Nat Prod 2006; 69:400-402

Suzgec S, Bitis L, Sozer U, Ozcelik H, Zapp J, Kiemer AK, Mericli F, Mericli AH Chem Nat Compd 2009;

Xu Y, Guo ZJ, Wu N Fitoterapia 2010; 81:1091-1093

Meriçli AH, Meriçli F, Ulubelen A, Bahar M, Ilarslan R, Algül G, Desai HK, Teng Q, Pelletier SW Pharmazie

Pirildar S, Unsal Gurer C, Kocyigit M, Zapp J, Kiemer AK, Meriçli AH Chem Nat Compd 2013; 48:1115-1116

Mariani C, Braca A, Vitalini S, De Tommasi N, Visioli F, Fico G Phytochemistry 2008; 69:1120-1126

Wangchuk Ph, Keller PA, Pyne SG, Taweechotipatr M, Tonsomboon A, Rattanajak R, Kamchonwongpaisan S

Wangchuk P, Bremmer JB, Samten, Skelton BW, White AH, Rattanajak R, Kamchonwongpaisan S J

Wangchuk P, Bremmer JB, Samosorn S J Nat Prod 2007; 70:1808-1811

Zafar S, Ahmad MA, Siddiqui TA Fitoterapia 2002; 73:535-556

Wada K, Nihira M, Ohno Y J Ethnopharmacol 2006; 105:89-94

Ono T, Hayashida M, Uekusa K, Lai CF, Hayakawa H, Nihira M, Ohno Y Leg Med 2009; 11:132-135

Burdel'naya EV, Zhunusova MA, Turmukhambetov AZ, Seidakhmetova RB, Shul'ts EE, Gatilov YV, Adekenov

Chodoeva A, Bosc JJ, Guillon J, Decendit A, Petraud M, Absalon Ch, Vitry Ch, Jarry Ch, Robert J Bioorg Med

Song MJ, Kim H J Ethnopharmacol 2011; 137:167-175

Jeong HJ, Whang WK, Kim IH Planta Med 1997; 63:329-334

Batbayar N, Enkhzaya S, Tunsag J, Batsuren D, Rycroft DS, Sproll S, Bracher F Phytochemistry 2003; 62:543-

Shrestha PM, Katz A J Nat Prod 2004; 67:1574-1576

Meriçli AH, Yazici S, Eroglu-Ozkan E, Sen B, Kurtoglu S, Ozcelik H, Zapp J, Kiemer AK, Mericli F Chem Nat Compd 2012; 48: 525-526 

1101 2005.

Meriçli F, Meriçli AH, Ulubelen A, Desai HK, Pelletier SW J Nat Prod 2001; 64:787-789

Meriçli F, Meriçli AH, Tan N, Özçelik H, Ulubelen A Sci Pharm 1999; 67:313-318

Meriçli AH, Meriçli F, Desai HK, Ilarslan R, Ulubelen A, Pelletier SW Pharmazie 2001; 55:696-698

Xiong J, Tan NH, Ji ChJ, LuY, Gong NB Tetrahedron Lett 2008; 49:4851-4853

Jiang SH, Yang PM, Zhou H, Zhu DY Planta Med 2002; 68:1147-1149

Tang QF, Ye WC, Liu JH, Y ChH Phytochem Lett 2012; 5:397-400

Jiang SH, Wang HQ, Li YM, Lin SJ, Tan JJ, Zhu DY Chin Chem Lett 2007; 18:409-411

Shen Y, Zuo AX, Jiang ZY, Zhang XM, Wang HL, Chen JJ Helv Chim Acta 2011; 94:268-272

Zhang F, Peng SL, Liao X, Yu KB, Ding LS Planta Med 2005; 71:1073-1076

Sun JY, Li TC J Chem Res 2009; 5:306-307

Zhou XL, Chen DL, Chen QH, Wang FP J Nat Prod 2005; 68:1076-1079

Hong YH, Peacher WG Chinese Herb Medicine and Therapy, Oriental Healing Institute of U.S.A., Los Angeles, 1986. p 162

Bensky D, Gamble A Chinese Herbal Medicine, Eastland Press, Seattle, 1991. pp 428-430

Gao LM, Wei XM, Yang L Chin Chem Lett 2005; 16:475-478

Cao JX, Li LB, Jiang SP, Tian RR, Chen XL, Peng SL, Zhang J, Zhu HJ Helv Chim Acta 2008; 91:1954-1960

Yang XD, Yang S, Yang J, Zhao JF, Zhang HB, Li L Helv Chim Acta 2008; 91:569-573

He YQ, Ma ZY, Wei XM, Du BZh, Jin ZX, Yao BH, Gao LM Fitoterapia 2010; 81:929-931

He YQ, Yao BH, Ma ZhY J Pharm Anal 2011; 1:57-59

Wang YB, Huang R, Zhang HB, Li L Helv Chim Acta 2005; 88:1081-1084

Qu SJ, Tan CH, Liu ZL, Jiang SH, Yu L, Zhu DY Phytochem Lett 2011; 4:144-146

Yang S, Yang XD, Zhao JF, Zhang HB, Li L Helv Chim Acta 2007; 90:1160-1164

Kang Y, Łuczaj ŁJ, Ye S Genet Resour Crop Evol 2012; 59:1569-1575

Pharmacopoea Hungarica, Pesti Könyvnyomda-Részvény-Társulat, Budapest, 1871.

Pharmacopoea Hungarica Editio Secunda, Pesti Könyvnyomda-Részvény-Társulat, Budapest, 1888.

Pharmacopoea Hungarica Editio Tertia, Pesti Könyvnyomda-Részvény-Társulat, Budapest, 1909.

Csupor D, Borcsa B, Heydel B, Hohmann J, Zupkó I, Ma Y, Widowitz U, Bauer R Pharm Biol 2011; 49:1097-

EDQM homepage: https://extranet.edqm.eu/4DLink1/4DCGI/Web_View/mono/2470;

https://extranet.edqm.eu/4DLink1/4DCGI/Web_View/mono/2429 Accessed: 17 March 2013

Pharmacopoeia of the People's Republic of China. Vol. I, People's Medical Publishing House, Beijing, China,

Wang J, van der Heijden R, Spijksma G, Reijmers T, Wang M, Xu G, Hankemeier T, van der Greef J J Chromatogr A 2009; 1216:2169-2178

Hanuman JB, Katz A J Nat Prod 1994; 57:105-115

Friese J, Gleitz J, Gutser UT, Heubach JF, Matthiesen T, Wilffert B, Selve N Eur J Pharmacol 1997; 337:165174 

171

111 Chem Biodivers 2004; 1327-1335 Chem 2012; 54:343-351

Ethnopharmacol 2009; 126:31-41

2007; 113:560-563 1999; 16:15-23 $60: 472-474$ 46:286-290

Voss L, Voss JM, McLeay L, Sleigh JW Eur J Pharmaco/ 2008; 584:291-296

Hardick DJ, Blagbrough IS, Cooper G, Potter BVL, Critchley T, Wonnacott S J Med Chem 1996; 39:4860-4866

Sultankhodzhaev MN, Khan MTH, Moin M, Choudhary MI, Atta-Ur-Rahman Nat Prod Res 2005; 19:517-522

Shaheen F, Ahmad M, Khan MTH, Jalil S, Ejaz A, Sultankhodjaev MN, Arfan M, Choudhary MI, Atta-urRahman Phytochemistry 2005; 66:935-940

Guo L, Dong Z, Guthrie H J Pharmacol Toxicol Methods 2009; 60:130-151

Desai HK, Hart BP, Caldwell RW, Jiangzhong-Huang, Pelletier SW J Nat Prod 1998; 61:743-748

Mazur NA, Ivanova LA, Pavlova TS, Biull Vsesoiuznogo Kardiol Nauchn Tsentra AMN SSSR 1986; 9:30-33

Liu SS, Liu IM, Lai MC, Cheng JT J Ethnopharmacol 2005; 99:379-383

Wang J, van der Heijden R, Spruit S, Hankermeier T, Chan K, van der Greef J, Xu G, Wang M J

Wang DP, Lou HY, Huang L, Hao XJ, Liang GY, Yang ZC, Pan WD Bioorg Med Chem Lett 2012; 22:4444-4446

Shu H, Arita H, Hayashida M, Sekiyama H, Hanaoka K J Ethnopharmacol 2006; 103:398-405

Shu H, Arita H, Hayashida M, Chiba S, Sekiyama H, Hanaoka K J Ethnopharmacol 2006; 106:263-271

Shu H, Hayashida M, Chiba S, Sekiyama H, Kitamura T, Yamada Y, Hanaoka K, Arita H J Ethnopharmacol

Shu H, Hayashida M, Huang W, An K, Chiba S, Hanaoka K, Arita H J Ethnopharmacol 2008; 117:158-165

Wu G, Huang W, Zhang H, Li Q, Zhou J, Shu H J Ethnopharmacol 2011; 136:254-259

Wang CF, Gerner P, Wang SY, Wang GK Anesthesiology 2007; 107:82-90

Kawata Y, Ma CM, Meselhy MR, Nakamura N, Wang H, Hattori M, Namba T, Satoh K, Kuraishi Y J Trad Med

Kukel CF, Jennings KR Can J Physiol Pharmacol 1994; 72:104-107

Hardick DJ, Cooper G, Scott-Ward T, Blagbrough IS, Potter BV, Wonnacott S FEBS Lett 1995; 365:79-82

Wada K, Ishizuki S, Mori T, Bando H, Murayama M, Kawahara N Biol Pharm Bull 1997; 20:978-982

Atta-ur-Rahman, Nashreen A, Akhtar F, Shekhani MS, Clardy J, Parvez M, Choudhary MI J Nat Prod 1997;

González-Coloma A, Guadaño A, Gutiérrez C, Cabrera R, de la Peña E, Reina M J Agric Food Chem 1998;

Ulubelen A, Meriçli AH, Meriçli F, Neşet K, Ferizli AG, Emekci M, Pelletier SW Phytoter Res 2001; 15:170-

González-Coloma A, Reina M, Guadaño A, Martínez-Díaz R, Díaz JG, García-Rodriguez J, Alva A, Grandez M

Şener B, Orhan I, Özçelik B ARKIVOC 2007; VII:265-272

Chodoeva A, Bosc JJ, Guillon J, Costet P, Decendit A, Mérillon JM, Léger JM, Jarry C, Robert J Eur J Med

Wada K, Hazawa M, Takahashi K, Mori T, Kawahara N, Kashiwakura J Nat Prod 2007; 70:1854-1858

Wada K, Ohkoshi E, Morris-Natschke, Bastow KF, Lee KH Bioorg Med Chem Lett 2012; 22:249-252 

270 41:810-814

Gao F, Li YY, Wang D, Huang X, Liu Q Molecules 2012, 17:5187-5194

He YQ, Ma ZY, Wei XM, Liu DJ, Du BZ, Yao BH, Gao LM Chem Biodivers 2011; 8:2104-2109

Gao LM, Yan HY, He YQ, Wei XM J Integr Plant Biol 2006; 48:364-369

Chang JG, Shih PP, Chang CP, Chang JY, Wang FY, Tseng J Planta Med 1994; 60:576-578

Li M, He J, Jiang LL, Ng ESK, Wang H, Lam FFY, Zhang YM, Tan NH, Shaw PC J Ethnopharmacol 2013;

Kolak U, Öztürk M, Özgökçe F, Ulubelen A Phytochemistry 2006; 67:2170-2175

Fu M, Wu M, Qiao Y, Wang Z Pharmazie 2006; 61:735-741

Chan TYK Forensic Sci Int 2012; 223:25-27

Ito K, Tanaka S, Funayama M, Mizugaki M J Anal Toxicol 2000; 24:348-353

Bonnici K, Stanworth D, Simmonds MSJ, Mukherjee E, Ferner RE Lancet 2010; 376:1616

Lin CC, Chan TY, Deng JF Ann Emerg Med 2004; 43:574-579

Kolev ST, Leman P, Kite GC, Stevenson PC, Shaw D, Murray VS Human Exp Toxicol 1996; 15:839-842

Tai YT, But PPH, Young K, Lau CP Lancet 1992; 340:1254-1256

Chan TYK, Tomlinson B, Tse LKK, Chan JCN, Chan WWM, Critchley JAJH Vet Hum Toxicol 1994; 36:452-455

Zeng ZP, Jiang JG Brit J Pharmacol 2010; 159:1374-1391

Kolev ST, Leman P, Kite GC, Stevenson PC, Shaw D, Murray VS Hum Exp Toxicol 1996; 15:839-842

Chan TYK Clin Toxicol 2009; 47:279-285

Zhao Z, Liang Z, Chan K, Lu G, Lee ELM, Chen H, Li L Planta Med 2010; 76:1975-1986

Shaw D Planta Med 2010; 76:20012-2018

Lai CK, Poon WT, Chan YW J Anal Toxicol 2006; 30:426-433

Chan TYK Hum Exp Toxicol 2011; 30:2023-2026

Munnecom THC, van Kraaij DJW, van Westreenen JC Int J Cardiol 2011: 152:e37-e39

Chan TYK Forensic Sci Int 2012; 222:1-3

Arlt EM, Keller T, Wittmann H, Monticelli F Leg Med 2012; 14:154-156

Larabi K, Soulillou A, Mattys M, Lucchini MJ, Fanton Y, Tafani B Presse Med 2013; 42:353-354

Liu Q, Zhuo L, Liu L, Zhu S, Sunnassee A, Liang M, Zhou L, Liu Y Forensic Sci Int 2011; 212:e5-e9

Dominois-Heraud AM, Schmitt C, De Matteis O, Tichadou L, de Haro L Ann Fr Anesth Reanim 2012; 31:262-

Lu GH Dong ZQ, Wang Q, Qian GS, Huang WH, Jiang ZH, Leung KSY, Zhao ZZ Planta Med 2010; 76:825-830

Ito K, Ohyama Y, Konishi Y, Tanaka S, Mizugaki M Planta Med 1997; 63:75-79

Kaneko R, Hattori S, Furuta S, Hamajima M, Hirata Y, Watanabe K, Seno H, Ishii A J Mass Spectrom 2006;

Wang ZH, Guo D, He Y, Hu C, Zhang J Phytochem Anal 2004; 15:16-20

Ohta H, Seto Y, Tsunoda N J Chromatography B 1997; 691:351-356

Hayashida M, Hayakawa H, Wada K, Yamada T, Nihira M, Ohno Y Leg Med 2003; 5:S101-S104

Zhang HG, Sun Y, Duan MY, Chen YJ, Zhong DF, Zhang HQ Toxicon 2005; 46:500-506 

Priest BT, Schmalhofer WA, Smith MM, Tarpley JW, Williams BS, Martin WJ, Parsons WH Bioorg Med Chem Lett 2005; 15:2943-2947

Wang Z, Wang Z, Wen J, He Y J Pharm Biomed Anal 2007; 45:145-148

Nakae H, Fujita Y, Igarashi T, Tajimi K, Endo S Biomed Res 2008; 29:225-231

Usui K, Hayashizaki Y, Hashiyada M, Nakano A, Funayama M Leg Med 2012; 14:126-133

Chung KKW, Chen SPL, Ng SW, Mak TWL, Leung KSY Talanta 2012; 97:491-498

Tang L, Gong Y, Lv C, Ye L, Liu L, Liu Z J Ethnopharmacol 2012; 141:736-741

Tang L, Ye L, Lv C, Zheng Z, Gong Y, Liu Z Toxicol Lett 2011; 202:47-54

Ye Ling, Tang L, Gong Y, Lv C, Zheng Zh, Jiang Z, Liu Z Xenobiotica 2011; 41:46-58

Xin Y, Pi Z, Song F, Liu Z, Liu S Chin J Chem 2012, 30:656-664

Fan YF, Xie Y, Liu L, Ho HM, Wong YF, Liu ZQ, Zhou H J Ethnopharmacol 2012; 141:701-708

Bai Y, Desai HK, Pelletier SW J Nat Prod 1994; 57:963-970

Borcsa B, Widowitz U, Csupor D, Forgo P, Bauer R, Hohmann J Fitoterapia 2011; 82:365-368

Forgo P, Botond B, Csupor D, Fodor L, Berkecz R, Molnár VA, Hohmann J Planta Med 2011; 77:368-373

van Beek TA, van Veldhuizen A, Lelyveld GP, Piron I, Lankhorst PP Phytochem Anal 1993; 4:261-268

Boido V, Edwards OE, Handa KL, Kolt RJ, Purushothaman KK Can J Chem 1984; 62:778-784

Pelletier SW Alkaloids: Chemical and Biological Perspectives Vol. Il., Wiley \& Sons, New York, Chichester, Brisbane, Toronto, Singapore, 1984. pp 399

De la Fuente G, Ruíz-Mesia L Phytochemistry 1995; 39:1459-1465

Gonzalez AG, de la Fuente G, Reina M, Díaz R, Timón I Phytochemistry 1986; 25:1971-1973

Hajdú Z, Forgó P, Löffler B, Hohmann J Biochem Sys Ecol 2005; 33:1081-1085

Csupor D, Forgo P, Máthé I, Hohmann J Helv Chim Acta 2004; 87:2125-2130

Pelletier SW Alkaloids: Chemical and Biological Perspectives Vol. II., Wiley \& Sons, New York, Chichester, Brisbane, Toronto, Singapore, 1984. pp 205-462

Hanuman JB, Katz A Phytochemistry 1994; 36:1527-1535

De la Fuente G, Orribo T, Gavin JA, Acosta RD Heterocycles 1993; 36:1455-1458

González-Coloma A, Reina M, Mediaveitia A, Guadaño A, Santana O, Martínez-Díaz R, Ruis-Mesía L, Alva A, Grandez M, Díaz R, Gavín JA, de la Fuente G J Chem Ecol 2004, 30:1393-1408

Yang M, Sun J, Lu Z, Chen G, Guan S, Liu X, Jiang B, Ye M, Guo DA J Chromatogr A 2009; 1216:2045-2062

Tarnawa I, Bölcskei H, Kocsis P Recent Pat CNS Drug Disc 2007; 2:57-78

Lai J, Hunter JC, Porreca F Curr Opin Neurobiol 2003; 13:291-297

De Bruin ML, Pettersson M, Meyboom RHB, Hoes AW, Leufkens HGM Eur Heart J 2005; 26:590-597

Sanguinetti MC, Tristani-Firouzi M Nature 2006; 440:463-469

Beike J, Frommherz L, Wood M, Brinkmann B, Köhler H Int J Legal Med 2004; 118:289-293

Ohta H, Seto Y, Tsunoda N J Chromatogr B 1997; 691:351-356.

Liang J, Brochu RM, Cohen CJ, Dick IE, Felix JP, Fisher MH, Garcia ML, Kaczorowski GJ, Lyons KA, Meinke PT, Baker MD, Wood JN Trends Pharmac Sci 2001; 22:27-31 
Bello-Ramírez AM, Buendía-Orozco J, Nava-Ocampo AA Fundam Clin Pharmacol 2003; 17:575-80

183 Gutser UT, Friese J, Heubach JF, Matthiesen T, Selve N, Wilffert B, Gleitz J Naunyn Schmiedeberg's Arch Pharmacol 1998; 357:39-48

Caravati EM, McCowan CL, Marshall SW Plants. In: Dart RC, ed. Medical Toxicology. Lippincott Williams \& Wilkins, Philadelphia, 2004. p 1701 German Homeopathic Pharmacopoeia. Vol. 1, Medpharm, Scientific Publishers Stuttgart, Germany, 2005. Jiang ZH, Xie Y, Zhou H, Wang JR, Liu ZQ, Wong YF, Cai X, Xu HX, Liu L Phytochem Anal 2005; 16:415-421 Wang Z, Wen J, Xing J, He Y J Pharm Biomed Anal 2006; 40:1031-1034 Kang XQ, Fan ZC, Zhang ZQ J Chromatogr Sci 2010; 48:860-865 Medicinal Plants in China. WHO Regional Publications Western Pacific Series 2, WHO Regional Office for the Western Pacific, Manila, 1989. p 5 


\section{ACKNOWLEDGEMENTS}

I wish to express my most grateful thanks to my chief supervisor, Prof. Dr. Judit Hohmann, for introducing me to the world of diterpene alkaloids and phytochemical research. I am greatly indebted to her for her professional guidance, continuous support and uncompromised help she has provided for me.

I wish to express my humble and most sincere gratitude to my co-supervisor, Dr. Dezsö Csupor assistant professor for his never ending encouragement, warm hearted reassurance, uncountable advices and profound humanity, with which he not only reinforced and inspired me, but also strengthened my perseverance at certain times of extreme difficulties.

I wish to thank to Prof. Dr. Imre Máthé and Prof. Dr. Judit Hohmann, former and current heads of the Department of Pharmacognosy, for placing the facilities at my disposal and providing me with all the opportunities to carry out my experimental work.

I owe special thanks to Dr. Attila Molnár V. (Department of Botany, University of Debrecen) for the identification and collection of the plant material.

My special thanks are due to my co-authors, namely Dr. Péter Forgó for the NMR measurements; Ute Widowitz, Barbara Heydel and Prof. Dr. Rudolf Bauer (Karl-Franzenz University, Graz, Austria) for the anti-inflammatory tests and titrimetric measurements, Dr. László Fodor (Gedeon Richter Plc.) for the Na 1.2 and hERG tests, and Róbert Berkecz (Department of Medical Chemistry, University of Szeged) for the mass spectra.

I am very grateful to all staff members at the Department of Pharmacognosy for their help and assistance, in particular to Erzsébet Hadárné Berta laboratory assistant, Dr. Andrea Vasas and Dr. Dóra Rédei assistant professors, and Dr. Katalin Veres research fellow for their unselfish help and advices given to my experimental work.

Last but not least I would love to express my grateful thanks to my most beloved mother, family and friends for all their help, support and encouragement, without which I could not accomplish this work. 
Annex I. Types of diterpene alkaloids

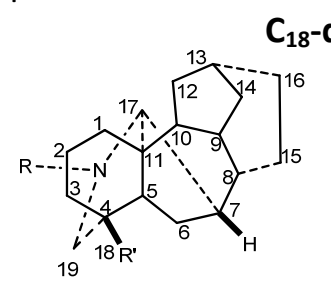

lappaconitine-type (I)

\section{8-diterpene alkaloids}

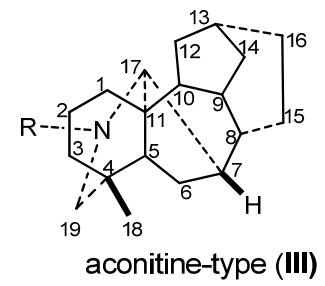

$\mathrm{C}_{19}$-diterpene alkaloids

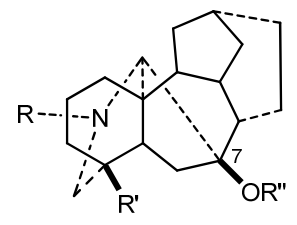

ranaconitine-type (II)

\section{$\mathrm{C}_{19}$-diterpene alkaloids}

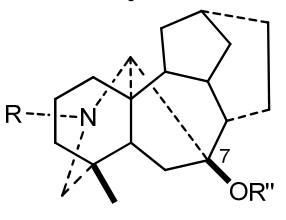

lycoctonine-type (IV)

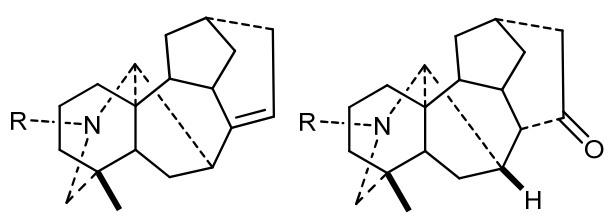

pyro-type (V)

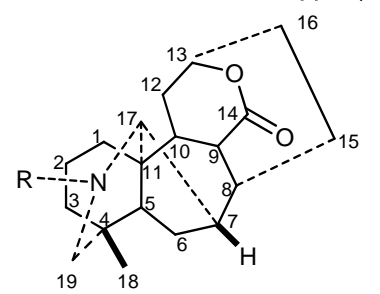

lactone-type (VI)

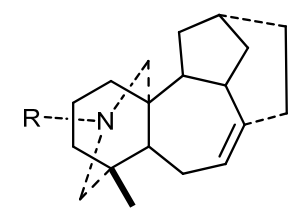

7,17-seco-type (VII)

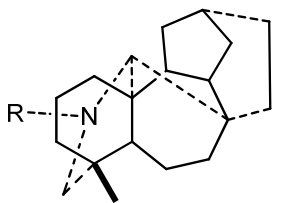

rearranged-type (VIII)

\section{$\mathrm{C}_{20}$-diterpene alkaloids}
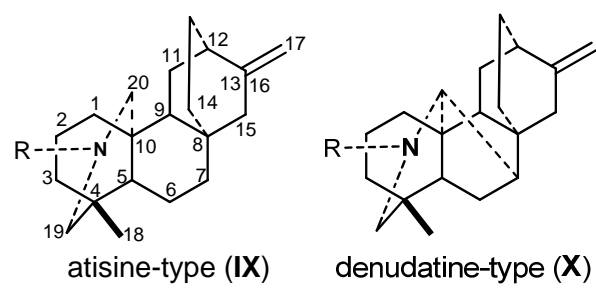
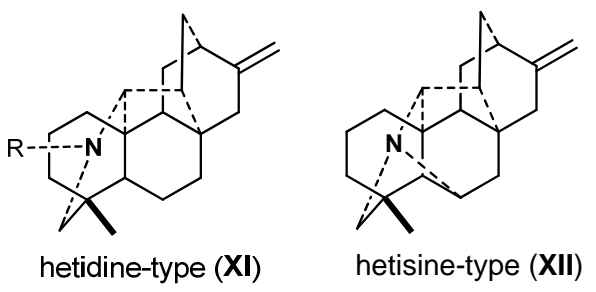

hetisine-type (XII)

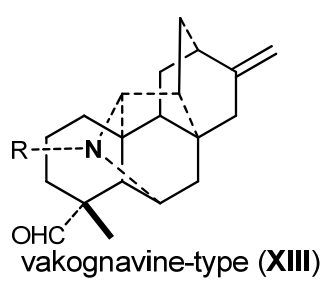

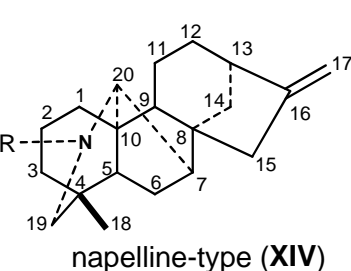

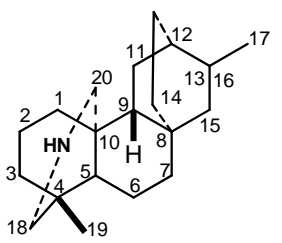

atidane-type (XVIII)

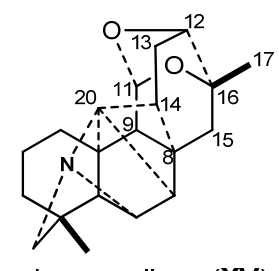

kusnezolines (XV)

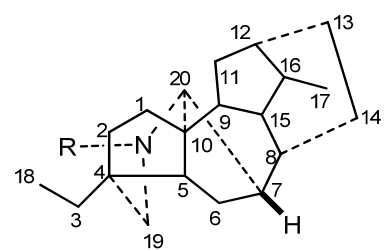

racemulosine-type (XVI)

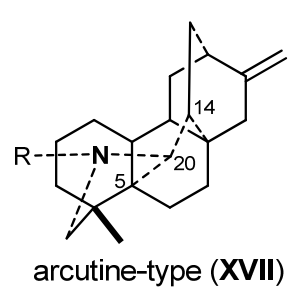

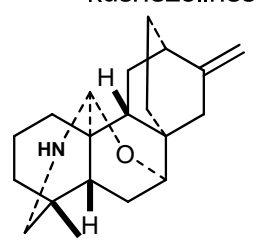

ajaconine-type (XIX)
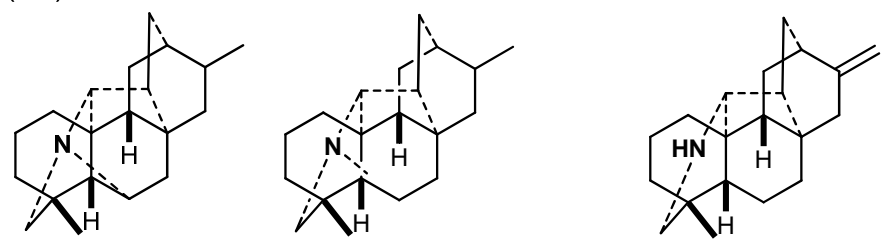

delnudine-type (XXII)
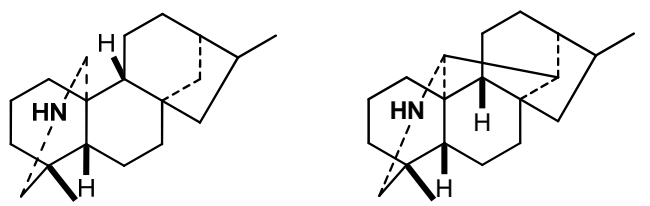

veatchine-type (XXIII) 14,20-cycloveatchine-type (XXIII) 
Annex II. Previously isolated or semisynthesised alkaloids tested in the bioassays of hERG and $\mathrm{Na}_{\mathrm{v}} 1.2$

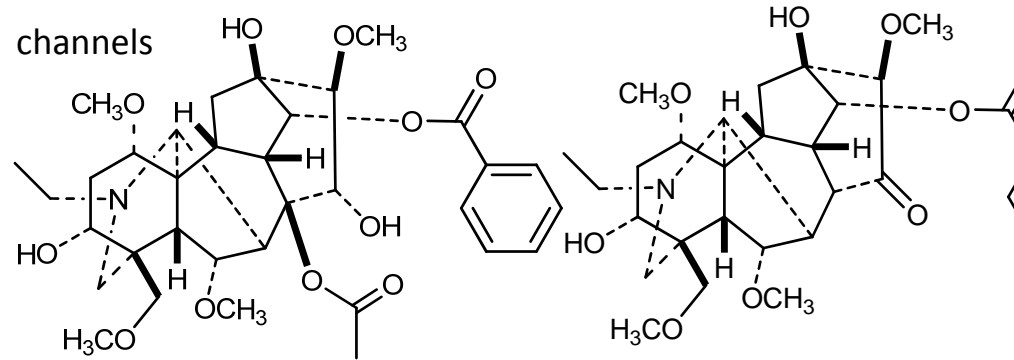

aconitine (5)

pyroaconitine (24)

14-BzA-8-O-palmitate (48)

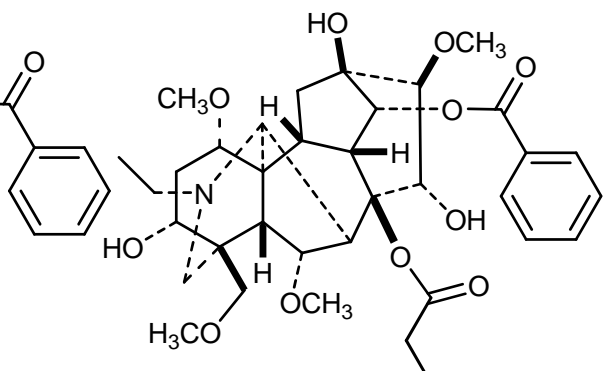

Alkaloids isolated from $A$. toxicum

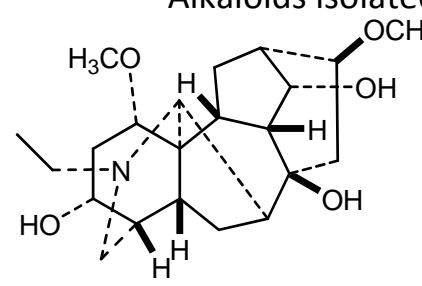

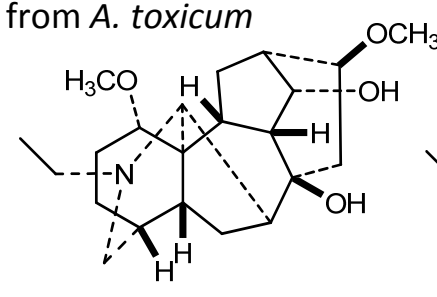

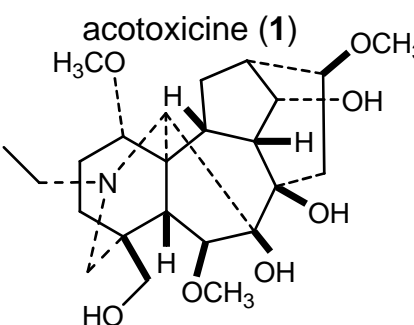

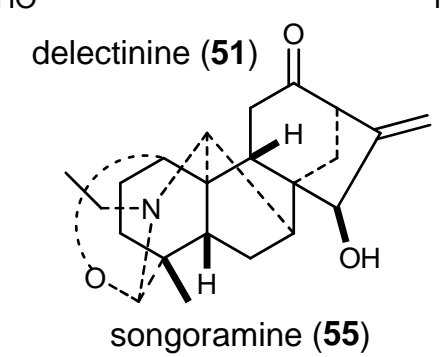

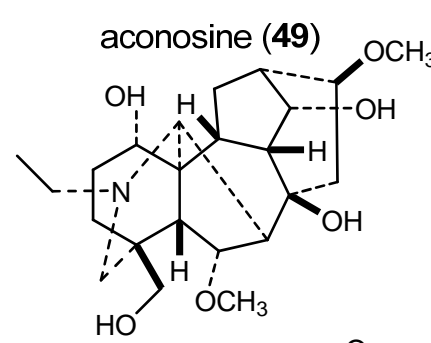

neolinine (52)

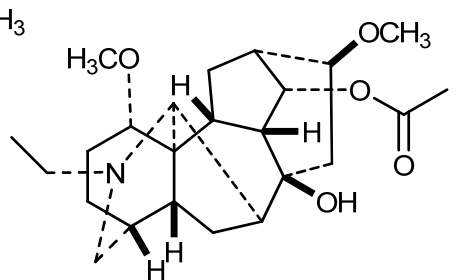

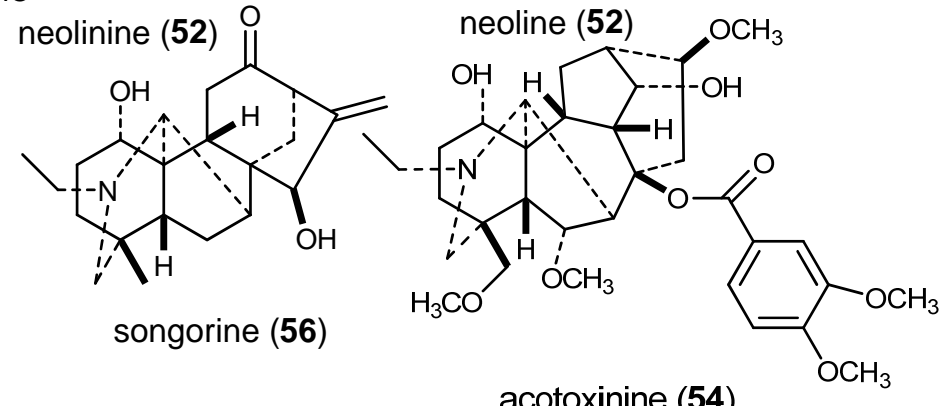

Alkaloids isolated from $A$. vulparia

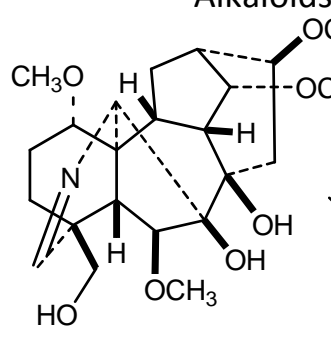

acovulparine (57)
$\mathrm{OCH}_{3}$

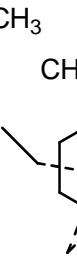

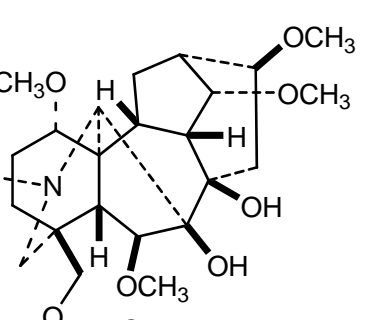<smiles>COC(=O)c1ccccc1NC(=O)CCC(=O)[O-]</smiles>

septentriodine (58)

acotoxinine (54)

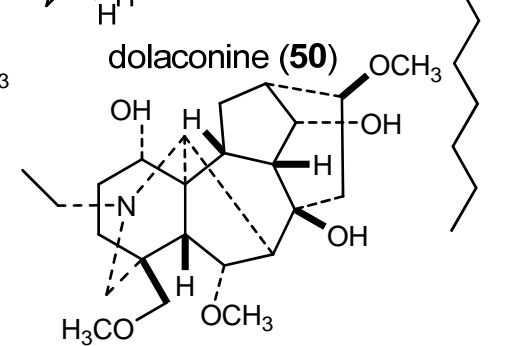

Alkaloids isolated from Consolida orientalis

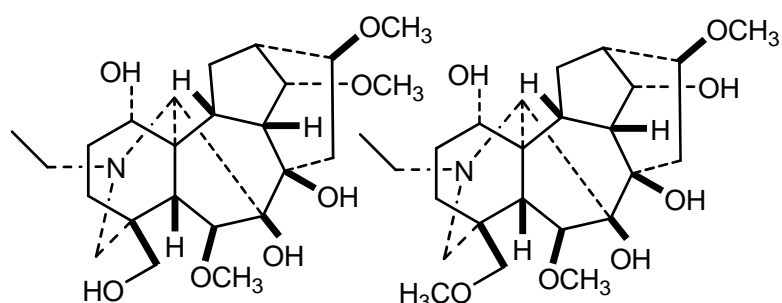

gigactonine (44)

delcosine (40)

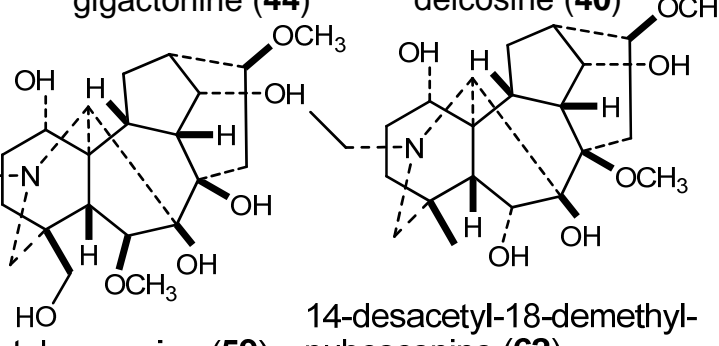

takaosamine (59) pubescenine (62) 
Annex III. Alkaloids isolated from A. anthora

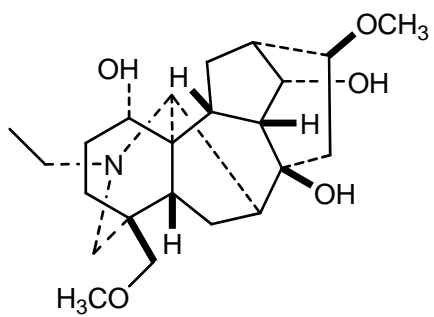

isotalatizidine

(ANT-1)

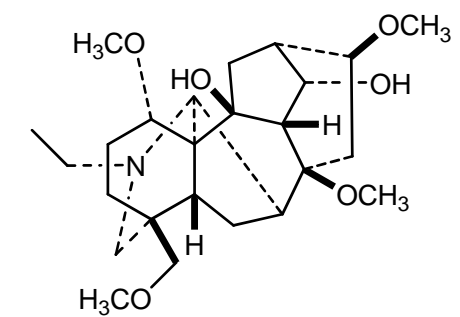

10-hydroxy-8-O-methyltalatizamine

(ANT-2)

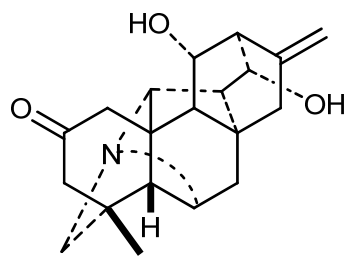

hetisinone

(ANT-3)

Alkaloids isolated from $A$. moldavicum
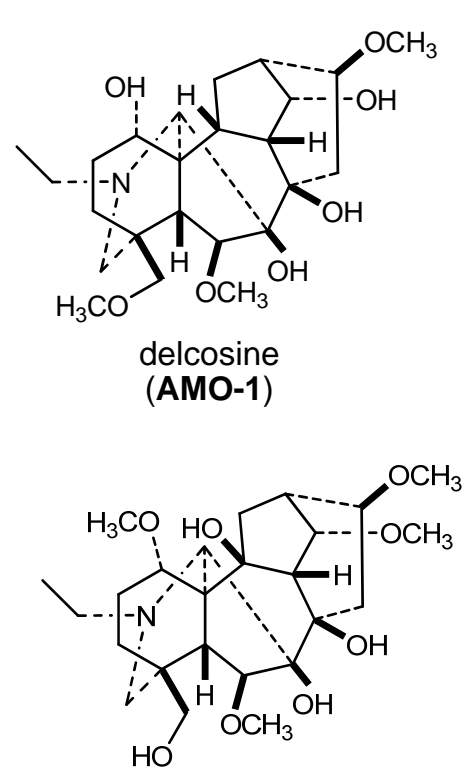

swatinine

(AMO-4)

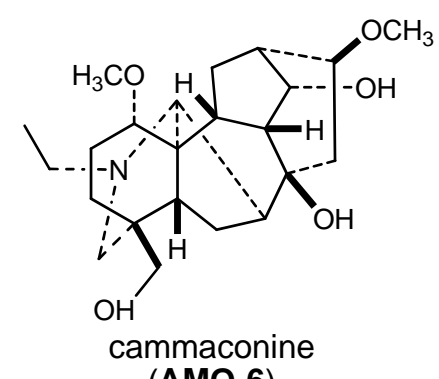

(AMO-6)
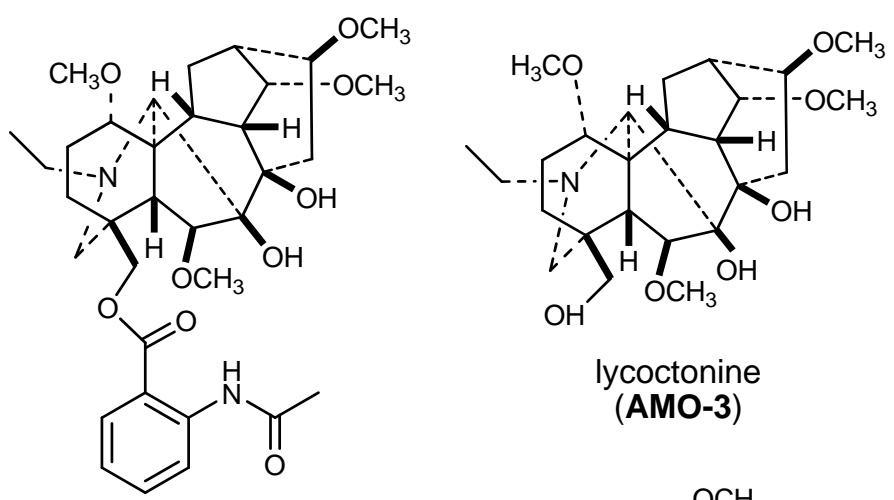

lycoctonine

(AMO-3)

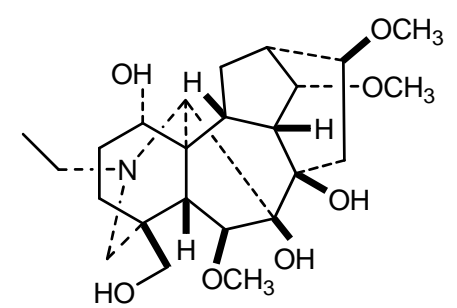

gigactonine

(AMO-5)
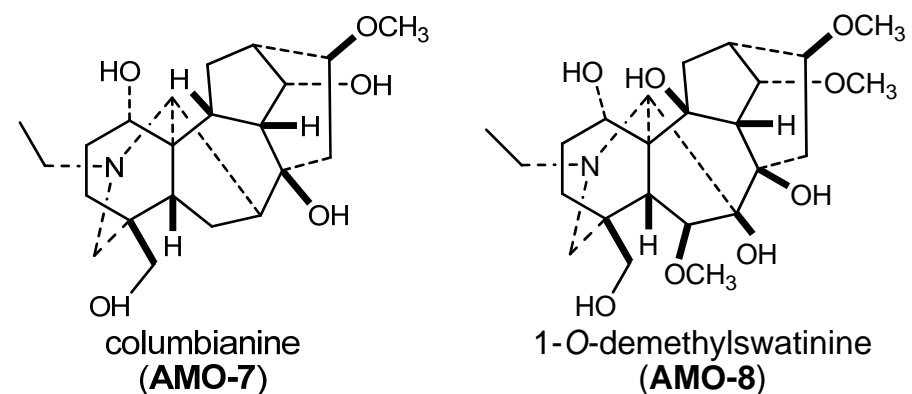

(AMO-8) 
Annex IV - Table A. NMR spectral data of 10-hydroxy-8-O- methyltalatizamine (ANT-2) isolated from A. anthora $\left[500 \mathrm{MHz}\left({ }^{1} \mathrm{H}\right), 125 \mathrm{MHz}\left({ }^{13} \mathrm{C}\right), \mathrm{CDCl}_{3}, \delta(\mathrm{ppm})(J=\mathrm{Hz})\right]$

\begin{tabular}{|c|c|c|c|c|}
\hline Atom & ${ }^{1} \mathrm{H}$ & ${ }^{13} \mathrm{C}$ & $\mathrm{HMBC}(\mathrm{H} \rightarrow \mathrm{C})$ & NOESY (H No.) \\
\hline 1 & $3.75 \mathrm{t}(4.8)$ & 78.6 & $2,10,11,17$ & $2 \beta, 3 \beta, 5,1-\mathrm{OCH}_{3}$, \\
\hline $2 \alpha$ & $2.28 \mathrm{ddd}(4.8,10.2,19.5)$ & 26.0 & 1 & $3 \alpha, 19 a$ \\
\hline $2 \beta$ & $2.04 \mathrm{~m}$ & & & 1 \\
\hline $3 \alpha$ & $1.75 \mathrm{~m}$ & 32.4 & 4,5 & $2 \alpha, 18 b, 19 a$ \\
\hline $3 \beta$ & $1.42 \mathrm{ddd}(5.0,10.8,15.0)$ & & 4,5 & 1,5 \\
\hline 4 & - & 38.4 & - & - \\
\hline 5 & $1.84 \mathrm{~s}$ & 42.1 & 4,17 & $1,3 \beta, 9,18 a$, \\
\hline $6 \beta$ & $1.82 \mathrm{dd}(18.8,7.7)$ & 24.1 & 8 & 9 \\
\hline $6 \alpha$ & $1.47 \mathrm{~m}$ & & 8,11 & $18 a, 18 b, 19 a, 19 b$ \\
\hline 7 & $2.41 \mathrm{~d}(7.4)$ & 39.4 & $5,8,9,11$ & $6 \alpha, 15 \alpha, 17,19 b, 8-\mathrm{OCH}_{3}$ \\
\hline 8 & - & 77.0 & - & - \\
\hline 9 & $1.99 \mathrm{~d}(4.7)$ & 55.5 & $8,10,14$ & $5,6 \beta, 14$ \\
\hline 10 & - & 81.1 & - & - \\
\hline 11 & - & 54.8 & - & - \\
\hline $12 \alpha$ & $2.66 \mathrm{~d}(16.1)$ & 39.1 & $10,11,13,14$ & 16,17 \\
\hline $12 \beta$ & $1.71 \mathrm{dd}(16.1,8.2)$ & & $10,14,16$ & 13,14 \\
\hline 13 & $2.50 \mathrm{~m}$ & 38.6 & $9,10,15$ & $12 \beta, 14,16-\mathrm{OCH}_{3}$ \\
\hline 14 & $4.59 \mathrm{t}(4.5)$ & 73.3 & & $9,12 \beta, 13$ \\
\hline $15 \alpha$ & $2.19 \mathrm{dd}(15.7,9.0)$ & 35.3 & $8,9,13,16$ & $7,16,17$ \\
\hline $15 \beta$ & $2.10 \mathrm{dd}(15.7,4.5)$ & & $8,13,16$ & $8-\mathrm{OCH}_{3}$ \\
\hline 16 & $3.33 \mathrm{dd}(8.9,4.5)$ & 81.8 & & $12 \alpha, 15 \alpha, 17$ \\
\hline 17 & $2.87 \mathrm{~s}$ & 63.3 & $5,6,10,11,19,20$ & $7,12 \alpha, 15 \alpha, 16,19 a, 21$ \\
\hline $18 a$ & $3.13 \mathrm{~d}(9.0)$ & 79.5 & $3,4,5,19$ & $5,6 \alpha, 19 b$ \\
\hline $18 \mathrm{~b}$ & $3.01 \mathrm{~d}(9.0)$ & & $3,4,5,19$ & $3 \alpha, 6 \alpha, 19 a, 19 b$ \\
\hline $19 a$ & $2.54 \mathrm{~d}(11.5)$ & 52.9 & $3,4,5,17$ & $2 \alpha, 3 \alpha, 6 \alpha, 17,18 b, 21$ \\
\hline $19 \mathrm{~b}$ & $2.02 \mathrm{~d}(11.6)$ & & $3,4,18,20$ & $6 a, 18 a, 18 b$ \\
\hline $20 a$ & $2.50 \mathrm{~m}$ & 49.4 & $17,19,21$ & 21 \\
\hline $20 \mathrm{~b}$ & $2.41 \mathrm{dq}(19.4,7.4)$ & & $17,19,21$ & 21 \\
\hline 21 & $1.08 \mathrm{t}(7.4)$ & 13.6 & 20 & $17,19 a, 20 a, 20 b$ \\
\hline 1-OMe & $3.28 \mathrm{~s}$ & 56.0 & 1 & 1 \\
\hline 8-OMe & $3.14 \mathrm{~s}$ & 48.2 & 8 & $7,15 \beta$ \\
\hline 16-OMe & $3.37 \mathrm{~s}$ & 56.4 & 16 & 13 \\
\hline 18-OMe & $3.31 \mathrm{~s}$ & 59.5 & 18 & $18 a, 18 b$ \\
\hline
\end{tabular}


Annex IV - Table B. NMR spectral data of 1-O-demethylswatinine (AMO-8) isolated from A. moldavicum $\left[500 \mathrm{MHz}\left({ }^{1} \mathrm{H}\right), 125 \mathrm{MHz}\left({ }^{13} \mathrm{C}\right), \mathrm{CDCl}_{3}, \delta(\mathrm{ppm})(J=\mathrm{Hz})\right]$

\begin{tabular}{|c|c|c|c|c|}
\hline Atom & ${ }^{1} \mathrm{H}$ & ${ }^{13} \mathrm{C}$ & $\mathrm{HMBC}(\mathrm{C} \rightarrow \mathrm{H})$ & NOESY \\
\hline 1 & 4.06 brs & 69.8 & $3 \alpha$ & $2 \alpha, 3 \alpha, 3 \beta, 12 \alpha$ \\
\hline $2 \alpha$ & $1.72 \mathrm{~m}$ & 34.6 & & 1 \\
\hline $2 \beta$ & $1.68 \mathrm{~m}$ & & & 5,9 \\
\hline $3 \alpha$ & $1.98 \mathrm{~m}$ & 26.7 & $18 a, 18 b, 19 a, 19 b$ & 1 \\
\hline $3 \beta$ & $1.47 \mathrm{~m}$ & & & 1 \\
\hline 4 & - & 38.2 & $6,5,18 a, 19 a, 19 b, 3 \alpha, 2 \beta$ & - \\
\hline 5 & $2.15 \mathrm{~s}$ & 40.8 & $6,17,18 b, 19 a, 19 b$ & $2 \beta, 6,9$ \\
\hline 6 & $4.03 \mathrm{~s}$ & 91.0 & 5, 6-OMe, 17 & $5,18 a, 19 a$ \\
\hline 7 & - & 87.2 & $5,6,15 \alpha, 15 \beta$ & - \\
\hline 8 & - & 76.8 & $14,6,8-\mathrm{OH}, 9,17,15 \alpha, 15 \beta$ & - \\
\hline 9 & $2.83 \mathrm{~d}(2.5)$ & 53.7 & $15 \alpha, 12 \alpha$ & $2 \beta, 5,14,8-\mathrm{OH}$ \\
\hline 10 & - & 83.0 & $9,12 \alpha$ & - \\
\hline 11 & - & 54.1 & $5,6,17,12 \alpha$ & - \\
\hline $12 \alpha$ & $2.34 \mathrm{~d}(15.1)$ & 41.0 & 16 & $1,16,17$ \\
\hline $12 \beta$ & 1.95 dd $(15.1,7.5)$ & & & 13,14 \\
\hline 13 & $2.58 \mathrm{dd}(7.4,4.6)$ & 38.2 & $9,12 \alpha, 15 \alpha$ & $12 \mathrm{~b}, 14$ \\
\hline 14 & $4.11 \mathrm{t}(4.6)$ & 82.9 & 14-OMe, $12 \alpha$ & $9,12 \beta, 13$ \\
\hline $15 \alpha$ & $2.63 \mathrm{dd}(14.7,8.5)$ & 34.6 & 8-OH, 9 & 16,17 \\
\hline $15 \beta$ & $1.80 \mathrm{dd}(14.7,8.3)$ & & & \\
\hline 16 & $3.26 \mathrm{dd}(8.5,8.3)$ & 82.0 & $9,12 \alpha, 12 \beta, 15 \alpha, 15 \beta, 16-\mathrm{OMe}$ & $12 \alpha, 15 \alpha, 17$ \\
\hline 17 & $2.74 \mathrm{~d}(1.7)$ & 66.4 & $5,19 a, 19 b$ & $12 \alpha, 15 \alpha, 16,20 a, 21$ \\
\hline $18 a$ & $3.70 \mathrm{~d}(10.5)$ & 66.9 & $3 \alpha, 19 a, 19 b$ & 6 \\
\hline $18 \mathrm{~b}$ & $3.40 \mathrm{~d}(10.5)$ & & & \\
\hline $19 a$ & $2.49 d(11.5)$ & 57.1 & $5,17,20$ & 6 \\
\hline $19 \mathrm{~b}$ & $2.45 \mathrm{~d}(11.5)$ & & & \\
\hline $20 a$ & $2.97 \mathrm{dq}(19.4,7.3)$ & 50.3 & $19 a$ & 17 \\
\hline $20 \mathrm{~b}$ & $2.85 \mathrm{dq}(19.4,7.3)$ & & & \\
\hline 21 & $1.11 \mathrm{t}(7.3)$ & 14.0 & 20a, 20b & 17 \\
\hline 1-OMe & - & - & - & - \\
\hline 6-OMe & $3.43 \mathrm{~s}$ & 58.0 & 6 & $8-\mathrm{OH}$ \\
\hline 14-OMe & $3.45 \mathrm{~s}$ & 57.8 & 14 & \\
\hline 16-OMe & $3.35 \mathrm{~s}$ & 56.3 & 16 & $8-\mathrm{OH}$ \\
\hline $1-\mathrm{OH}$ & $7.50 \mathrm{~s}$ & - & - & \\
\hline $8-\mathrm{OH}$ & $3.99 \mathrm{~s}$ & - & - & 9, 6-OMe, 16-OMe \\
\hline
\end{tabular}


Annex IV - Table C. NMR spectral data of isotalatizidine (ANT-1) isolated from A. anthora $\left[500 \mathrm{MHz}\left({ }^{1} \mathrm{H}\right), 125 \mathrm{MHz}\right.$ $\left.\left({ }^{13} \mathrm{C}\right), \mathrm{CDCl}_{3}, \delta(\mathrm{ppm})(J=\mathrm{Hz})\right]$

\begin{tabular}{|c|c|c|}
\hline Atom & ${ }^{1} \mathrm{H}$ & ${ }^{13} \mathrm{C}$ \\
\hline 1 & $3.72 \mathrm{~s}$ & 72.3 \\
\hline $2 \alpha$ & $1.58 \mathrm{~m}(2 \mathrm{H})$ & 29.8 \\
\hline \multicolumn{3}{|l|}{$2 \beta$} \\
\hline $3 \alpha$ & $1.86 \mathrm{~m}$ & 26.9 \\
\hline $3 \beta$ & $1.65 \mathrm{~m}$ & \\
\hline 4 & - & 37.3 \\
\hline 5 & $1.82 \mathrm{~m}$ & 41.7 \\
\hline $6 \beta$ & $1.90 \mathrm{~m}$ & 24.9 \\
\hline $6 \alpha$ & $1.65 \mathrm{~m}$ & \\
\hline 7 & $2.09 \mathrm{~m}$ & 45.2 \\
\hline 8 & - & 74.1 \\
\hline 9 & $2.22 \mathrm{t}(6.0,5.7)$ & 46.7 \\
\hline 10 & $1.84 \mathrm{~m}$ & 44.1 \\
\hline 11 & - & 48.6 \\
\hline $12 \alpha$ & $1.62 \mathrm{~m}$ & 28.3 \\
\hline $12 \beta$ & $2.04 \mathrm{~m}$ & \\
\hline 13 & $2.35 \mathrm{~m}$ & 39.9 \\
\hline 14 & $4.22 \mathrm{t}(5.0)$ & 75.9 \\
\hline $15 \alpha$ & $2.42 \mathrm{~m}$ & 42.3 \\
\hline $15 \beta$ & $2.07 \mathrm{~m}$ & \\
\hline 16 & $3.38 \mathrm{dd}(9.1,4.6)$ & 81.9 \\
\hline 17 & $2.82 \mathrm{~s}$ & 64.0 \\
\hline $18 a$ & $3.14 \mathrm{~d}(8.8)$ & 79.1 \\
\hline $18 \mathrm{~b}$ & $3.00 d(8.8)$ & \\
\hline $19 a$ & $2.34 \mathrm{~d}(10.9)$ & 56.6 \\
\hline $19 b$ & $2.10 \mathrm{~d}(10.9)$ & \\
\hline $20 a$ & $\begin{array}{l}2.55 \mathrm{dq}(12.7 \\
7.1)\end{array}$ & 48.5 \\
\hline $20 \mathrm{~b}$ & $\begin{array}{l}2.45 \mathrm{dq}(12.7 \\
7.1)\end{array}$ & \\
\hline 21 & $1.12 \mathrm{t}(7.1)$ & 13.0 \\
\hline 1-OMe & - & - \\
\hline 8-OMe & - & - \\
\hline 16-OMe & $3.34 \mathrm{~s}$ & 56.3 \\
\hline 18-OMe & $3.31 \mathrm{~s}$ & 59.4 \\
\hline
\end{tabular}

Annex IV - Table D. ${ }^{1} \mathrm{H}$ NMR spectral data of ajacine (AMO-2) and swatinine (AMO-4) isolated from A. moldavicum $\left[500 \mathrm{MHz}\left({ }^{1} \mathrm{H}\right), \mathrm{CDCl}_{3}, \delta(\mathrm{ppm})(J=\mathrm{Hz})\right]$

\begin{tabular}{|c|c|c|}
\hline Atom & AMO-4 & AMO-7 \\
\hline 1 & $3.58 \mathrm{t}(7.9,9.2)$ & 3.74 brs \\
\hline $2 \alpha$ & $2.15 \mathrm{~m}$ & $1.67 \mathrm{~m}$ \\
\hline $2 \beta$ & $2.15 \mathrm{~m}$ & $1.58 \mathrm{~m}$ \\
\hline $3 \alpha$ & $1.60 \mathrm{~m}$ & $2.10 \mathrm{~m}$ \\
\hline $3 \beta$ & $1.50 \mathrm{~m}$ & $1.91 \mathrm{~m}$ \\
\hline 4 & - & - \\
\hline 5 & $1.95 \mathrm{~s}$ & $1.84 \mathrm{~m}$ \\
\hline \multirow[t]{2}{*}{6} & $3.89 \mathrm{~s}$ & $1.92 \mathrm{~m}$ \\
\hline & & $1.62 \mathrm{~m}$ \\
\hline 7 & - & $2.10 \mathrm{~m}$ \\
\hline 8 & - & - \\
\hline 9 & $2.88 \mathrm{~d}(4.7)$ & $2.23 \mathrm{t}(5.9)$ \\
\hline 10 & - & $1.87 \mathrm{~m}$ \\
\hline 11 & - & - \\
\hline $12 \alpha$ & $3.07 d(15.7)$ & $2.06 \mathrm{~m}$ \\
\hline $12 \beta$ & $1.70 \mathrm{~m}$ & $1.60 \mathrm{~m}$ \\
\hline 13 & $2.49 \mathrm{dd}(7.8,4.6)$ & $2.34 \mathrm{~m}$ \\
\hline 14 & $4.10 \mathrm{t}(4.8,4.5)$ & $4.24 \mathrm{t}(5.0)$ \\
\hline $15 \alpha$ & $2.64 \mathrm{dd}(15.3,10.0)$ & $2.42 \mathrm{dd}(16.3,9.3)$ \\
\hline $15 \beta$ & $1.70 \mathrm{~m}$ & $2.07 \mathrm{~m}$ \\
\hline 16 & $3.17 \mathrm{t}(8.5,7.2)$ & $3.39 \mathrm{dd}(9.2,4.7)$ \\
\hline 17 & $2.84 \mathrm{~d}(2.1)$ & $2.82 \mathrm{~s}$ \\
\hline $18 a$ & $3.64 d(10.7)$ & $3.46 \mathrm{~d}(10.5)$ \\
\hline $18 b$ & $3.37 d(10.9)$ & $3.29 \mathrm{~d}(10.5)$ \\
\hline 19a & $2.60 \mathrm{~d}(12.0)$ & $2.36 \mathrm{~d}(10.7)$ \\
\hline $19 b$ & $2.32 \mathrm{~d}(12.0)$ & $2.08 d(10.8)$ \\
\hline $20 a$ & $2.90 \mathrm{~m}$ & $2.55 \mathrm{dq}(12.4,7.1)$ \\
\hline $20 b$ & $2.81 \mathrm{dq}(19.2,7.2)$ & $2.46 \mathrm{dq}(12.4,7.1)$ \\
\hline 21 & $1.05 \mathrm{t}(7.2)$ & $1.13 \mathrm{t}(7.1)$ \\
\hline 1-OMe & $3.26 \mathrm{~s}$ & - \\
\hline 6-OMe & $3.45 \mathrm{~s}$ & - \\
\hline 14-OMe & $3.44 \mathrm{~s}$ & - \\
\hline 16-OMe & $3.33 \mathrm{~s}$ & $3.35 \mathrm{~s}$ \\
\hline $1-\mathrm{OH}$ & - & 3.03 brs* \\
\hline $8-\mathrm{OH}$ & $4.08 \mathrm{~s}$ & \\
\hline
\end{tabular}




\section{APPENDICES}

The thesis is based on the following publications:

I. Forgo P, Borcsa B, Csupor D, Fodor L, Berkecz R, Molnár VA, Hohmann J

Diterpene alkaloids from Aconitum anthora and assessment of the hERG-inhibiting ability of Aconitum alkaloids

Planta Med 2011; 77:368-373

II. Borcsa B, Widowitz U, Csupor D, Forgo P, Bauer R, Hohmann J

Semisynthesis and pharmacological investigation of lipo-alkaloids prepared from aconitine Fitoterapia 2011; 82:365-368

III. Borcsa B, Csupor D, Forgo P, Widowitz U, Bauer R, Hohmann J Aconitum lipo-alkaloids - semisynthetic products of the traditional medicine Nat Prod Commun 2011; 6:527-536

IV. Csupor D, Borcsa B, Heydel B, Hohmann J, Zupkó I, Ma Y, Widowitz U, Bauer R Comparison of a specific HPLC determination of toxic aconite alkaloids in processed Radix aconiti with a titration method of total alkaloids

Pharm Biol 2011; 49:1097-1101 


\section{LIST OF PUBLICATIONS RELATED TO THE THESIS}

I. Forgo P, Borcsa B, Csupor D, Fodor L, Berkecz R, Molnár VA, Hohmann J

Diterpene alkaloids from Aconitum anthora and assessment of the hERG-inhibiting ability of Aconitum alkaloids

Planta Med 2011; 77:368-373

II. Borcsa B, Widowitz U, Csupor D, Forgo P, Bauer R, Hohmann J

Semisynthesis and pharmacological investigation of lipo-alkaloids prepared from aconitine Fitoterapia 2011; 82:365-368

III. Borcsa B, Csupor D, Forgo P, Widowitz U, Bauer R, Hohmann J

Aconitum lipo-alkaloids - semisynthetic products of the traditional medicine Nat Prod Commun 2011; 6:527-536

IV. Csupor D, Borcsa B, Heydel B, Hohmann J, Zupkó I, Ma Y, Widowitz U, Bauer R Comparison of a specific HPLC determination of toxic aconite alkaloids in processed Radix aconiti with a titration method of total alkaloids

Pharm Biol 2011; 49:1097-1101

V. Borcsa B, Fodor L, Csupor D, Forgo P, Molnár VA, Hohmann J

Diterpene alkaloids from Aconitum moldavicum and assessment of $\mathrm{Na}_{\mathrm{v}} 1.2$ sodium channel activity of Aconitum alkaloids (in press, Planta Med 2014; DOI: http://dx.doi.org/10.1055/s$\underline{0033-1360278}$ 